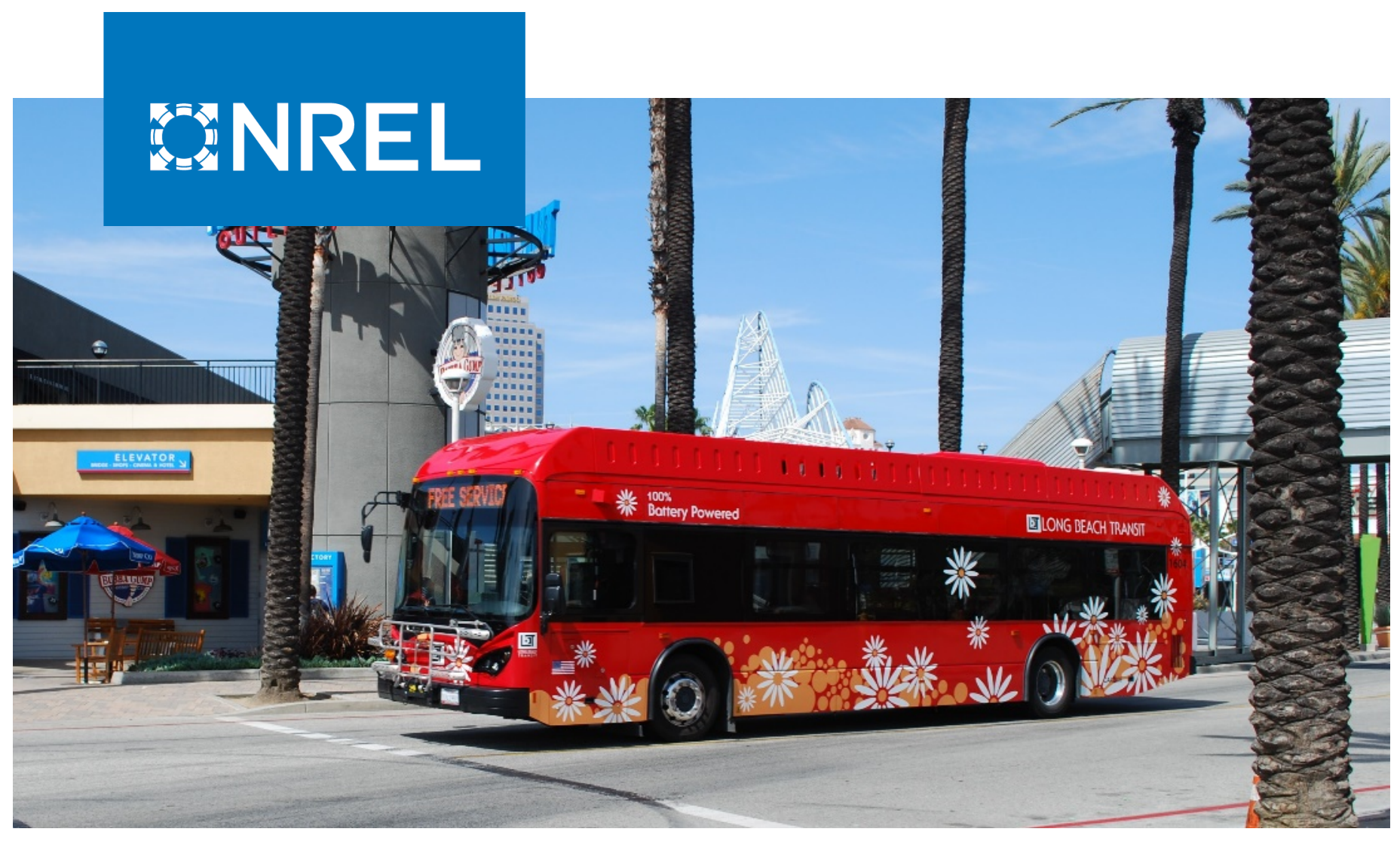

\title{
Long Beach Transit Battery Electric Bus Evaluation: Final Report
}

Leslie Eudy and Matthew Jeffers

National Renewable Energy Laboratory

NREL is a national laboratory of the U.S. Department of Energy Office of Energy Efficiency \& Renewable Energy

Operated by the Alliance for Sustainable Energy, LLC

This report is available at no cost from the National Renewable Energy Laboratory (NREL) at www.nrel.gov/publications.

\section{Technical Report}

NREL/TP-5400-75582

September 2020 


\title{
GHREL
}

\section{Long Beach Transit Battery Electric Bus Evaluation: Final Report}

\author{
Leslie Eudy and Matthew Jeffers
}

National Renewable Energy Laboratory

\section{Suggested Citation}

Eudy, Leslie and Matthew Jeffers. 2020. Long Beach Transit Battery Electric Bus

Evaluation: Final Report. Golden, CO: National Renewable Energy Laboratory. NREL/TP5400-75582. https://www.nrel.gov/docs/fy20osti/75582.pdf.

NREL is a national laboratory of the U.S. Department of Energy Office of Energy Efficiency \& Renewable Energy Operated by the Alliance for Sustainable Energy, LLC

This report is available at no cost from the National Renewable Energy Laboratory (NREL) at www.nrel.gov/publications.

Contract No. DE-AC36-08GO28308
Technical Report

NREL/TP-5400-75582

September 2020

National Renewable Energy Laboratory 15013 Denver West Parkway Golden, CO 80401 303-275-3000 • www.nrel.gov 


\section{NOTICE}

This work was authored by the National Renewable Energy Laboratory, operated by Alliance for Sustainable Energy, LLC, for the U.S. Department of Energy (DOE) under Contract No. DE-AC36-08GO28308. Funding for the work was provided by the California Air Resources Board. The views expressed herein do not necessarily represent the views of the DOE or the U.S. Government.

This report is available at no cost from the National Renewable Energy Laboratory (NREL) at www.nrel.gov/publications.

U.S. Department of Energy (DOE) reports produced after 1991 and a growing number of pre-1991 documents are available free via www.OSTI.gov.

Cover Photo by Leslie Eudy: NREL.

NREL prints on paper that contains recycled content. 


\section{Acknowledgments}

This report could not have been possible without the cooperation of the transit agencies, manufacturer partners, and others. Transit agency staff provided data on the zero-emission and baseline buses, reviewed analyses and reports, and participated in meetings to discuss the agency's overall experience. Manufacturers provided selected data and feedback and reviewed reports. The California Air Resources Board (CARB) provided funding for the second year of the evaluation. The authors thank the following individuals:

\section{California Air Resources Board}

Yachun Chow

Jennifer Lee

Jing Guo

Bo Yang

\section{Long Beach Transit (LBT)}

Briana Lozada

Steven Jorgensen

Oscar Sanchez

Samantha Ihlenfeldt

China Gipson

Enrique Medina

Teresa Lopez

Rolando Cruz (former LBT staff)

Andrew Choi (former LBT staff)

Tony Cohen (former LBT staff)

\section{BYD}

Bobby Hill

James Holtz

Macy Neshati (former BYD staff)

\section{Center for Transportation and the Environment}

Steve Clermont

Will Manget 


\section{List of Acronyms}

ATA VMRS

BEB

CARB

$\mathrm{CNG}$

dge

DOE

DOT

ESS

EV

FTA

gge

HVAC

HVIP

KMBRC

LBT

MBRC

mpdge

mpgge

NREL

OEM

PMI

SI

SOC

TIGGER

TOU

WAVE

ZEB
American Trucking Association Vehicle Maintenance Reporting Standards battery electric bus

California Air Resources Board

compressed natural gas

diesel gallon equivalent

U.S. Department of Energy

U.S. Department of Transportation

energy storage system

electric vehicle

Federal Transit Administration

gasoline gallon equivalent

heating, ventilation, and air conditioning

Hybrid and Zero-Emission Truck and Bus Voucher Incentive Project

kilometers between road calls

Long Beach Transit

miles between road calls

miles per diesel gallon equivalent

miles per gasoline gallon equivalent

National Renewable Energy Laboratory

original equipment manufacturer

preventive maintenance inspection

International System of Units

state of charge

Transit Investments for Greenhouse Gas and Energy Reduction

time of use

Wireless Advanced Vehicle Electrification

zero-emission bus 


\section{Executive Summary}

In March 2017, Long Beach Transit (LBT) began operating a fleet of 10 battery electric buses (BEBs) in its service area in Southern California. The agency has a commitment to clean technologies and operates low-emission compressed natural gas (CNG) and gasoline hybrid buses. The BEBs, purchased through a grant from the Federal Transit Administration, allow the agency to evaluate zero-emission technology for its operation. LBT is collaborating with the California Air Resources Board (CARB) and the U.S. Department of Energy's (DOE's) National Renewable Energy Laboratory (NREL) to evaluate the buses in revenue service.

LBT's BEBs are 40-foot BYD buses with a ferro-type lithium iron phosphate energy storage system (ESS), also produced by BYD. NREL is collecting data on a conventional fleet of eight Gillig compressed natural gas $(\mathrm{CNG})$ buses of similar age as the primary baseline comparison. LBT primarily operates the BEBs on its Passport route-a free shuttle service that travels around the waterfront area between the Queen Mary and downtown Long Beach. The agency installed 10 plug-in chargers for overnight charging of the BEBs at the bus depot. This is the primary means of charging the buses, although the agency also installed an inductive charging station at one of the stops on the Passport route. Table ES-1 provides a summary of BEB and baseline bus performance results for the second year of service (2019 data period).

Table ES-1. Summary of LBT Evaluation Results

\begin{tabular}{|c|c|c|}
\hline Data Item & BEB & CNG \\
\hline Number of buses & 10 & 8 \\
\hline Total mileage in evaluation period & 192,006 & 344,236 \\
\hline Average monthly mileage per bus & 1,600 & 3,586 \\
\hline Availability (target is $85 \%$ ) & $71.3 \%$ & $83.4 \%$ \\
\hline Fuel economy (kWh/mile for BEB or mpgge ${ }^{a}$ for $\mathrm{CNG}$ ) & 1.94 & 3.22 \\
\hline Fuel economy $\left(\mathrm{mpdge}^{\mathrm{b}}\right)$ & 19.35 & 3.69 \\
\hline Miles between road calls (MBRC)-bus ${ }^{c}$ & 4,416 & 17,828 \\
\hline MBRC-ESS onlyc & 70,656 & - \\
\hline Total maintenance cost ( $\$ /$ mile $)$ & 0.47 & 0.56 \\
\hline Maintenance cost-propulsion system only (\$/mile) & 0.04 & 0.21 \\
\hline Fuel cost (\$/mile) & 0.35 & 0.41 \\
\hline
\end{tabular}

The BEBs averaged 1,600 monthly miles per bus. This is lower than the baseline CNG bus fleet average of 3,586 monthly miles per bus. This is a direct result of the planned operation of the bus fleets, so this difference is expected. Toward the end of 2019, LBT began operating several $\mathrm{BEBs}$ on other routes than the Passport route.

The availability data presented are based on both morning and afternoon pull-out. Buses available for both pull-outs received credit for one day available; if a bus was available for morning pull-out, but not afternoon pull-out, that day counted as 0.5 available. The overall average availability for the BEBs was $71.3 \%$. The CNG fleet availability was $83.4 \%$. LBT purchased the fleet of 10 BEBs to electrify transit service on the Passport route, which does not require the entire fleet. In addition to tracking the daily availability of each BEB, NREL evaluated the effectiveness of the BEB fleet at fulfilling scheduled service on the Passport route. 
During the two-year evaluation period that includes 2018 and 2019 calendar years, the monthly percentage of the Passport route service that was electrified by the BEB fleet ranged from a minimum of $51.5 \%$ in June 2018 to a maximum of $97.6 \%$ in August 2019. The average was $83.9 \%$ for the 2019 data period.

The fuel economy for the BEB fleet on the Passport route varied seasonally from a maximum of 23.6 miles per diesel gallon equivalent (mpdge) in March 2018 to a minimum of 18.4 mpdge in September 2018. The fuel economy for the CNG fleet was very consistent throughout the year, averaging 3.6 mpdge in random-dispatch service, equivalent to 3.3 mpdge on the Passport route. The overall average of 20.7 mpdge for the BEB fleet is 5.9 times the randomly dispatched CNG buses and 6.3 times the CNG buses in service on the slower-speed Passport route.

The BEBs are typically charged overnight at the depot. Since the BEBs were placed into service, LBT has been subject to three different electricity rate structures beginning with TOU-EV-6, switching to TOU-EV-4 in September 2018, and then to TOU-EV-8 in April 2019. LBT was subject to time-of-use charges and demand charges under the first two electric vehicle (EV) rate schedules. The demand charges were waived for the third electricity rate schedule, lowering the per-unit cost for LBT by approximately $50 \%$, on average. The average overall electricity price during the 2019 data period (based on utility billing periods) was $\$ 0.160$ per $\mathrm{kWh}$. This is equivalent to approximately $\$ 6.02$ per diesel gallon equivalent (dge), which is approximately four times the average $C N G$ price of $\$ 1.51$ per dge. The corresponding fuel cost per mile for each fleet was $\$ 0.35$ per mile for the BEBs and $\$ 0.41$ per mile for the CNG fleet. (This cost does not include potential incentive funding.)

The maintenance costs for both fleets include overall cost per mile and cost per mile by vehicle system. Warranty costs are not included in the calculations. During the evaluation period, the BEBs were under warranty and the $\mathrm{CNG}$ buses were not under warranty. The maintenance cost for the BEBs ( $\$ 0.47$ per mile) was $16 \%$ lower than that of the CNG buses ( $\$ 0.56$ per mile). The total propulsion-related maintenance cost for the BEBs was $81 \%$ lower than that of the $\mathrm{CNG}$ buses; this is influenced by the respective warranty periods for the bus fleets.

One of NREL's goals for advanced technology vehicle evaluation is to document the experience of early-adopter transit agencies and share critical lessons learned with the rest of the industry to increase the successful deployment of these vehicles elsewhere in similar service. LBT reports having a good relationship with BYD and that the original equipment manufacturer (OEM) has worked closely with the agency to identify and solve the early issues with the buses.

Key lessons learned reported previously are still relevant and include the following:

Assemble an effective project team: LBT reports that a good project team leads to a better product collectively. This project could not have progressed without the commitment of each member of the team working for a successful deployment of BEBs and continual improvement.

Expect growing pains with new technologies: LBT experienced challenges in implementing the new technology from an OEM that was new to the U.S. market and in the process of completing its new bus manufacturing facility. The team encountered more issues than expected at the initial deployment. Some issues were with bus components, such as doors and wheelchair 
lifts. While these components are not part of the advanced technology, the time needed to solve the issues delayed deployment of the affected buses.

Plan for sufficient training: LBT reports that there is a steep learning curve for implementing a new technology bus. Some of the agency's early challenges arose from maintaining the buses. The necessary maintenance skill set did not exist at the agency at the time of initial deployment. An agency needs to ensure enough time is planned for the OEM to train staff in maintaining the buses.

Begin planning infrastructure early in the project: Completing installation of needed BEB charging infrastructure by the time the buses are delivered can be a balancing act. An agency needs to begin planning early in the process and anticipate potential issues that could delay the installation.

Route planning: The effective range of a BEB depends on many factors including battery capacity, duty cycle, operator driving style, terrain, and heating/air conditioning use. An agency needs to understand how the buses perform in their specific service to select the best routes for the BEBs. Agencies should select route blocks that are within the demonstrated range of the buses. In some cases, an agency may need to reduce hours for blocks to be within bus capabilities. 


\section{Table of Contents}

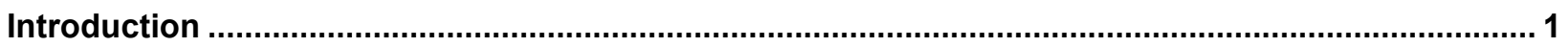

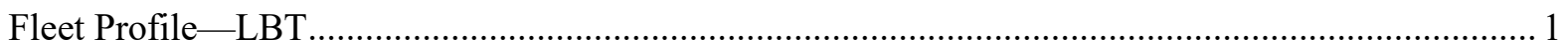

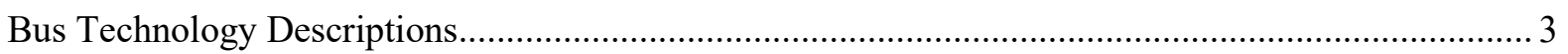

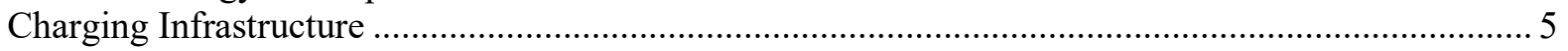

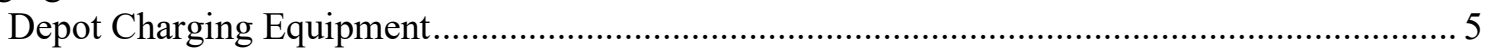

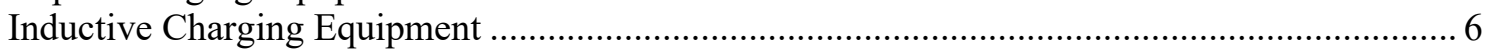

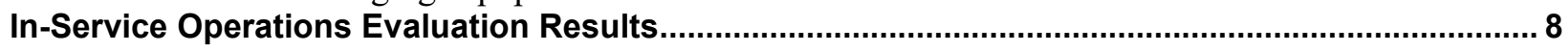

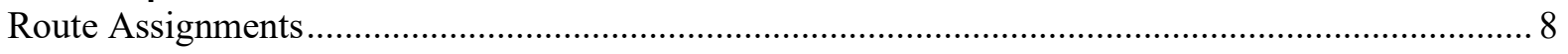

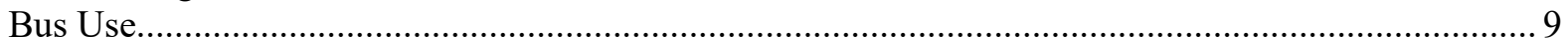

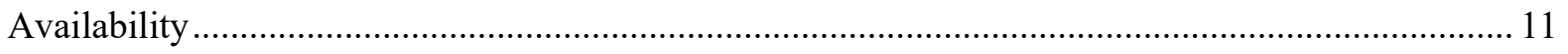

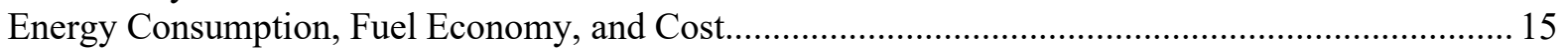

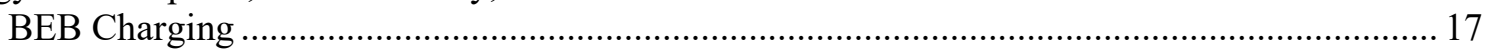

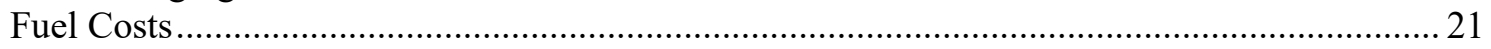

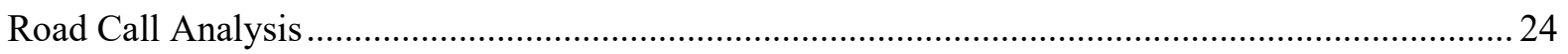

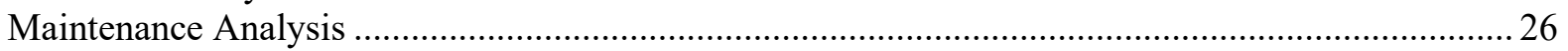

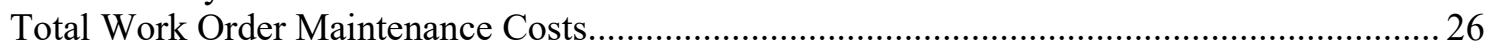

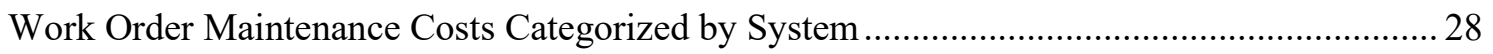

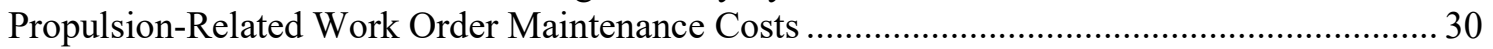

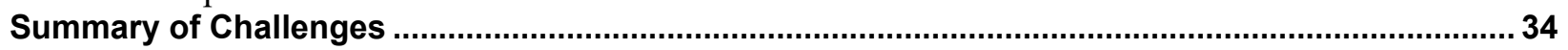

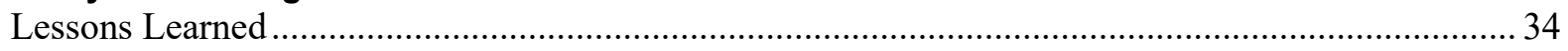

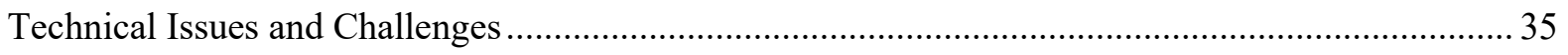

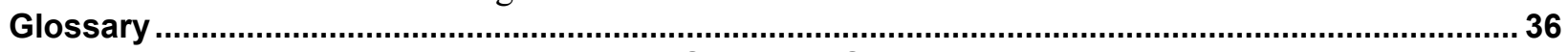

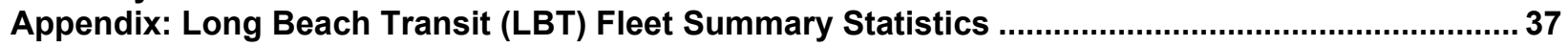

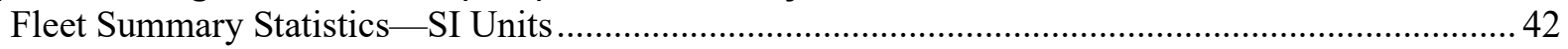




\section{List of Figures}

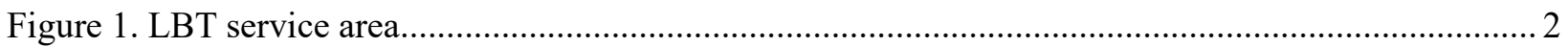

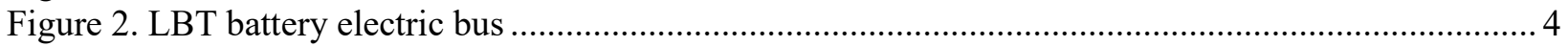

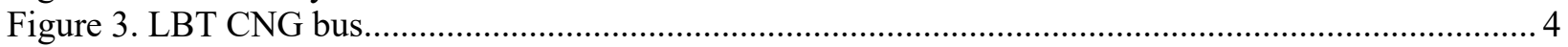

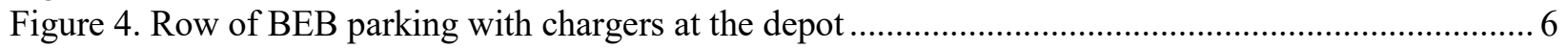

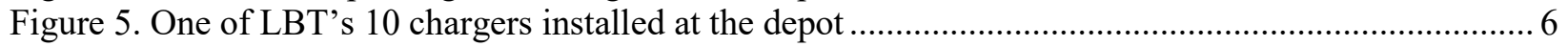

Figure 6. WAVE inductive charging station installed at the Long Beach Convention Center .................... 7

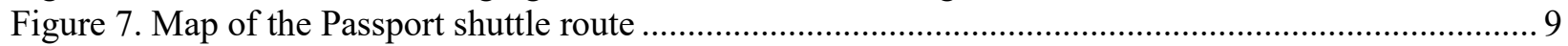

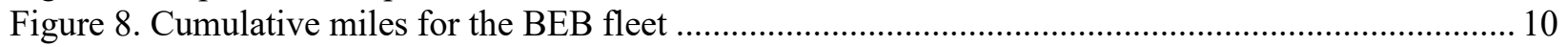

Figure 9. Average monthly miles for BEB and CNG fleets (Evaluation Period) ................................... 11

Figure 10. Monthly availability and reasons for unavailability for the BEB fleet (Evaluation Period)...... 12

Figure 11. Monthly availability by bus for the BEB fleet (Evaluation Period) ..................................... 13

Figure 12. Monthly availability by bus for the CNG fleet (Evaluation Period)....................................... 13

Figure 13. Overall availability for the BEB and CNG fleets (2019 Data Period).................................... 14

Figure 14. Monthly Passport service fulfilled by BEB fleet (Evaluation Period)...................................... 15

Figure 15. Monthly fuel economy for the BEB and CNG fleets (Evaluation Period) .............................. 17

Figure 16. Monthly average minimum SOC for the BEB fleet (Evaluation Period) ................................. 18

Figure 17. Electric utility daily power profiles for depot charging in 2018 ......................................... 19

Figure 18. Electric utility daily power profiles for depot charging in 2019............................................ 19

Figure 19. Electric utility daily cumulative energy profiles for depot charging in 2019 .........................20

Figure 20. Monthly total depot charges by bus for the BEB fleet (Evaluation Period) ............................ 20

Figure 21. Electric utility component costs for depot charging (Evaluation Period)............................... 21

Figure 22. CNG fuel component costs (Evaluation Period) …............................................................. 22

Figure 23. Equivalent monthly average fuel price for the BEB and CNG fleets (Evaluation Period)........ 23

Figure 24. Monthly average fuel cost per mile for the BEB and CNG fleets (Evaluation Period).............24

Figure 25. Fuel cost per mile for the BEB fleet under each electricity rate schedule ...............................2 24

Figure 26. Cumulative bus MBRC and propulsion-related MBRC (Evaluation Period).......................... 26

Figure 27. Monthly scheduled and unscheduled maintenance cost per mile (Evaluation Period).............. 28

Figure 28. Monthly parts and labor maintenance cost per mile (Evaluation Period)................................. 28

Figure 29. Monthly maintenance cost per mile by system for the BEB fleet (Evaluation Period) ............. 30

Figure 30. Monthly maintenance cost per mile by system for the CNG fleet (Evaluation Period) ............ 30

Figure 31. Monthly maintenance cost per mile by propulsion subsystem for the BEB fleet (Evaluation

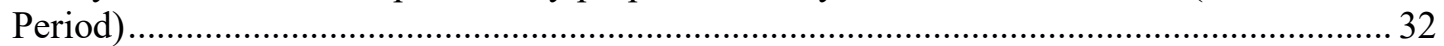

Figure 32. Monthly maintenance cost per mile by propulsion subsystem for the CNG fleet (Evaluation

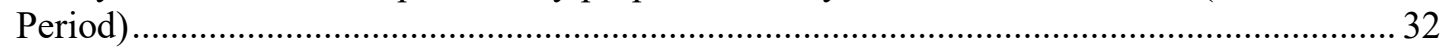




\section{List of Tables}

Table ES-1. Summary of LBT Evaluation Results .............................................................................

Table 1. System Descriptions for the BEBs and CNG Buses ....................................................... 3

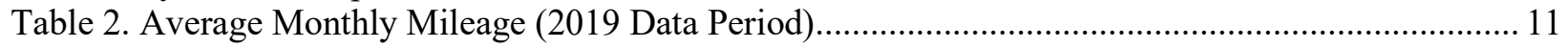

Table 3. Availability for the BEB and CNG Buses (2019 Data Period) ................................................. 12

Table 4. Summary of Availability and Unavailability by Category (2019 Data Period).......................... 14

Table 5. BEB Mileage, Energy Consumption, and Equivalent Fuel Economy (2019 Data Period)........... 16

Table 6. CNG Bus Mileage, Fuel Consumption, and Fuel Economy (2019 Data Period) ....................... 16

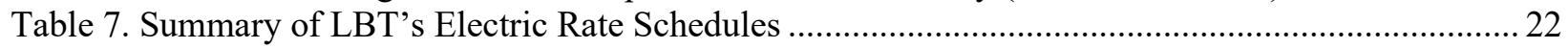

Table 8. Road Calls and MBRC (Evaluation Period) .......................................................................... 25

Table 9. Total Work Order Maintenance Costs (2019 Data Period) ....................................................... 27

Table 10. Work Order Maintenance Cost per Mile by System ${ }^{\mathrm{a}}$ (2019 Data Period)................................ 29

Table 11. Propulsion-Related Work Order Maintenance Costs by System (2019 Data Period)................. 33

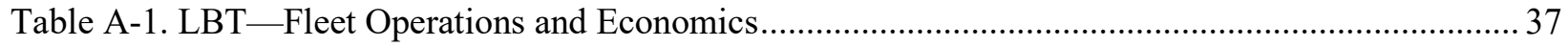

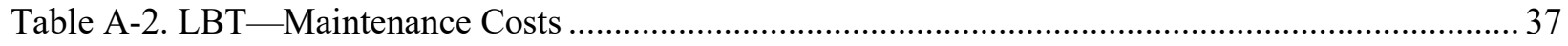

Table A-3. LBT - Breakdown of Maintenance Costs by System ........................................................... 38

Table A-3. LBT - Breakdown of Maintenance Costs by System (continued) ........................................... 39

Table A-3. LBT -Breakdown of Maintenance Costs by System (continued) ......................................... 40

Table A-3. LBT -Breakdown of Maintenance Costs by System (continued) ......................................... 41

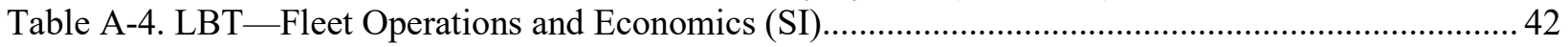

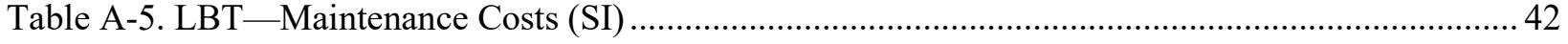




\section{Introduction}

Beginning in March 2017, Long Beach Transit (LBT) began operating a fleet of 10 battery electric buses (BEBs) in its service area in Southern California. These electric buses, produced by BYD, are 40-foot buses that are typically charged overnight but are also equipped with an inductive charging system from WAVE (Wireless Advanced Vehicle Electrification) for supplemental on-route charging. LBT is collaborating with the California Air Resources Board (CARB) and the U.S. Department of Energy's (DOE's) National Renewable Energy Laboratory (NREL) to evaluate the buses in revenue service. CARB has been monitoring the progress of zero-emission buses (ZEBs) being demonstrated in California and other parts of the United States, primarily through evaluations conducted by NREL. The introduction of opportunity fast charging addressed the early range issues that were a challenge for deployment of BEBs and resulted in a number of transit agencies adopting battery electric buses. CARB has enlisted NREL to conduct a third-party evaluation of the LBT fleet to understand BEB performance and its potential as a replacement for conventional bus technology.

NREL has been evaluating advanced technology buses under funding from DOE and the U.S. Department of Transportation's Federal Transit Administration (FTA). NREL uses a standard data collection and analysis protocol originally developed for DOE heavy-duty vehicle evaluations. The objectives of these evaluations are to provide comprehensive, unbiased evaluation results of advanced technology bus development and performance compared to conventional baseline vehicles.

NREL evaluated the first year of LBT's BEB fleet under FTA funding and published a report covering results from January 2018 through December 2018. ${ }^{1}$ CARB provided funding to cover a second year of evaluation. NREL published a progress report on the fleet covering the first half of $2019 .^{2}$ This report provides an update to the previous reports and is focused on the second year of operation from January 2019 through December 2019. Data are provided on a selection of compressed natural gas (CNG) buses as a baseline comparison. However, the CNG buses are operated on different routes at higher speeds, which affects the ability to directly compare mileage and fuel economy results.

\section{Fleet Profile-LBT}

LBT provides public transit service in a 100-square-mile area of southeastern Los Angeles County and northwestern Orange County, serving the cities of Long Beach, Lakewood, Signal Hill, Artesia, Bellflower, Carson, Cerritos, Compton, Downey, Hawaiian Gardens, Los Alamitos, Norwalk, Paramount and Seal Beach. LBT operates a variety of fixed-route bus service and demand-responsive "Dial-A-Lift" paratransit service to several communities in the LBT service area. LBT contracts with a third-party provider for its complimentary paratransit services within three-quarters of a mile of any fixed-route bus service. LBT's current fleet of 249 buses serves

\footnotetext{
${ }^{1}$ Leslie Eudy and Matthew Jeffers, "Zero-Emission Bus Evaluation Results: Long Beach Transit Battery Electric Buses,” FTA Report No. 0163, https://www.transit.dot.gov/research-innovation/zero-emission-bus-evaluationresults-long-beach-transit-battery-electric-buses.

${ }^{2}$ Leslie Eudy and Matthew Jeffers, "Long Beach Transit Battery Electric Bus Progress Report, Data Period Focus: Jan. 2019 through Jun. 2019,” Golden, CO: National Renewable Energy Laboratory, NREL/PR-5400-73740, www.nrel.gov/docs/fy20osti/73740.pdf.
} 
36 fixed routes. The agency has a commitment to clean technologies and operates low-emission $\mathrm{CNG}$ and gasoline-electric hybrid buses. The bus fleet comprises approximately $50 \% \mathrm{CNG}$ buses, $35 \%$ gasoline-electric hybrids, $10 \%$ standard diesels, and 5\% battery electric buses.

In 2011, LBT was awarded a \$6.7 million grant through FTA's Transit Investments for Greenhouse Gas and Energy Reduction (TIGGER) program to fund an electric bus pilot project. The agency selected BYD through a competitive bidding process to build ten 40 -foot BEBs. The BEBs primarily operate on LBT's Passport route - an eight-mile free-fare circulator around downtown Long Beach. In late 2019, LBT began operating a selection of BEBs on routes $181 / 182$ and 45/46. The BEBs are charged overnight at the depot, with the potential for supplemental charging at the Convention Center stop through an inductive charging station by WAVE. The agency brought in the Center for Transportation and the Environment to manage the project. Figure 1 shows a map of LBT's general service area and the Passport circulator route.

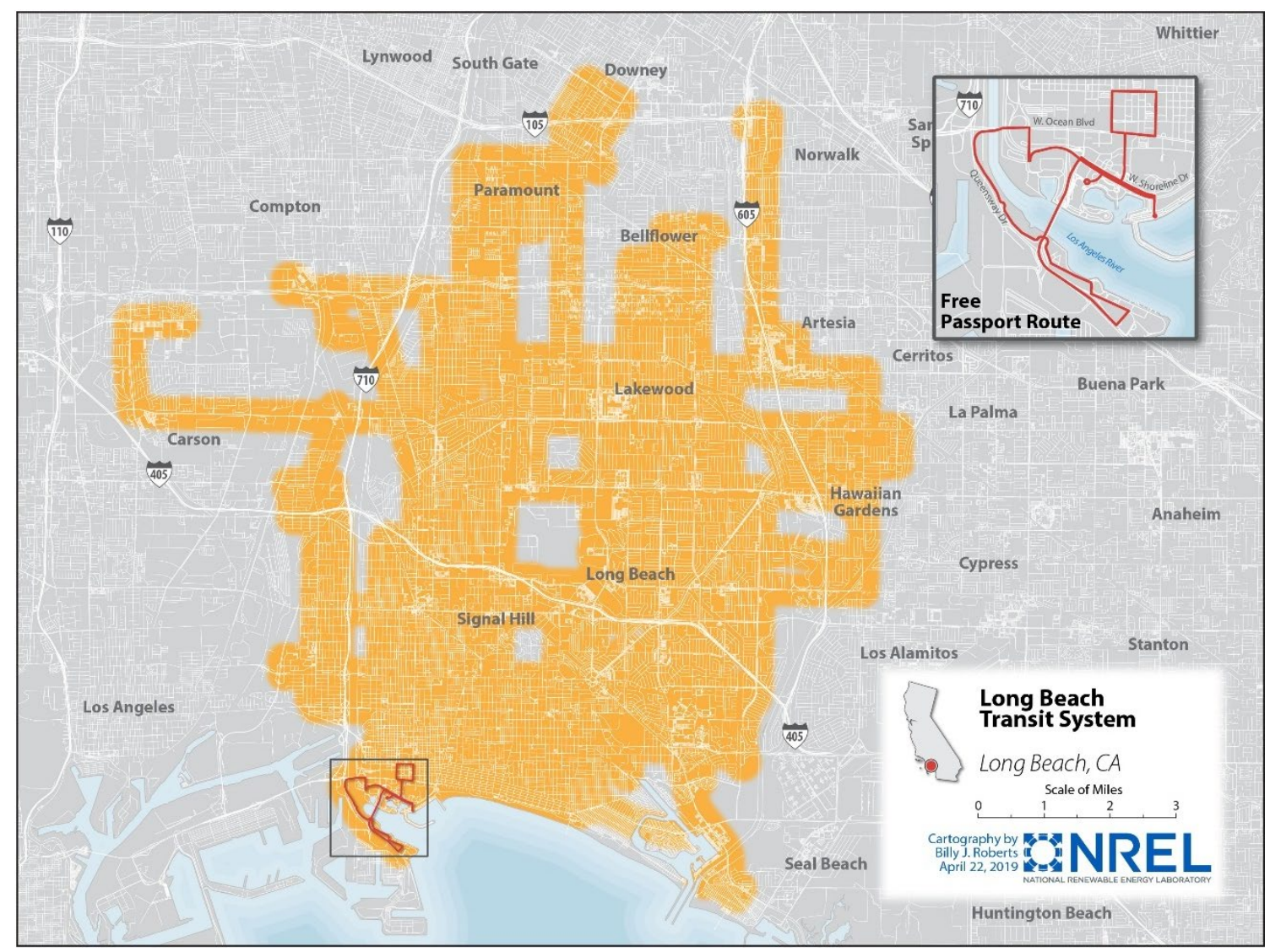

Figure 1. LBT service area 


\section{Bus Technology Descriptions}

LBT's BEBs are 40-foot BYD buses with a ferro-type lithium iron phosphate energy storage system (ESS), also produced by BYD. NREL is collecting data on a conventional fleet of eight Gillig CNG buses of similar age as the primary baseline comparison. Table 1 provides selected specifications for each bus type. The BEB purchase cost in the table includes the buses, LBT equipment (cameras, bike rack, radio), spare parts, training, and diagnostic equipment from BYD. The BEB cost also includes the WAVE inductive charging equipment that is installed onboard the bus. ${ }^{3}$ It does not include any stationary charging infrastructure (depot chargers or off-board WAVE inductive charging equipment) or installation costs for the charging equipment. A portion of the bus cost was offset by Hybrid and Zero-Emission Truck and Bus Voucher Incentive Project (HVIP) credits totaling \$1.13 million. Figure 2 is a photo of one of the BEBs. A baseline CNG bus is pictured in Figure 3.

Table 1. System Descriptions for the BEBs and CNG Buses

\begin{tabular}{|c|c|c|}
\hline Vehicle System & BEB & CNG \\
\hline Number of buses in evaluation & 10 & 8 \\
\hline Bus manufacturer & BYD & Gillig \\
\hline Bus year and model & 20176120 LGEV & 2014 G27B102N4 \\
\hline Length (ft) & 40.2 & 40 \\
\hline GVWR $^{\mathrm{a}}(\mathrm{Ib})$ & 43,431 & 41,600 \\
\hline ESS & $\begin{array}{l}\text { Ferro-type lithium iron } \\
\text { phosphate }\left(\mathrm{LiFePO}_{4}\right)\end{array}$ & N/A \\
\hline Electric drive motor or engine & $\begin{array}{c}\text { BYD-TYC90A Traction Motor } \\
90 \mathrm{~kW} \\
\end{array}$ & $\begin{array}{c}\text { Cummins ISL G280 } \\
280 \text { horsepower }\end{array}$ \\
\hline Accessories & Electric & Mechanical \\
\hline Energy storage or fuel capacity & $\begin{array}{c}324 \mathrm{kWh} \text { (original) } \\
360 \mathrm{kWh} \text { (ESS upgrade) }\end{array}$ & $25,304 \mathrm{SCF}^{\mathrm{b}}$ at $3,500 \mathrm{psi}$ \\
\hline On-board charging equipment & $\begin{array}{c}\text { 50-kW WAVE inductive } \\
\text { charging system }\end{array}$ & N/A \\
\hline Bus purchase cost (\$/bus) & $\$ 1,002,550$ & $\$ 546,314$ \\
\hline
\end{tabular}

BYD extended the bumper-to-bumper warranty of the buses to the full 12 years of the bus life. The battery warranty ensures $70 \%$ of base capacity for 12 years. Base capacity for LBT is $80 \%$ of the original capacity of $324 \mathrm{kWh}$.

${ }^{3}$ Receiving pad and electronics that allow a bus to be charged inductively 


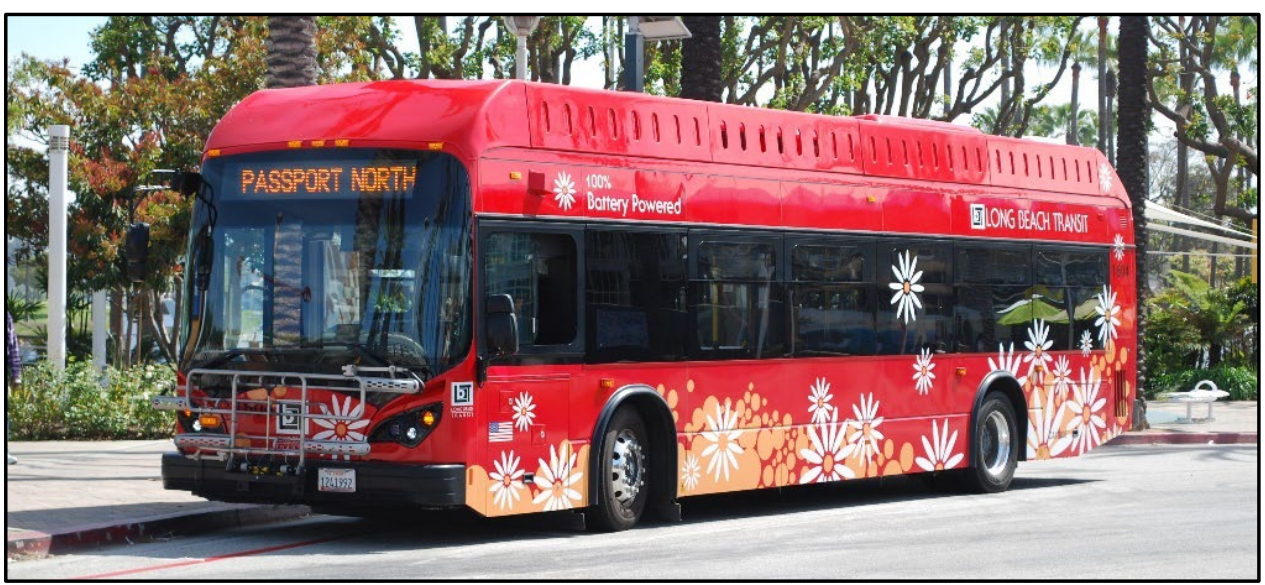

Figure 2. LBT battery electric bus

Photo by Leslie Eudy, NREL

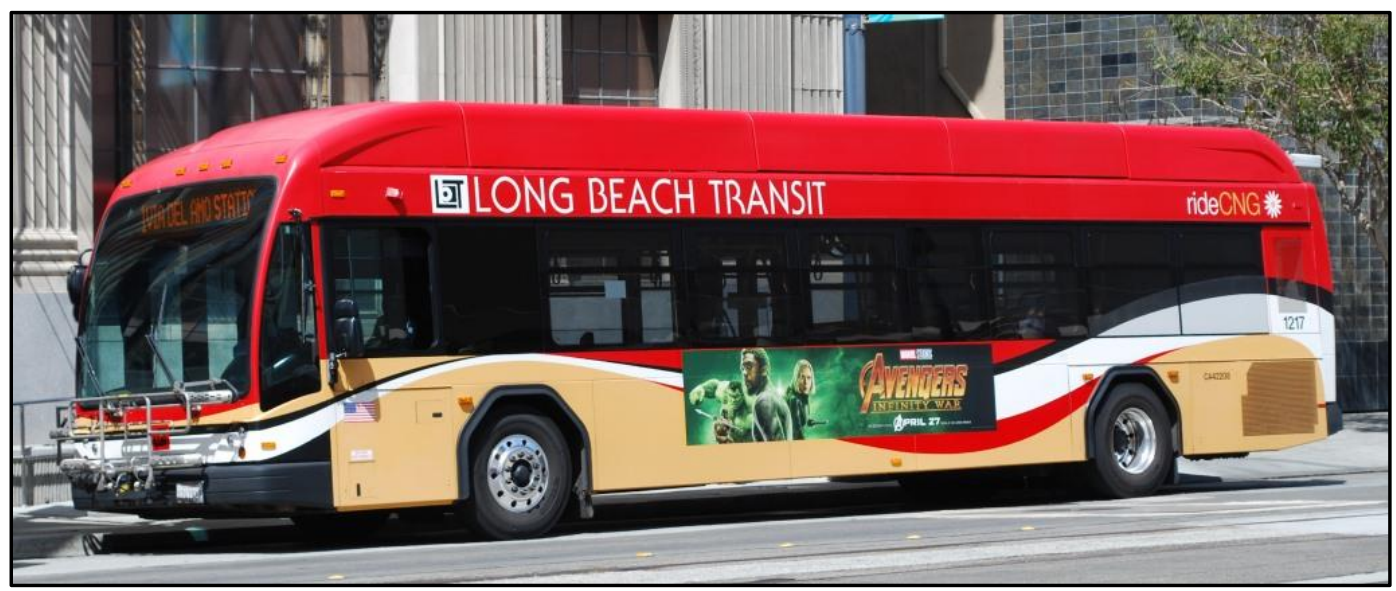

Figure 3. LBT CNG bus

Photo by Leslie Eudy, NREL 


\section{Charging Infrastructure}

\section{Depot Charging Equipment}

LBT dedicated 10 parking spaces along a wall of the facility to accommodate charging the buses. Individual chargers, provided by BYD, are installed along the wall at the head of each parking space (Figure 4). Figure 5 is a photo of one of the $80-\mathrm{kW}$ chargers. At the end of each day, the buses are serviced, parked, and plugged in for overnight charging. The 80-kW BYD chargers have two charging connectors per dispenser and each BEB has two charging receptacles. Both connectors from a dispenser are plugged into the same bus to provide the maximum power for every charging session. Two connectors from a single charging dispenser cannot be used to charge two BEBs at once. Overnight depot charging is LBT's primary means of charging the buses. The agency built its infrastructure to accommodate up to 40 chargers to allow for future growth of the BEB fleet. The charging is managed through a real-time monitoring system. At the onset of the pilot program, LBT managed electric demand costs by beginning charging of the buses after 10 p.m., when the electric utility's time-of-use (TOU) rate was lowest. This schedule has relaxed over the past year because the utility rate has been updated to waive demand charges (explained further in the next section). Four buses are typically charged simultaneously, and as each bus finishes charging, the system cycles through the remaining buses.

LBT reports that the overall cost of the infrastructure installation was $\$ 949,230$. This includes the following:

- Cost for Southern California Edison to bring power to the facility

- Electrical substation equipment and installation

- Electrical work

- Site earthwork and pavement

- Installation of charging pedestals (not including the capital cost for the charging pedestals)

The capital cost for the depot charging pedestals was approximately $\$ 9,900$ each. 


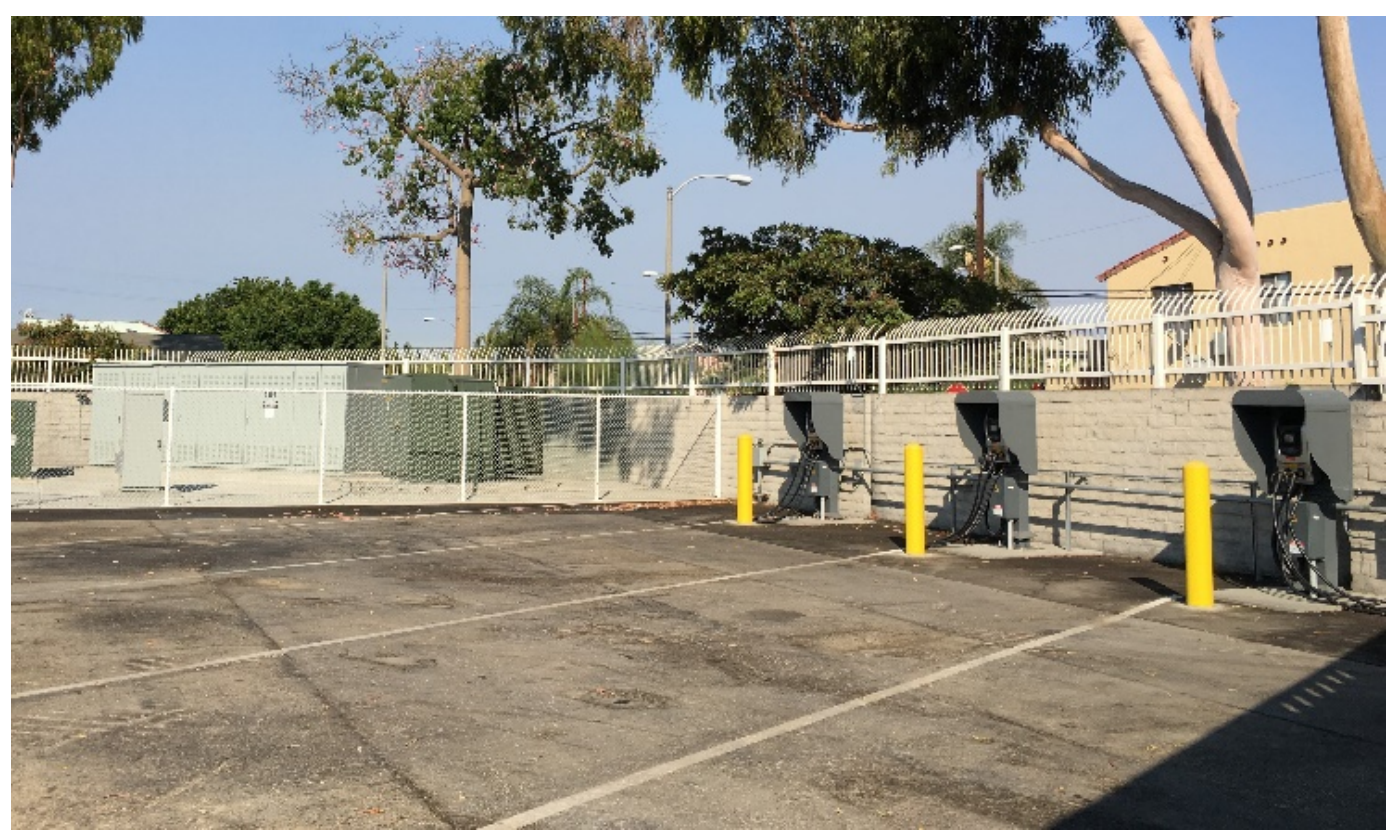

Figure 4. Row of BEB parking with chargers at the depot

Photo from Long Beach Transit

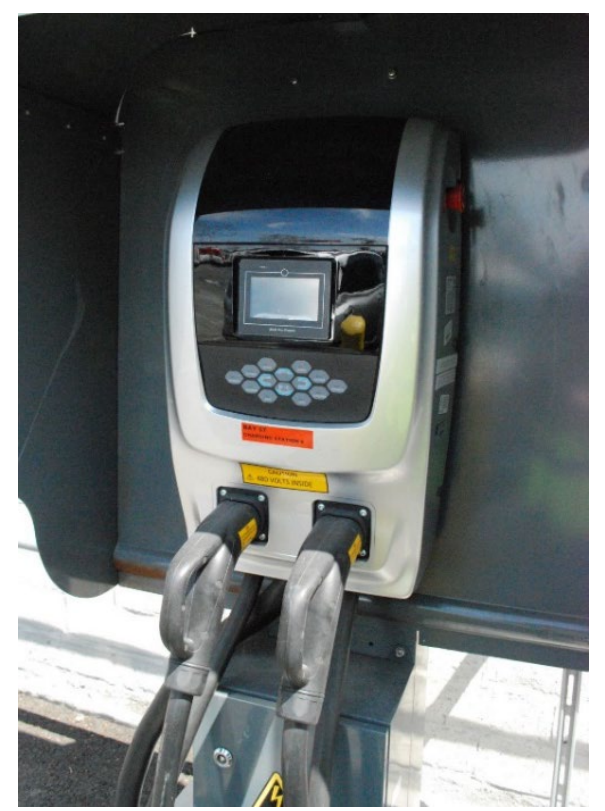

Figure 5. One of LBT's 10 chargers installed at the depot

Photo by Leslie Eudy, NREL

\section{Inductive Charging Equipment}

LBT installed a Wireless Advanced Vehicle Electrification (WAVE) inductive charger at the Convention Center stop on the Passport route to test the capabilities of the on-route charging system and provide supplemental charging to extend the bus range, if needed. The original station was planned for the Queen Mary stop, which is the end point on the route. The Passport route schedule includes time for operators to take a break at this stop, which made it an ideal 
location for the charger. Challenges getting all parties in agreement for constructing the station at this stop resulted in the need to choose another location for the inductive charger. The Long Beach Convention Center was eventually selected as the inductive charging site. Construction was delayed because of an annual event - the Grand Prix — which required use of the roads around the city, including in front of the Convention Center. Installation involved installing concrete pads for the charging equipment (WAVE electrical system cabinets and components) and utility power, trenching for connector cables from the charging equipment to the charging pad, completion of connections, and verifying system functions. Once the approvals were received, the installation of the WAVE equipment took about two months. LBT reports that the overall time for installing the WAVE charger took longer than expected because the project included other aspects that encountered delays and complications.

Once the charger installation was complete, a WAVE field engineer verified and tested all the inductive equipment connections and functions on the bus (charge receiving side), then tested the charger equipment (charge transmitting side) to ensure it could provide an adequate charge. Commissioning for the first bus took about 4 hours; subsequent buses took less time.

The agency has not used the charger on a regular basis because the BEB range meets current block schedules. Figure 6 shows the WAVE inductive charging station at the Convention Center. The charging equipment is in the foreground of the picture and the circular charging pad is on the street. The overall cost of the project was $\$ 1.5$ million. This includes earthwork, electrical work, WAVE equipment installation, technical services, management, and contractor fees. It does not include the capital cost of the WAVE inductive charging equipment at the station which cost around $\$ 350,000$.

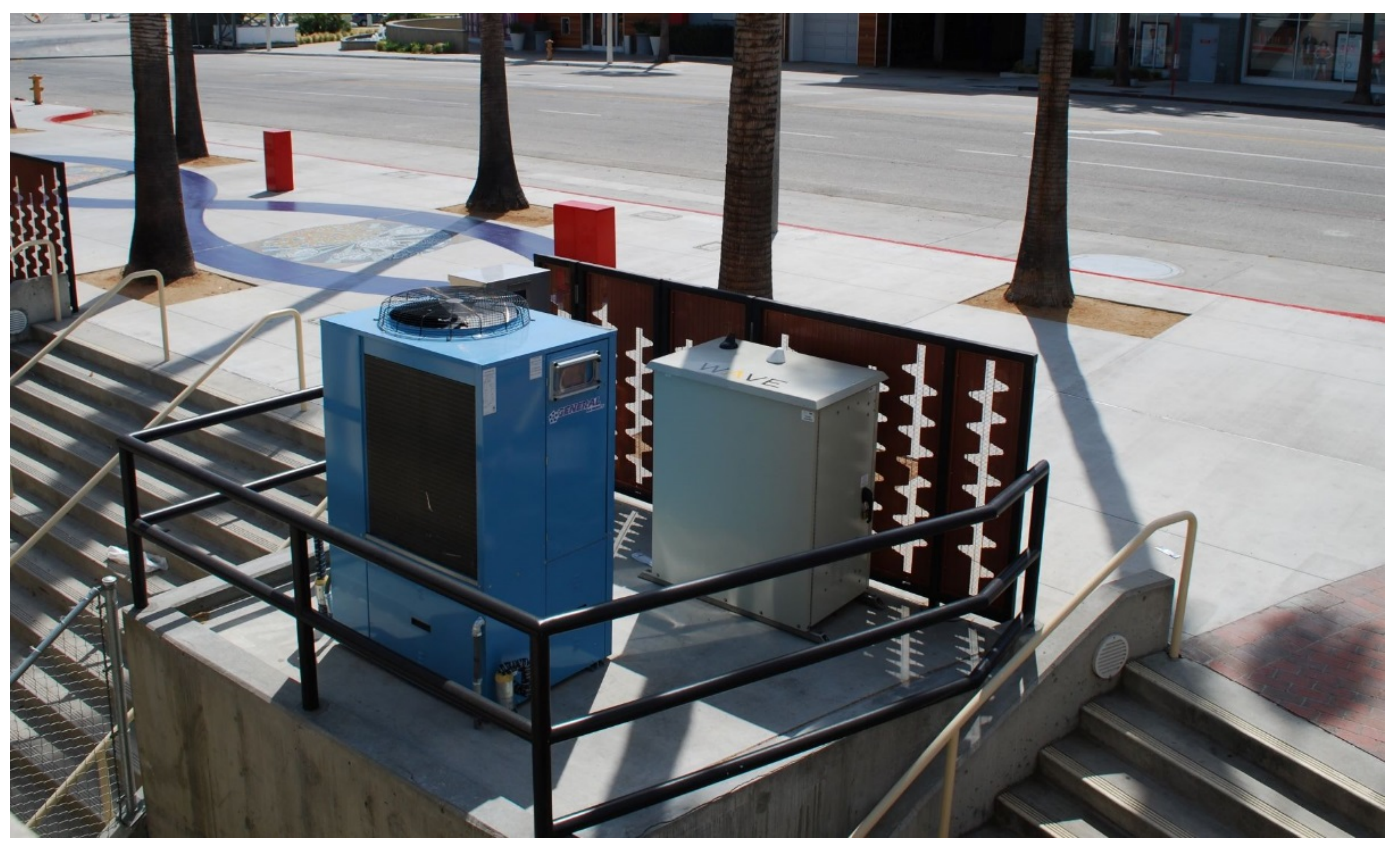

Figure 6. WAVE inductive charging station installed at the Long Beach Convention Center Photo by Leslie Eudy, NREL 


\section{In-Service Operations Evaluation Results}

LBT began placing the BEBs into service in March 2017. NREL follows a standard evaluation protocol, outlined in a previous report, that establishes the start - or clean point — of the evaluation period. ${ }^{4}$ This report focuses on the second full year of operation after the clean point, from January 2019 through December 2019 (2019 data period). To show overall trends, most of the figures include the full 2-year evaluation period of 2018 and 2019 (evaluation period). The averages included in the figures are for the full evaluation period and do not necessarily match the averages in the tables.

\section{Route Assignments}

The BEBs are planned to operate on the Passport route, which is a free shuttle that travels around the waterfront area between the Queen Mary and downtown Long Beach. Figure 7 shows the Passport route. The route operates every day of the week. LBT has three service adjustments each year that could change the number of buses required for this and other routes. During the evaluation, the number of buses required on the Passport route ranged from four to six buses on weekdays and from five to eight buses on weekends. In September 2019, LBT began operating the BEBs on other routes, although the majority were assigned to the Passport route. For the last half of $2019,80 \%$ of the BEB operation days were on the Passport route. The selected baseline CNG buses are randomly dispatched with the rest of LBT's total bus fleet. Based on scheduled blocks, the average speed for the agency overall is $10.3 \mathrm{mph}$. The average speed of the Passport route is $8.1 \mathrm{mph}$. NREL collected data on CNG buses previously operated on the Passport route to provide a baseline fuel economy comparison for buses in the same service.

\footnotetext{
${ }^{4}$ Leslie Eudy and Matthew Jeffers, "Section 2: Zero-Emission Bus Evaluations Planned," in Zero-Emission Bus Evaluation Results: King County Metro Battery Electric Buses, FTA Report No. 0118, February 2018, https:/www.transit.dot.gov/sites/fta.dot.gov/files/docs/research-innovation/115086/zero-emission-bus-evaluationresults-king-county-metro-battery-electric-buses-fta-report-no-0118.pdf.
} 


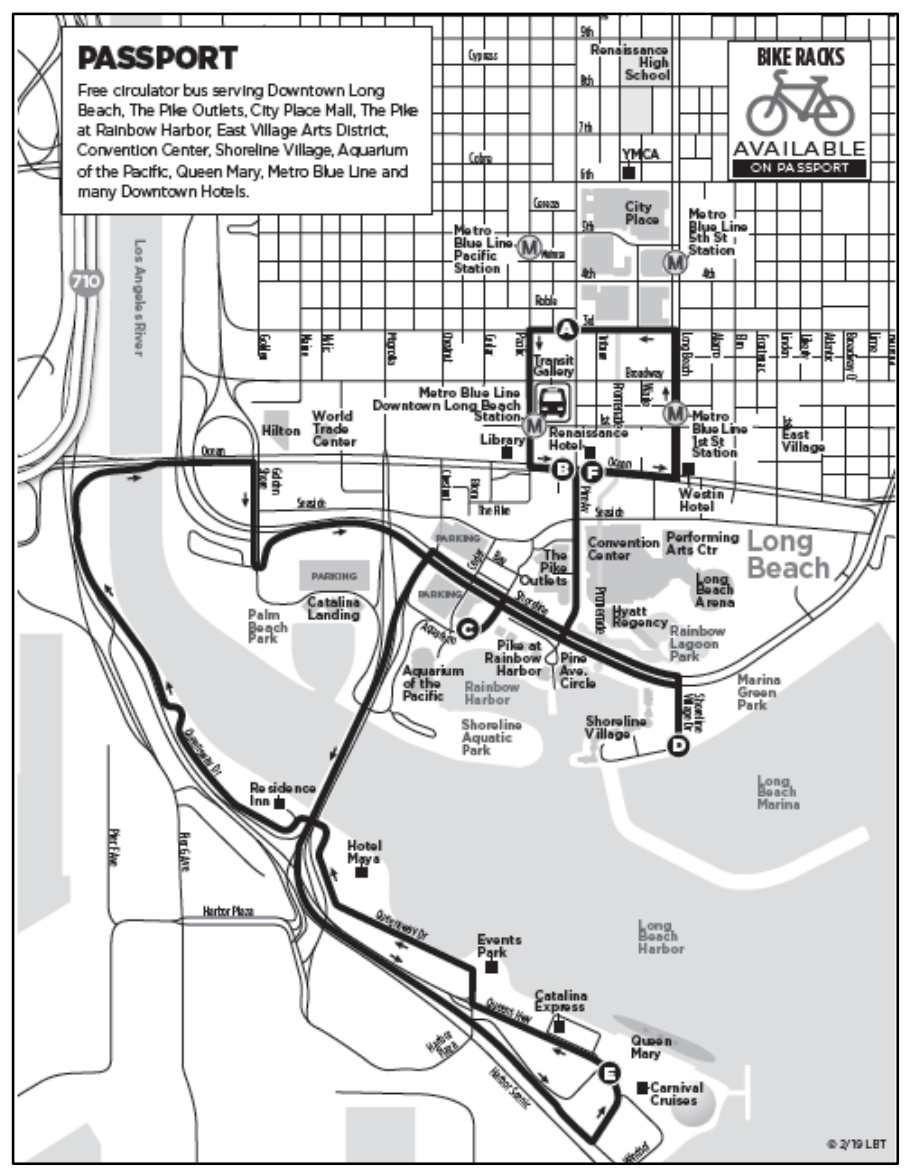

Figure 7. Map of the Passport shuttle route

Image from LBT

\section{Bus Use}

Figure 8 tracks the accumulated mileage of the BEBs since they were placed into service. The first in-service month for each bus is marked along the trend line. Since the first few BEBs began entering service, the BEB fleet has accumulated more than 462,000 combined miles as of the end of the two-year evaluation period. During 2019, LBT accumulated over 192,000 miles on the BEB fleet. 


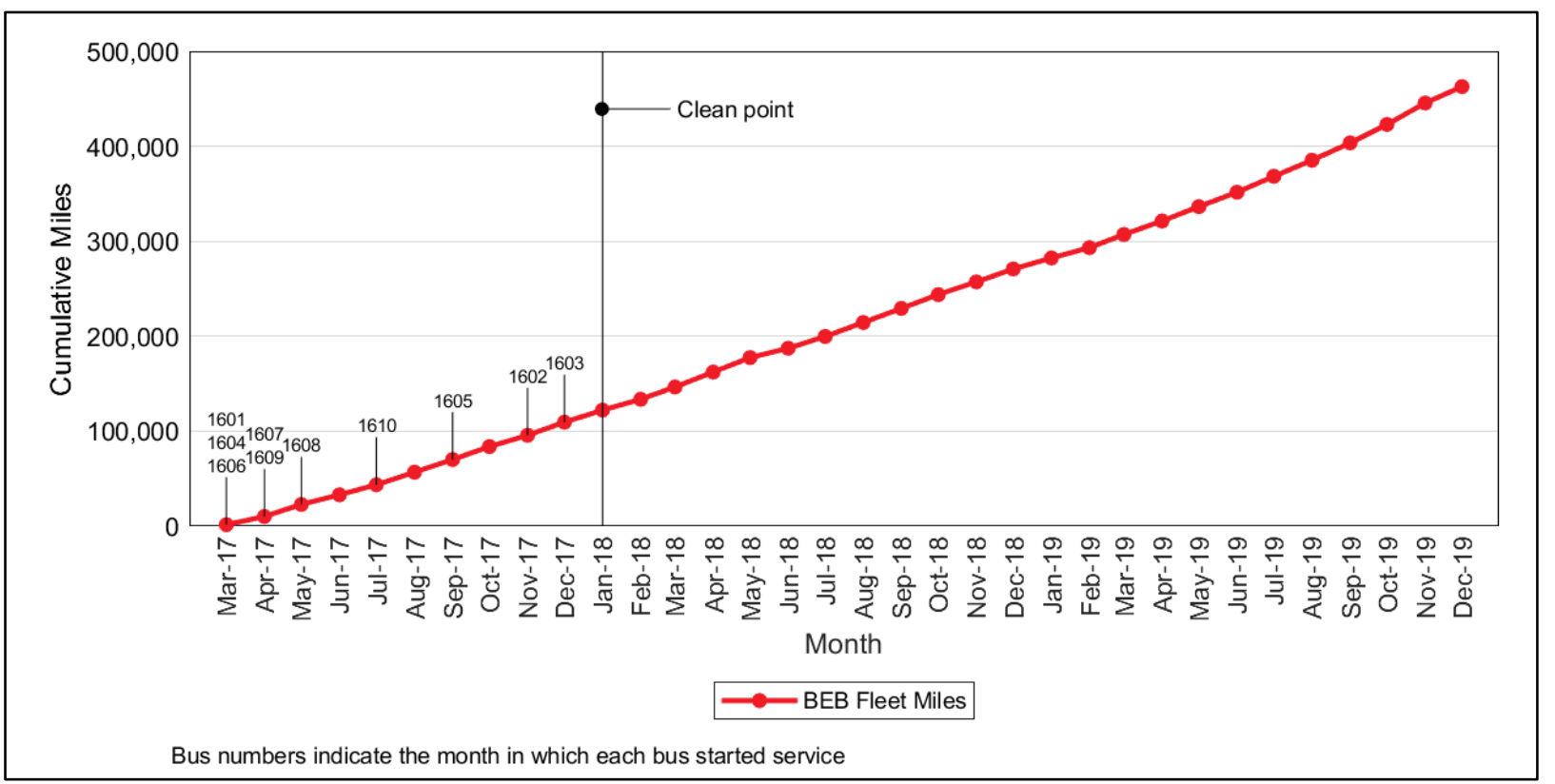

Figure 8. Cumulative miles for the BEB fleet

Table 2 provides the evaluation period mileage for each bus and the average monthly mileage by bus type, which is also displayed in Figure 9. The monthly mileage of the BEBs has increased over what was reported previously. In 2019, the BEBs averaged 1,600 monthly miles per bus. While this is lower than the baseline CNG bus fleet average of 3,586 monthly miles per bus, this is a direct result of the planned operation of the bus fleets in different service. 
Table 2. Average Monthly Mileage (2019 Data Period)

\begin{tabular}{|c|c|c|c|}
\hline Bus \# & Miles & $\begin{array}{c}\text { Bus } \\
\text { Months }\end{array}$ & $\begin{array}{c}\text { Average } \\
\text { Monthly } \\
\text { Mileage }\end{array}$ \\
\hline 1601 & 23,338 & 12 & 1,945 \\
\hline 1602 & 15,234 & 12 & 1,270 \\
\hline 1603 & 19,649 & 12 & 1,637 \\
\hline 1604 & 17,927 & 12 & 1,494 \\
\hline 1605 & 25,086 & 12 & 2,091 \\
\hline 1606 & 20,664 & 12 & 1,722 \\
\hline 1607 & 24,696 & 12 & 2,058 \\
\hline 1608 & 16,533 & 12 & 1,378 \\
\hline 1609 & 10,811 & 12 & 901 \\
\hline 1610 & 18,068 & 12 & 1,506 \\
\hline $\begin{array}{c}\text { BEB } \\
\text { Fleet }\end{array}$ & $\mathbf{1 9 2 , 0 0 6}$ & $\mathbf{1 2 0}$ & $\mathbf{1 , 6 0 0}$ \\
\hline
\end{tabular}

\begin{tabular}{|c|c|c|c|}
\hline Bus \# & Miles & $\begin{array}{c}\text { Bus } \\
\text { Months }\end{array}$ & $\begin{array}{c}\text { Average } \\
\text { Monthly } \\
\text { Mileage }\end{array}$ \\
\hline 1521 & 46,594 & 12 & 3,883 \\
\hline 1522 & 46,586 & 12 & 3,882 \\
\hline 1523 & 43,819 & 12 & 3,652 \\
\hline 1524 & 49,069 & 12 & 4,089 \\
\hline 1525 & 46,815 & 12 & 3,901 \\
\hline 1526 & 29,627 & 12 & 2,469 \\
\hline 1527 & 43,589 & 12 & 3,632 \\
\hline 1528 & 38,137 & 12 & 3,178 \\
\hline & & & \\
\hline & & & \\
\hline $\begin{array}{l}\text { CNG } \\
\text { Fleet }\end{array}$ & $\mathbf{3 4 4 , 2 3 6}$ & $\mathbf{9 6}$ & $\mathbf{3 , 5 8 6}$ \\
\hline
\end{tabular}

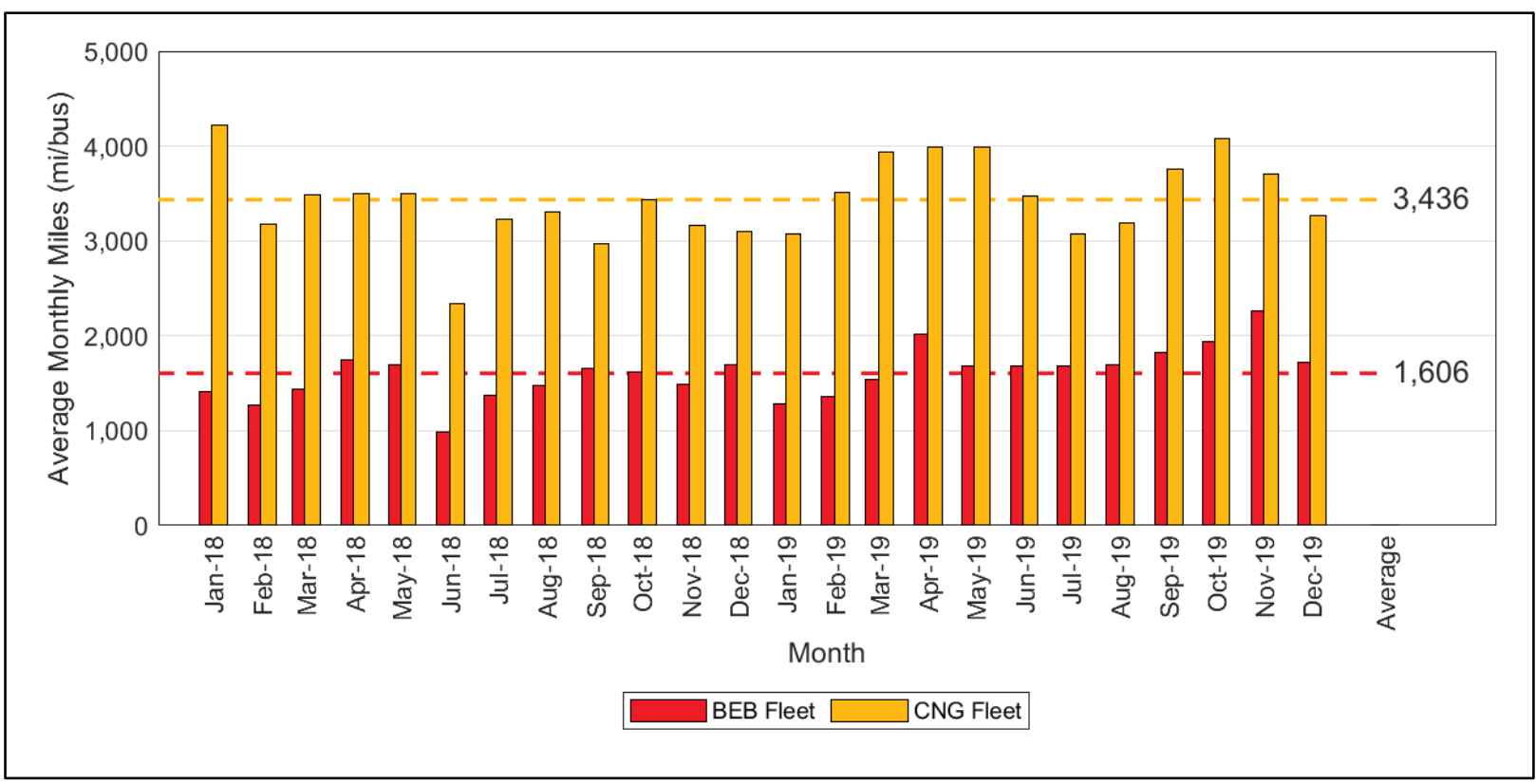

Figure 9. Average monthly miles for BEB and CNG fleets (Evaluation Period)

\section{Availability}

The availability analysis focuses on the 2019 data period. Planned service for LBT is seven days per week for both the BEB and CNG bus fleets; however, the Passport route does not require all 10 buses to meet service. The data presented are based on availability at both morning and afternoon pull-out. Buses available for both pull-outs would get credit for one day available; if a bus was available for morning pull-out but not afternoon pull-out, that day would count as 0.5 available. The overall average availability for the BEBs during the 2019 data period was $71.3 \%$. The CNG fleet availability was $83.4 \%$. Table 3 provides the availability for each bus and the overall fleet totals. 
Table 3. Availability for the BEB and CNG Buses (2019 Data Period)

\begin{tabular}{|c|c|c|c|c|c|c|c|}
\hline Bus \# & $\begin{array}{l}\text { Planned } \\
\text { Days }\end{array}$ & $\begin{array}{l}\text { Available } \\
\text { Days }\end{array}$ & $\begin{array}{c}\% \\
\text { Availability }\end{array}$ & Bus \# & $\begin{array}{l}\text { Planned } \\
\text { Days }\end{array}$ & $\begin{array}{l}\text { Available } \\
\text { Days }\end{array}$ & $\begin{array}{c}\% \\
\text { Availability }\end{array}$ \\
\hline 1601 & 311 & 252 & $81.0 \%$ & 1521 & 365 & 314.5 & $86.2 \%$ \\
\hline 1602 & 294 & 189.5 & $64.5 \%$ & 1522 & 365 & 306.5 & $84.0 \%$ \\
\hline 1603 & 349.5 & 239 & $68.4 \%$ & 1523 & 361.5 & 329.5 & $91.1 \%$ \\
\hline 1604 & 318 & 219 & $68.9 \%$ & 1524 & 365 & 324 & $88.8 \%$ \\
\hline 1605 & 309 & 248.5 & $80.4 \%$ & 1525 & 365 & 321.5 & $88.1 \%$ \\
\hline 1606 & 343.5 & 285.5 & $83.1 \%$ & 1526 & 358 & 210.5 & $58.8 \%$ \\
\hline 1607 & 365 & 259.5 & $71.1 \%$ & 1527 & 365 & 322 & $88.2 \%$ \\
\hline 1608 & 310 & 227.5 & $73.4 \%$ & 1528 & 365 & 297.5 & $81.5 \%$ \\
\hline 1609 & 206 & 107.5 & $52.2 \%$ & & & & \\
\hline 1610 & 365 & 234.5 & $64.2 \%$ & & & & \\
\hline BEB Fleet & $3,171.0$ & $2,262.5$ & $71.3 \%$ & CNG Fleet & $2,909.5$ & $2,426.0$ & $83.4 \%$ \\
\hline
\end{tabular}

Figure 10 tracks the monthly average availability for the BEBs and CNG buses as line series along the top of the chart. The stacked columns in the figure show the number of days that the BEBs were unavailable, organized into six categories - general bus maintenance, preventive maintenance (PM), electric drive system, energy storage system (ESS), bus charging issues and transmission. The general bus maintenance category includes anything that does not fall into one of the other categories.

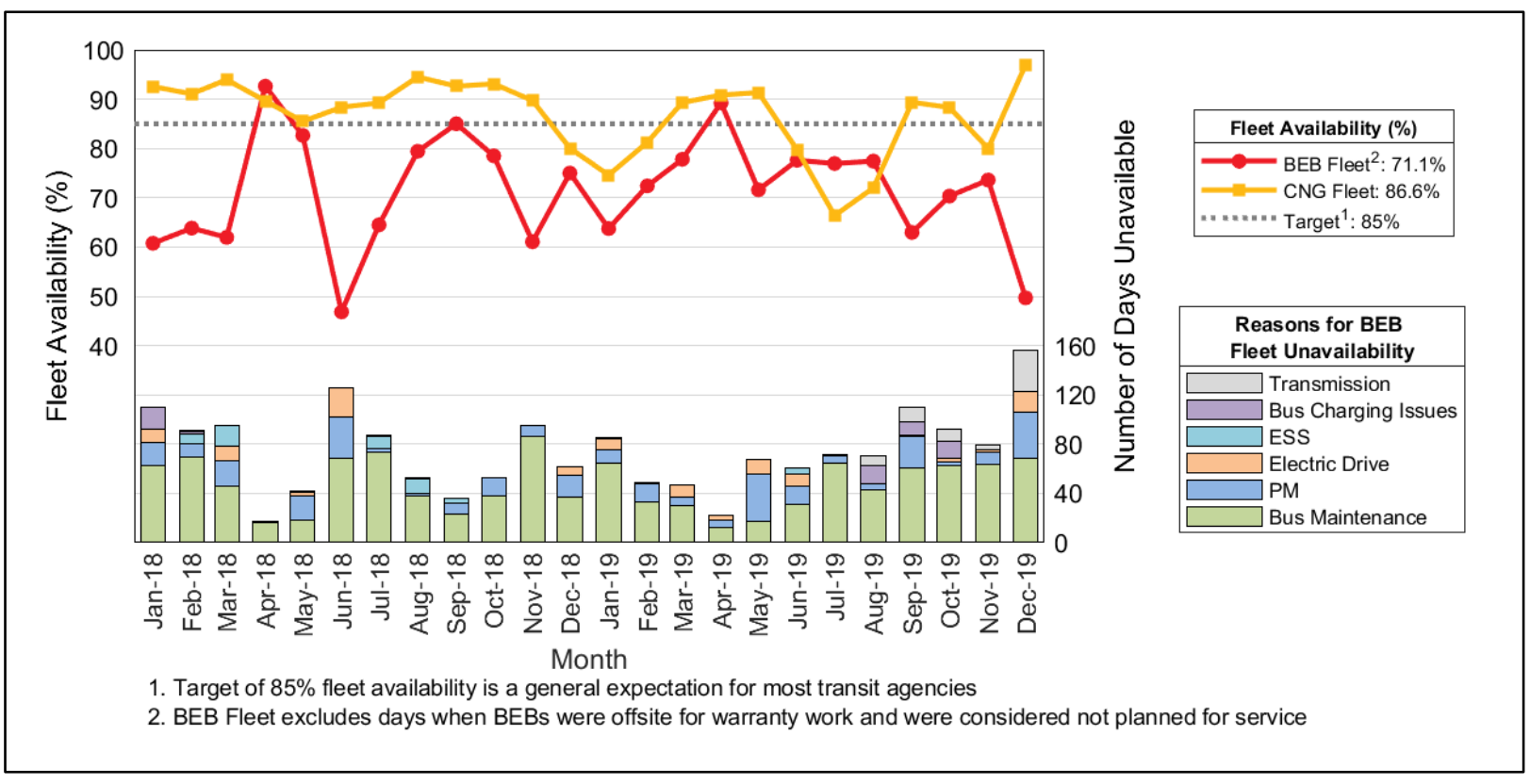

Figure 10. Monthly availability and reasons for unavailability for the BEB fleet (Evaluation Period)

Figure 11 and Figure 12 display the monthly availability by individual bus for the BEB and CNG fleets, respectively. The top edge of each stacked area chart corresponds to the overall fleet availability trend, and the layers represent the relative contribution of each bus to the total 
monthly availability of the fleet. Periods when a bus was less available show up as narrower layers for those months. The legends in the figures contain the average availability of each bus during the two years of operation displayed in the chart. The overall average for the bus fleet as a whole is also displayed (note that individual bus percentage numbers displayed are not additive to the fleet total, but the underlying number of days available and days planned for each bus are additive to the fleet total).

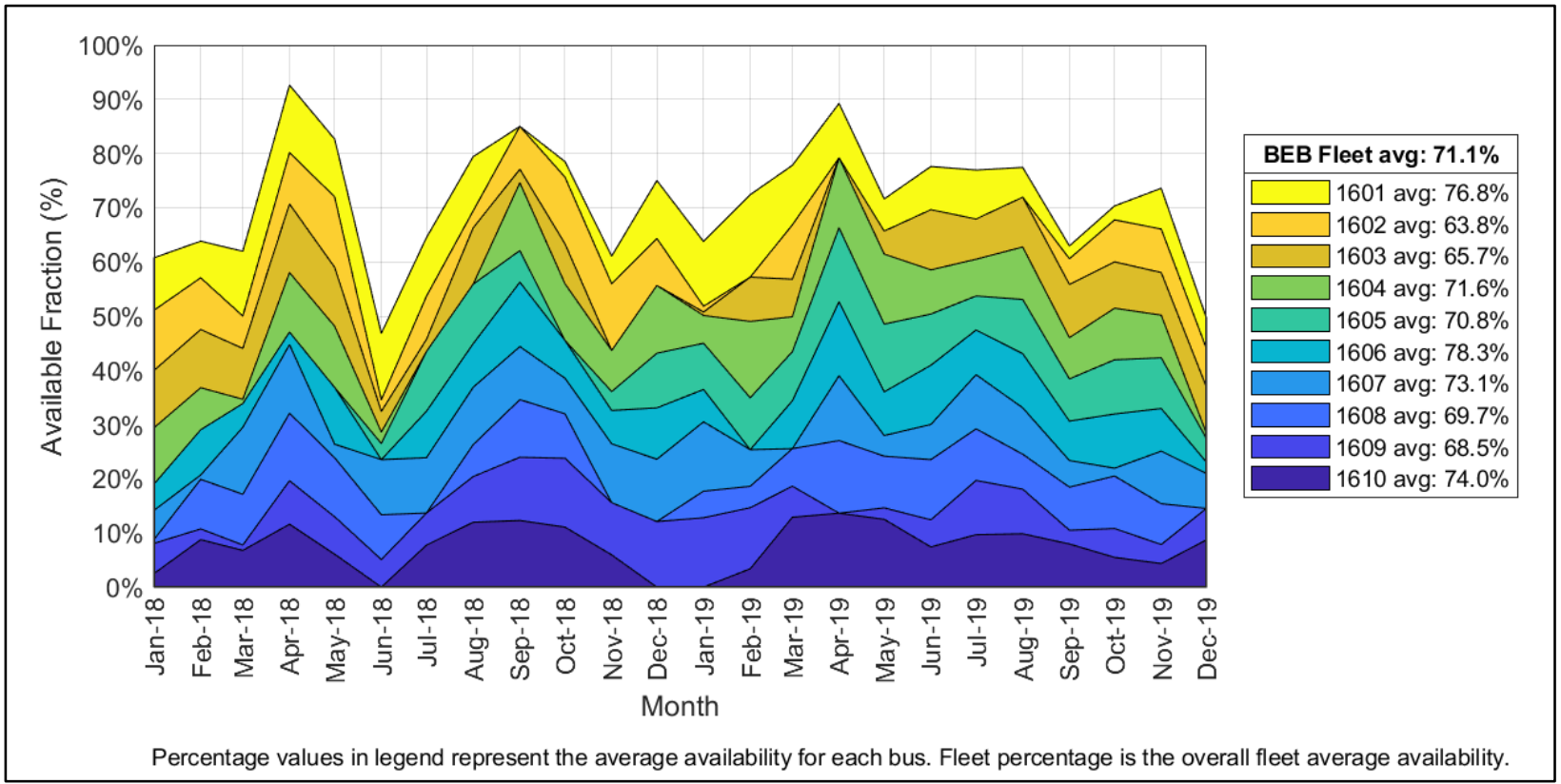

Figure 11. Monthly availability by bus for the BEB fleet (Evaluation Period)

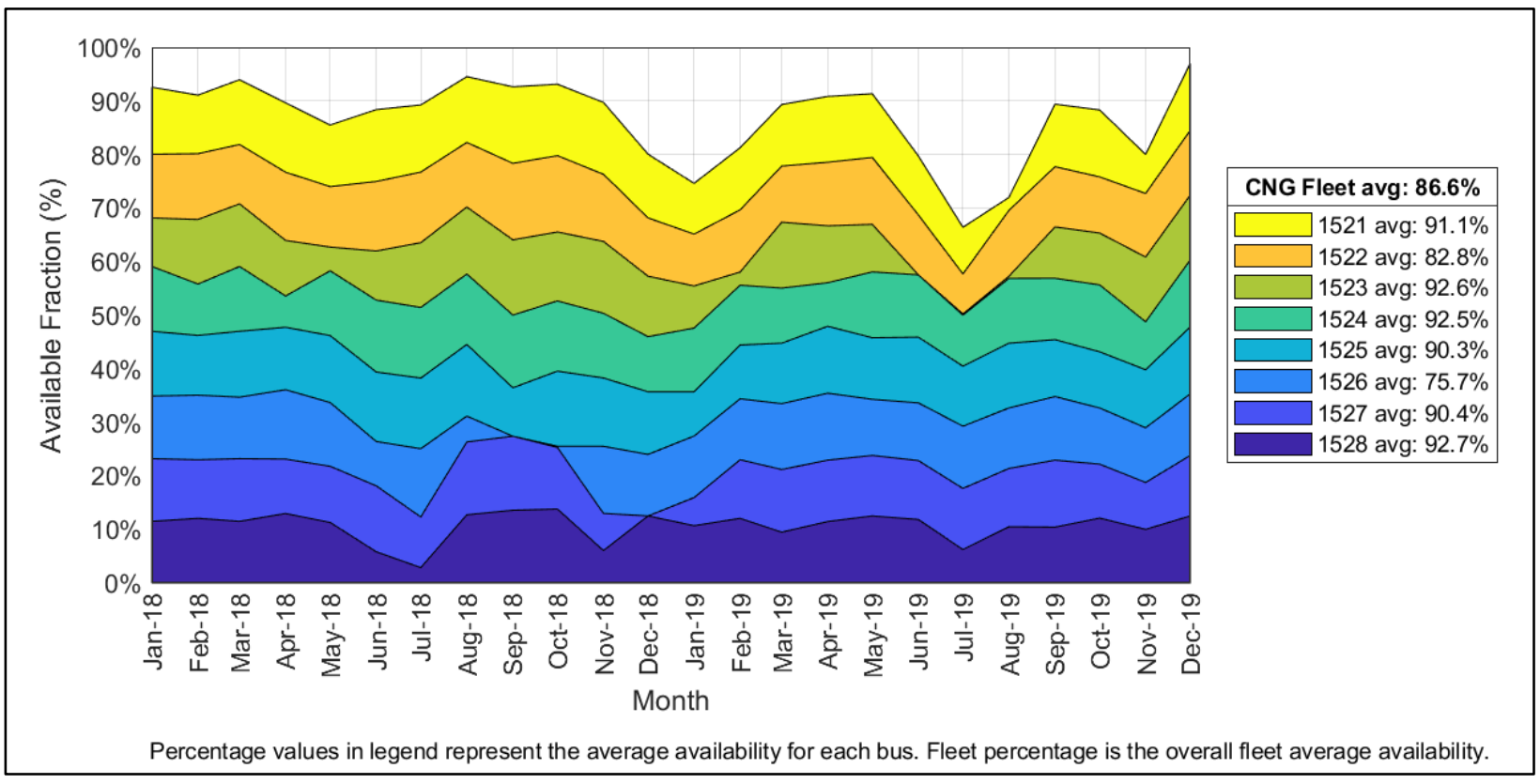

Figure 12. Monthly availability by bus for the CNG fleet (Evaluation Period) 
Figure 13 shows the overall percentage of available days for the BEB and CNG fleets, the percentage of days each fleet was unavailable for service, and the reasons for unavailability. The unavailability categories are general bus maintenance, preventive maintenance (PM), electric drive system, energy storage system (ESS), charging issues, transmission and engine. The electric drive, ESS, and charging issues categories apply only to the BEB fleet, and the engine category applies only to the $\mathrm{CNG}$ fleet. These pie charts represent fleet availability during the second year of the evaluation, from January 2019 through December 2019. Table 4 corresponds to Figure 13 and provides a breakdown of the number of days and availability percentages for each category.

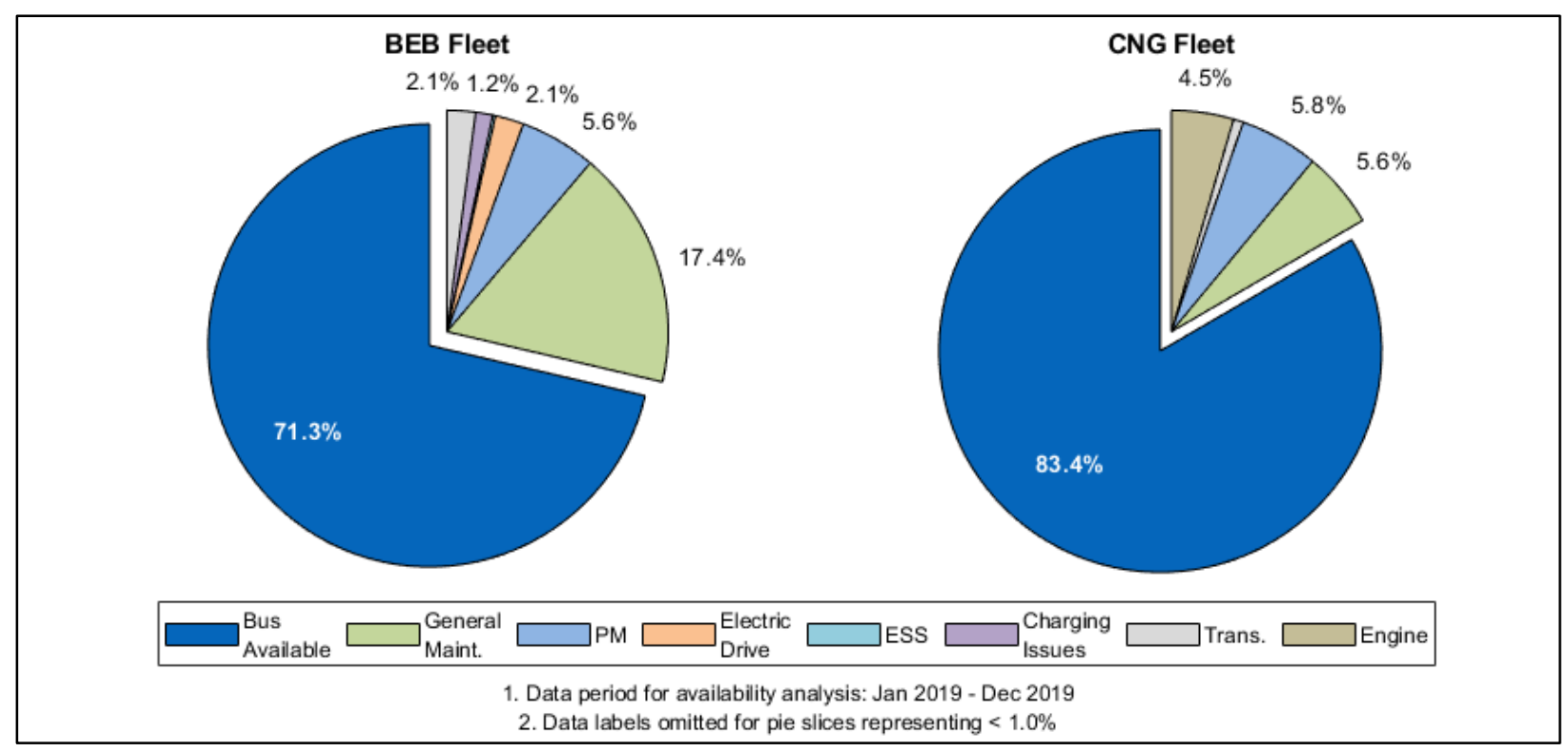

Figure 13. Overall availability for the BEB and CNG fleets (2019 Data Period)

Table 4. Summary of Availability and Unavailability by Category (2019 Data Period)

\begin{tabular}{|l|c|c|c|c|}
\hline \multicolumn{1}{|c|}{ Category } & $\begin{array}{c}\text { BEB } \\
\text { \# Days }\end{array}$ & $\begin{array}{c}\text { BEB } \\
\%\end{array}$ & $\begin{array}{c}\text { CNG } \\
\text { \# Days }\end{array}$ & $\begin{array}{c}\text { CNG } \\
\%\end{array}$ \\
\hline Planned Days & $3,171.0$ & - & $2,909.5$ & - \\
\hline Days Available & $2,262.5$ & 71.3 & $2,426.0$ & 83.4 \\
\hline Days Unavailable & 908.5 & 28.7 & 483.5 & 16.6 \\
\hline General Bus Maintenance & 553.0 & 17.4 & 163.0 & 5.6 \\
\hline Preventive Maintenance & 177.5 & 5.6 & 167.5 & 5.8 \\
\hline Electric Drive & 66.0 & 2.1 & - & - \\
\hline ESS & 6.5 & 2.1 & - & - \\
\hline Charging Issues & 39.5 & 1.2 & - & - \\
\hline Transmission & 66.0 & 2.1 & 21.0 & .07 \\
\hline Engine & - & - & 132.0 & 4.5 \\
\hline
\end{tabular}

Many of the issues affecting availability involved general bus systems not related to the advanced technology. General bus issues included problems with doors, axels, suspension, fire 
suppression, air system, cameras, and wheelchair ramps. Advanced technology issues included problems with the inductive charging system, electric drive, and high-voltage batteries.

LBT purchased the fleet of 10 BEBs to electrify transit service on the Passport route, which does not require the entire $\mathrm{BEB}$ fleet. In addition to tracking the daily availability of each $\mathrm{BEB}, \mathrm{NREL}$ evaluated the effectiveness of the BEB fleet against LBT's goal of fulfilling all scheduled service on the Passport route (Figure 14). Spare CNG buses were used to fill in any time there were not enough BEBs available. LBT has three service adjustments each year. During most of the evaluation period, the Passport service required only six buses on weekdays and eight buses on weekends to meet daily service. Figure 14 shows the monthly percentage of the Passport route service that was electrified by the BEB fleet, ranging from a minimum of $51.5 \%$ in June 2018 to a maximum of $97.6 \%$ in August 2019. The average was $83.9 \%$ for the 2019 data period.

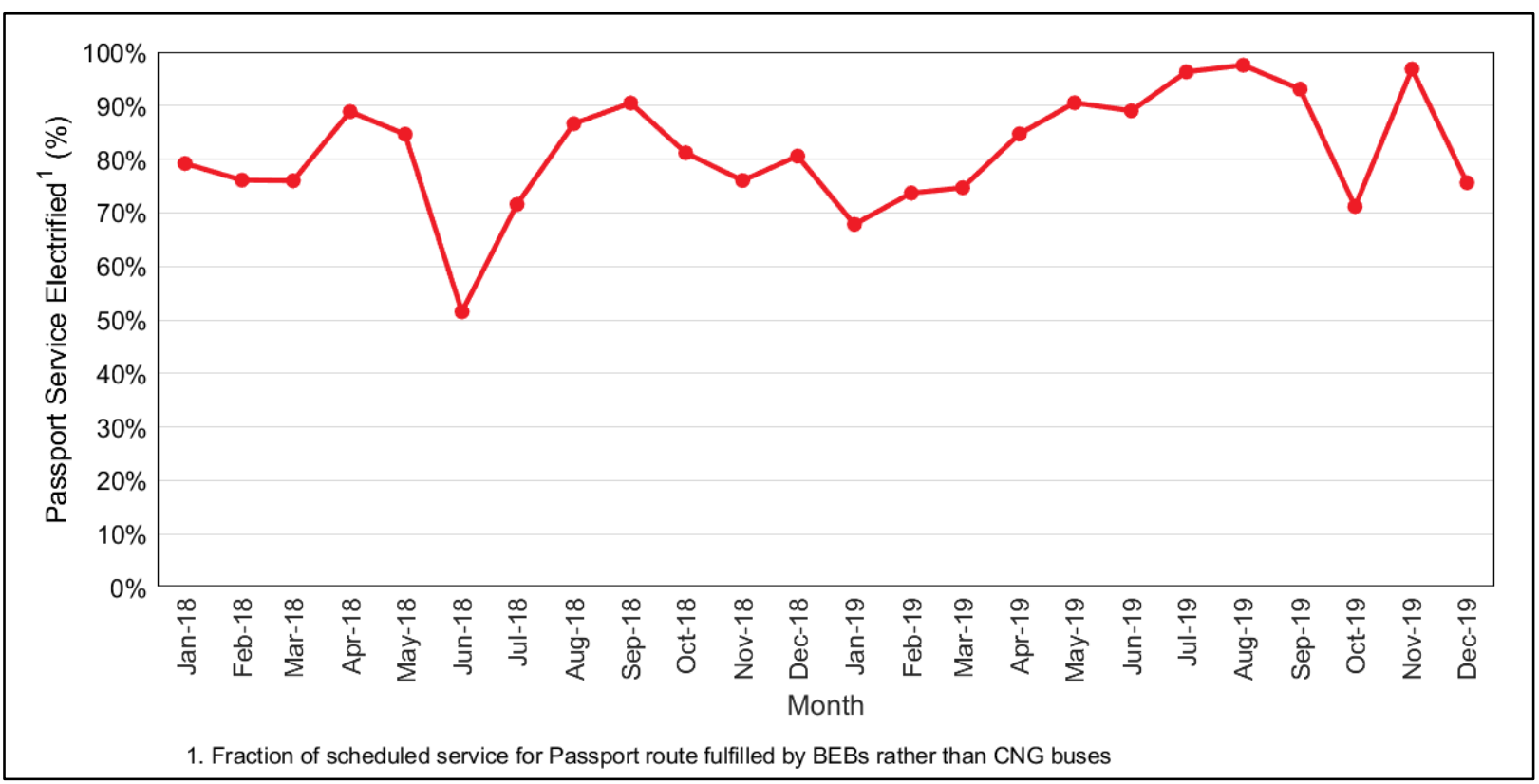

Figure 14. Monthly Passport service fulfilled by BEB fleet (Evaluation Period)

\section{Energy Consumption, Fuel Economy, and Cost}

Table 5 lists the per-bus mileage, energy consumption, efficiency, and equivalent fuel economy for the BEB fleet. Table 6 provides the per-bus mileage, fuel consumption, and fuel economy for the CNG fleet. Electricity consumption in kilowatt-hours $(\mathrm{kWh})$ was converted to diesel gallon equivalent (dge) according to the per-unit energy content of each fuel. CNG consumption was reported by the agency in dge and was also converted to gasoline gallon equivalent (gge) for reference. The conversion factor used for electricity was $37.64 \mathrm{kWh} / \mathrm{dge}$, and the conversion factor used for CNG was 1.146 gge/dge. 
Table 5. BEB Mileage, Energy Consumption, and Equivalent Fuel Economy (2019 Data Period)

\begin{tabular}{|c|c|c|c|c|c|}
\hline Bus & $\begin{array}{c}\text { Mileage } \\
\text { (fuel base) }\end{array}$ & $\begin{array}{c}\text { Energy } \\
\text { Consumption } \\
\text { (kWh) }\end{array}$ & $\begin{array}{c}\text { Fuel } \\
\text { Consumption } \\
\text { (dge) }\end{array}$ & $\begin{array}{c}\text { Efficiency } \\
\text { (kWh/mi) }\end{array}$ & $\begin{array}{c}\text { Fuel } \\
\text { Economy } \\
\text { (mpdge) }\end{array}$ \\
\hline 1601 & 21,729 & $42,773.4$ & $1,136.5$ & 1.97 & 19.12 \\
\hline 1602 & 14,453 & $26,413.6$ & 701.8 & 1.83 & 20.59 \\
\hline 1603 & 17,394 & $32,548.9$ & 864.8 & 1.87 & 20.11 \\
\hline 1604 & 16,652 & $33,695.3$ & 895.3 & 2.02 & 18.60 \\
\hline 1605 & 24,528 & $47,206.4$ & $1,254.3$ & 1.92 & 19.56 \\
\hline 1606 & 19,234 & $36,474.2$ & 969.1 & 1.90 & 19.85 \\
\hline 1607 & 23,595 & $46,627.8$ & $1,238.9$ & 1.98 & 19.04 \\
\hline 1608 & 15,024 & $29,446.1$ & 782.4 & 1.96 & 19.20 \\
\hline 1609 & 10,036 & $20,291.9$ & 539.2 & 2.02 & 18.61 \\
\hline 1610 & 16,641 & $33,182.8$ & 881.7 & 1.99 & 18.87 \\
\hline BEB Fleet & $\mathbf{1 7 9 , 2 8 6}$ & $\mathbf{3 4 8 , 6 6 0 . 4}$ & $\mathbf{9 , 2 6 4 . 1}$ & $\mathbf{1 . 9 4}$ & $\mathbf{1 9 . 3 5}$ \\
\hline
\end{tabular}

Table 6. CNG Bus Mileage, Fuel Consumption, and Fuel Economy (2019 Data Period)

\begin{tabular}{|c|c|c|c|c|c|}
\hline Bus & $\begin{array}{c}\text { Mileage } \\
\text { (fuel base) }\end{array}$ & $\begin{array}{c}\text { Fuel } \\
\text { Consumption } \\
\text { (gge) }\end{array}$ & $\begin{array}{c}\text { Fuel } \\
\text { Consumption } \\
\text { (dge) }\end{array}$ & $\begin{array}{c}\text { Fuel Economy } \\
\text { (mpgge) }\end{array}$ & $\begin{array}{c}\text { Fuel } \\
\text { Economy } \\
\text { (mpdge) }\end{array}$ \\
\hline 1521 & 45,105 & $13,577.2$ & $11,847.0$ & 3.32 & 3.81 \\
\hline 1522 & 41,840 & $12,731.9$ & $11,109.4$ & 3.29 & 3.77 \\
\hline 1523 & 43,341 & $14,009.5$ & $12,224.2$ & 3.09 & 3.55 \\
\hline 1524 & 48,112 & $15,640.0$ & $13,646.9$ & 3.08 & 3.53 \\
\hline 1525 & 45,158 & $13,975.6$ & $12,194.6$ & 3.23 & 3.70 \\
\hline 1526 & 28,087 & $8,594.7$ & $7,499.4$ & 3.27 & 3.75 \\
\hline 1527 & 42,394 & $12,781.4$ & $11,152.6$ & 3.32 & 3.80 \\
\hline 1528 & 36,987 & $11,582.0$ & $10,106.1$ & 3.19 & 3.66 \\
\hline CNG Fleet & $\mathbf{3 3 1 , 0 2 4}$ & $\mathbf{1 0 2 , 8 9 2 . 4}$ & $\mathbf{8 9 , 7 8 0 . 2}$ & $\mathbf{3 . 2 2}$ & $\mathbf{3 . 6 9}$ \\
\hline
\end{tabular}

Figure 15 shows the monthly average fuel economy in miles per diesel gallon equivalent (mpdge) for the BEB and CNG bus fleets. A vehicle's drive cycle is an important factor in the fuel economy it can attain. Included in the fuel economy analysis are historical data of a fleet of LBT's 1200-series CNG buses operating on the Passport route from September 2015 through August 2016. The monthly averages have been aligned with the calendar months for 2019 and plotted in the figure for reference. Also plotted in Figure 15 is the average daily high temperature recorded at Long Beach Daugherty Airport ${ }^{5}$ to highlight seasonal variation of fuel economy.

The fuel economy for the CNG fleet is very consistent throughout the evaluation period, averaging 3.3 mpdge on the Passport route and 3.6 mpdge in random-dispatch service. The fuel economy for the BEB fleet is relatively consistent but demonstrates minor seasonal variation

\footnotetext{
${ }^{5}$ NOAA National Centers for Environmental Information, “Climate Data Online," https://www.ncdc.noaa.gov/cdoweb/datatools/lcd?prior $=\mathrm{N}$.
} 
throughout the full evaluation period. The maximum monthly fuel economy was 23.6 mpdge in March 2018 and the minimum was 18.4 mpdge in September 2018. Although other operating factors also play a role in the fuel economy, this trend loosely corresponds inversely to the ambient temperature, as interior heating and cooling loads can have a significant impact on the overall bus efficiency. The overall average of 19.9 mpdge for the BEB fleet is 5.5 times that of the randomly dispatched CNG buses and 6.1 times the CNG buses in service on the slower-speed Passport route.

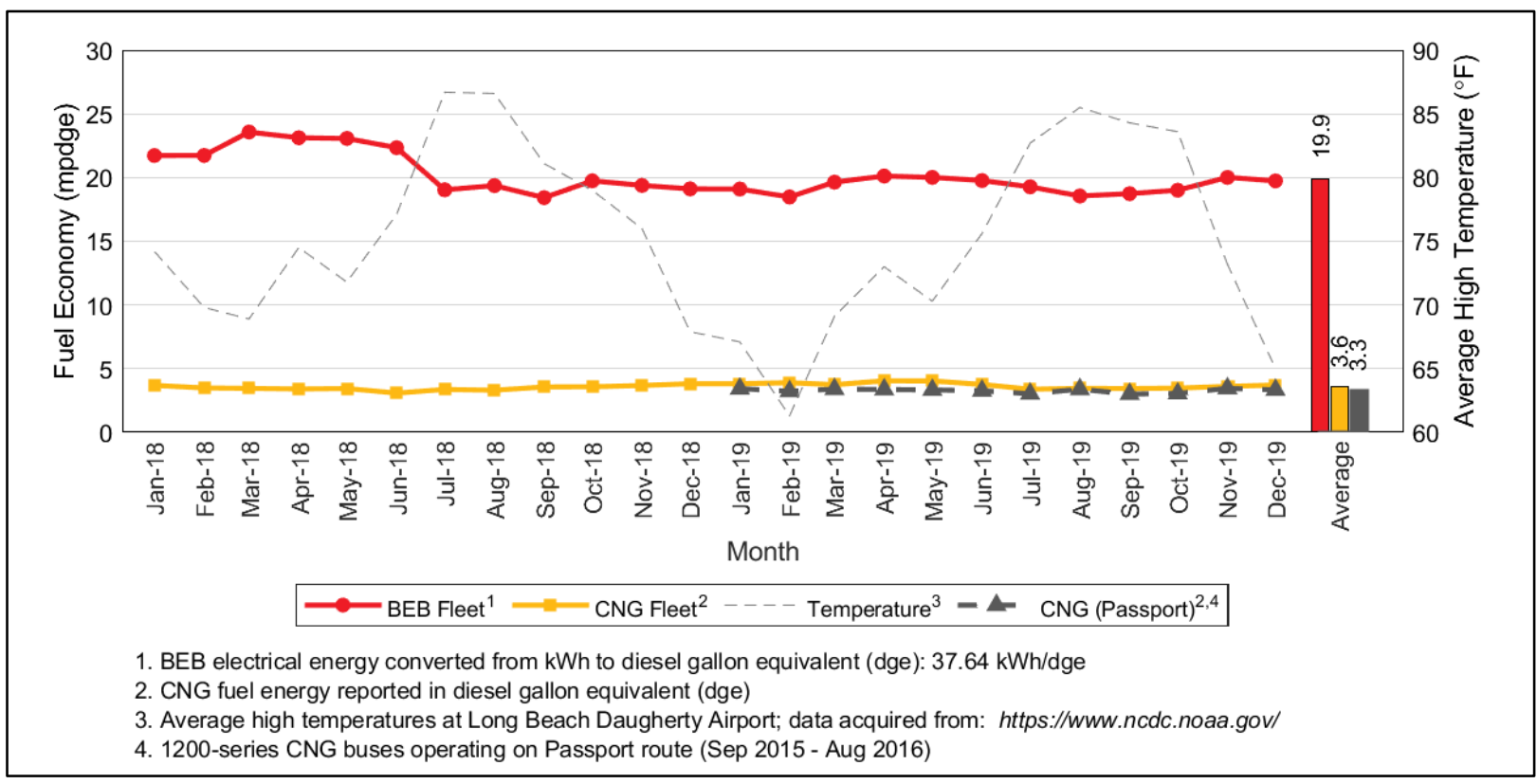

Figure 15. Monthly fuel economy for the BEB and CNG fleets (Evaluation Period)

\section{BEB Charging}

Although the WAVE inductive charger installed on the route has been commissioned, LBT staff reports that the supplemental charging has not been needed to meet service. Therefore, LBT is using only overnight depot charging for the 10-bus fleet. The typical daily routine for the BEBs after operating on the Passport route is to return to the depot and park in a designated parking spot with a plug-in charger. Figure 16 shows the average minimum state of charge (SOC) for the BEB fleet by month, which represents the remaining SOC when the BEBs return to the depot at the end of each day and begin charging. During the two-year evaluation period, the consistent operation of the BEBs has resulted in relatively consistent discharging of $50 \%-60 \%$ of the usable stored energy to complete daily route service. 


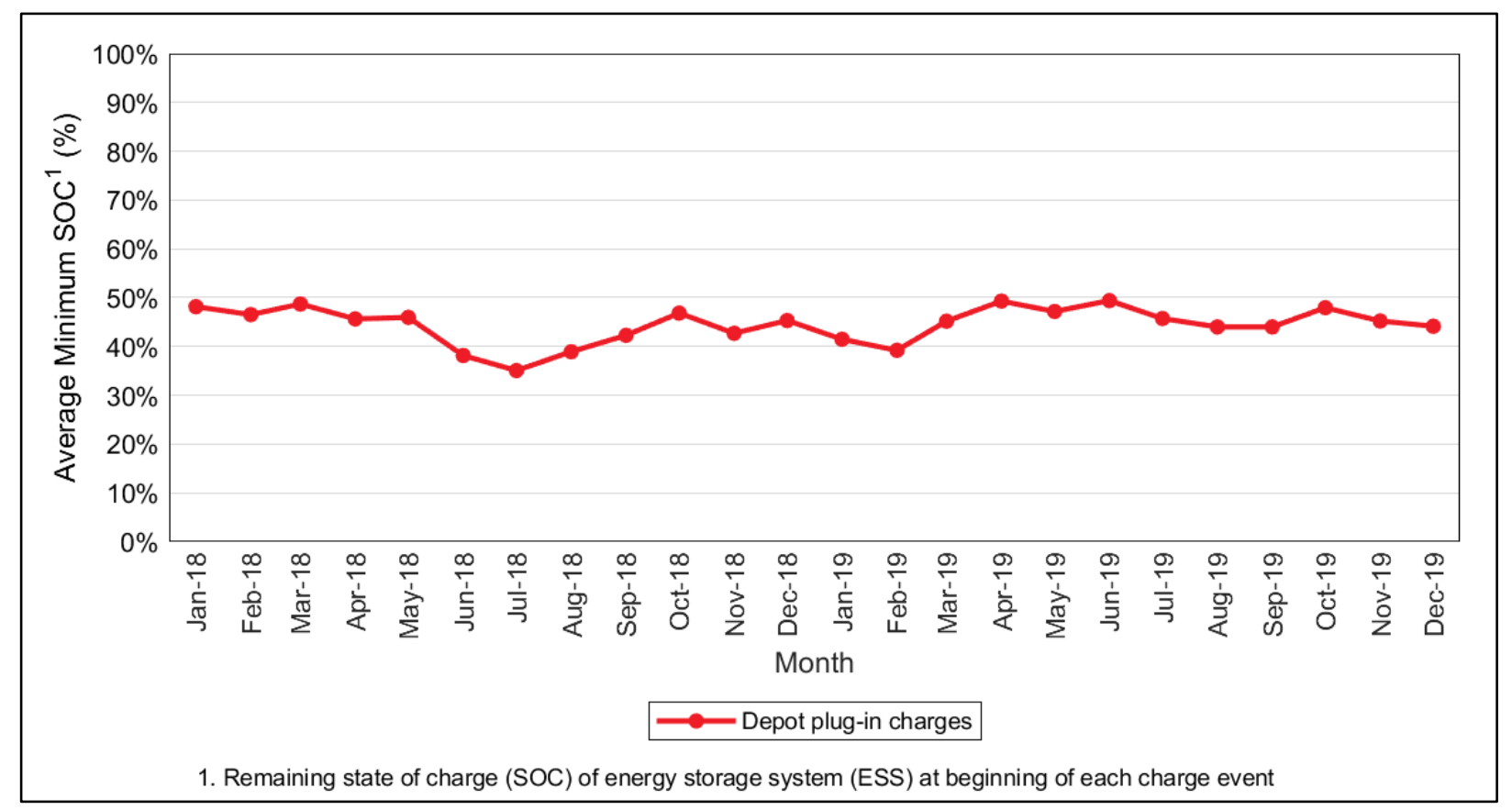

Figure 16. Monthly average minimum SOC for the BEB fleet (Evaluation Period)

Figure 17 and Figure 18 display the daily charging profiles of the BEB fleet from the perspective of the utility meter for 2018 and 2019, respectively. The peak power per 15-minute interval is overlaid for each day to reveal the typical charging pattern at the depot. The charts are timeshifted by 12 hours to show continuous overnight charging periods. In 2018 (Figure 17), LBT delayed the start of charging until after 10 p.m. to coincide with the lowest-cost TOU rates to minimize electricity consumption charges. To manage the peak power demand and minimize associated demand charges, LBT also limited the number of buses charging concurrently to four BEBs. The chargers cycle through the BEBs, charging four at a time until all BEBs are fully charged. The $80-\mathrm{kW}$ chargers produce a peak demand of $320 \mathrm{~kW}$ for four BEBs charging concurrently. The peak power profile tapers off throughout the early morning as the remaining BEBs reach full charge. During the 2019 data period (Figure 18), LBT relaxed these constraints, with staggered charging normally beginning around 9 p.m. and peak power allowed to increase up to $400 \mathrm{~kW}$ or higher. These changes in fleet charging behavior were in response to changes in the utility rate schedule discussed in the fuel costs section below.

Figure 19 displays the cumulative energy consumption profile for each overnight charging period in 2019. This corresponds to Figure 18 and shows charging normally beginning around 9 p.m. and ending around 5 a.m. The daily cumulative energy consumption for the depot chargers is typically around $1,400 \mathrm{kWh}$. 


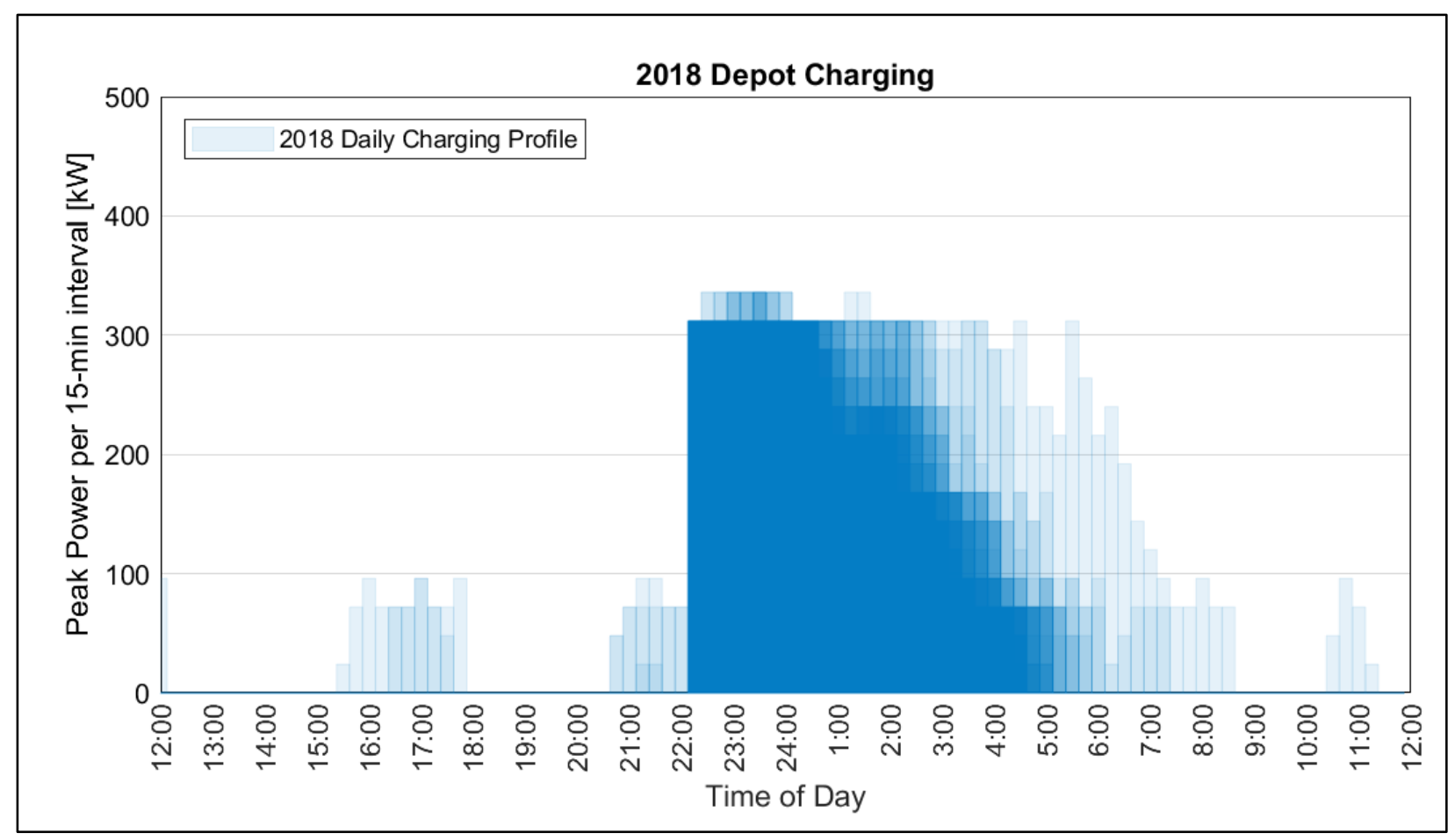

Figure 17. Electric utility daily power profiles for depot charging in 2018

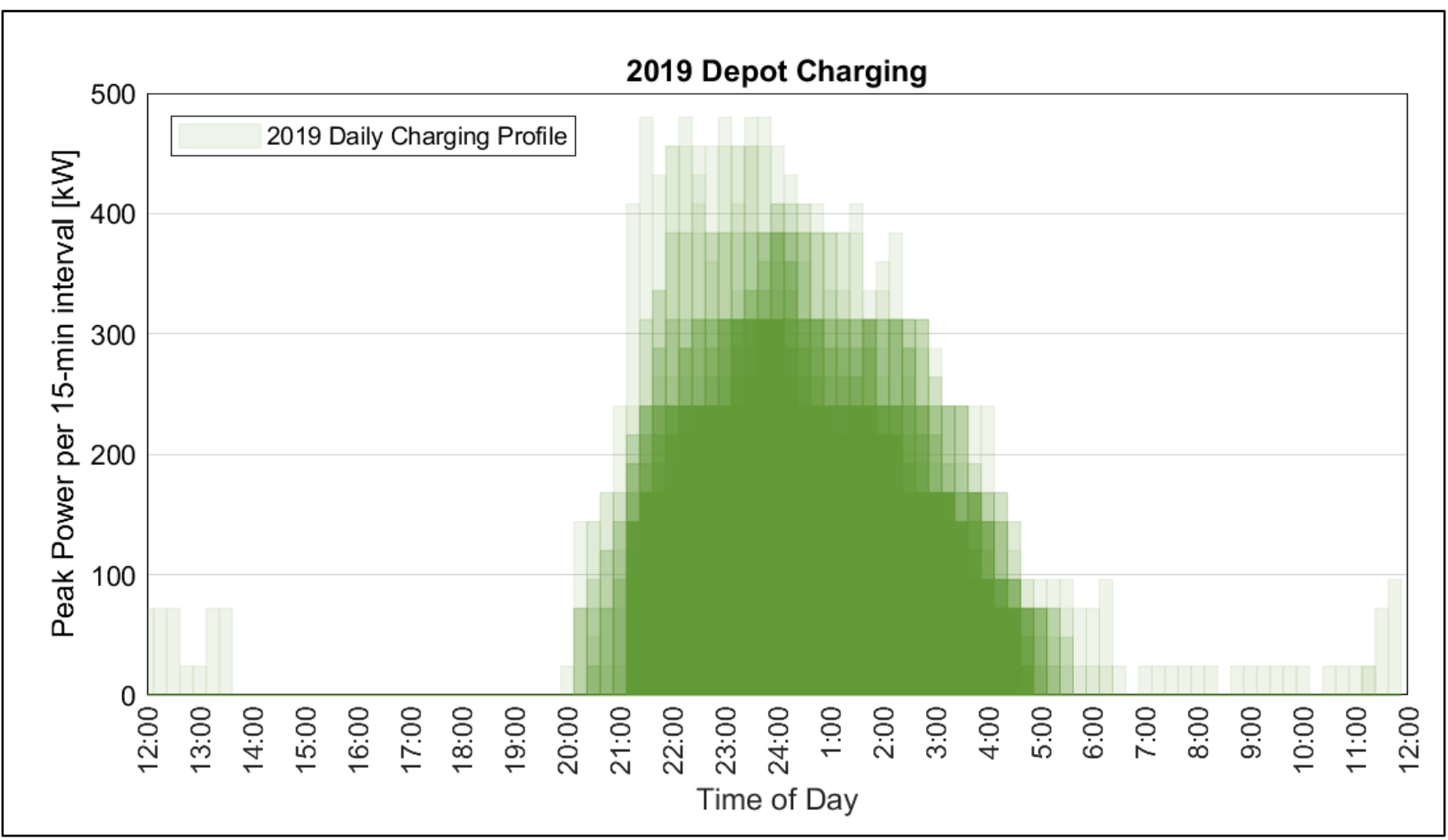

Figure 18. Electric utility daily power profiles for depot charging in 2019 


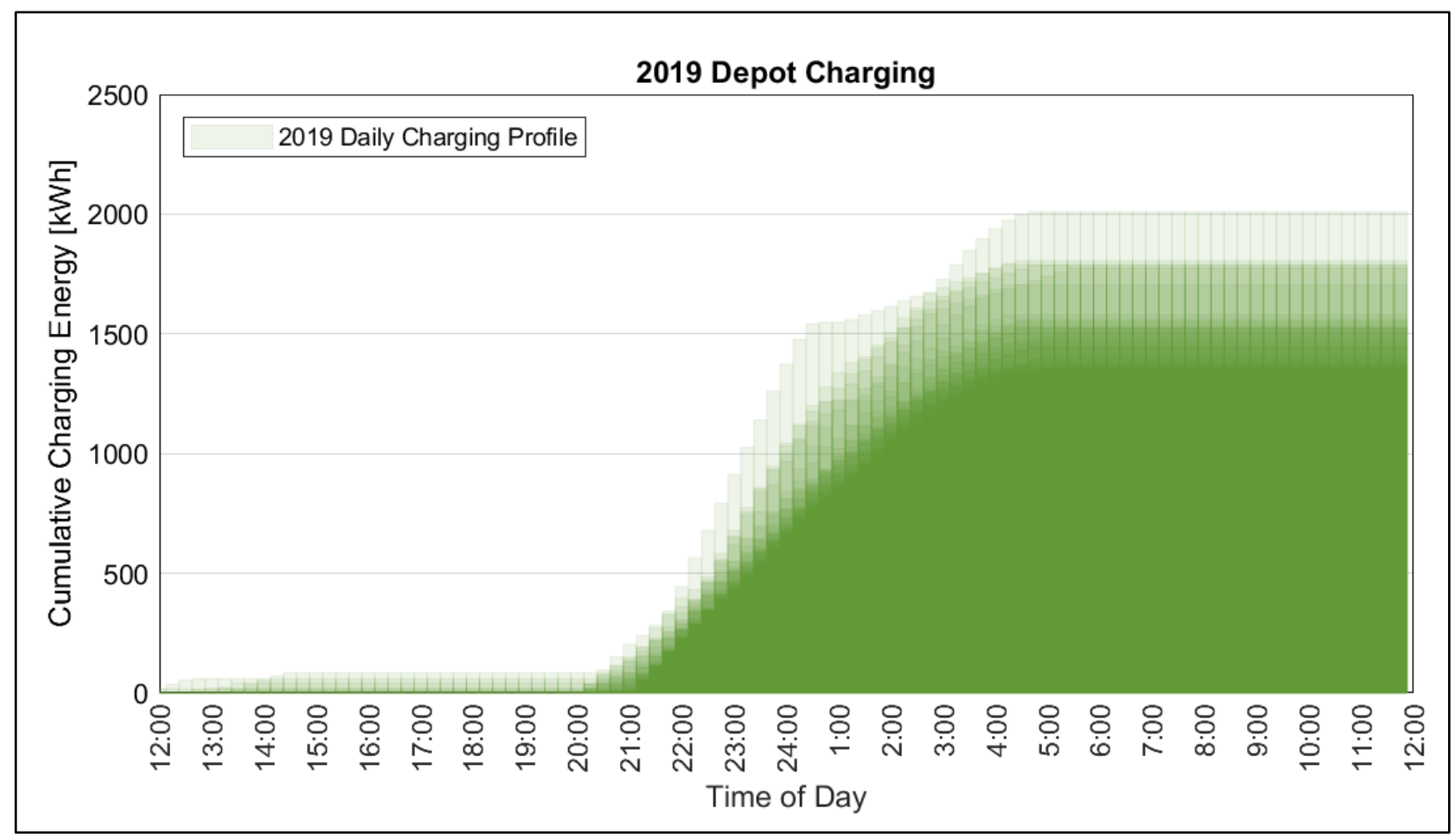

Figure 19. Electric utility daily cumulative energy profiles for depot charging in $\mathbf{2 0 1 9}$

Figure 20 shows the total number of monthly depot charges recorded for each BEB. The buses typically receive one overnight charge per day of service. Thus, these columns generally follow the BEB fleet availability and Passport route electrification trends shown above. The number at the top of each column indicates the fleet total. The legend displays the average charges per month for each BEB and for the fleet overall, which is nearly 160 total depot charges per month.

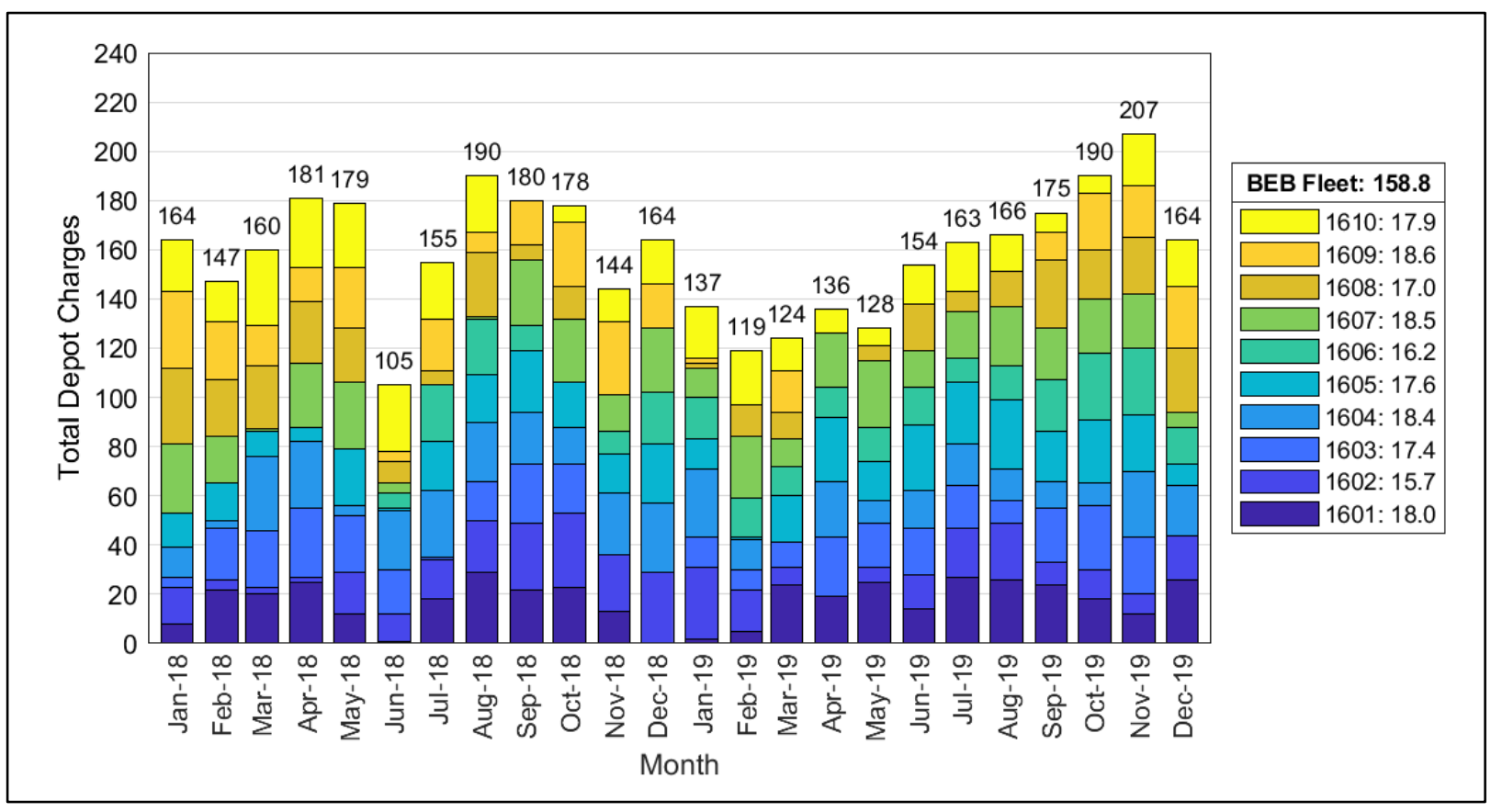

Figure 20. Monthly total depot charges by bus for the BEB fleet (Evaluation Period) 


\section{Fuel Costs}

Southern California Edison is LBT's electric utility provider. Since the BEBs were placed into service, LBT has been subject to three different electricity rate structures beginning with TOU-EV-6, switching to TOU-EV-4 in September 2018, and then to TOU-EV-8 in April 2019. Figure 21 shows the cost components that comprise the monthly electric utility bill. The stacked columns in the figure correspond to the monthly billing periods for the utility and do not exactly match the calendar months. LBT was subject to time-of-use charges and demand charges under the first two EV rate schedules. The demand charges were waived for the third electricity rate schedule, lowering the per-unit cost for LBT by approximately $50 \%$, on average. Throughout the evaluation, LBT primarily charged the BEBs overnight during the lowest rate periods. During the first two rate schedules, charges for electricity demand had a significant impact on overall cost - averaging $61 \%$ of the bill each month. With no demand charges, the new rate schedule (TOU-EV-8) resulted in half the electricity cost of the previous periods for approximately the same monthly energy consumption. This is very beneficial for the agency because it charges its buses overnight at the depot. The TOU-EV-8 rate would not result in the same savings for an agency that operates buses using on-route charging. Day charging would result in more electricity billed in the on-peak and mid-peak rates which would result in higher costs. Demand charges are expected to be phased back in after five years, at a rate of approximately $20 \%$ per year.

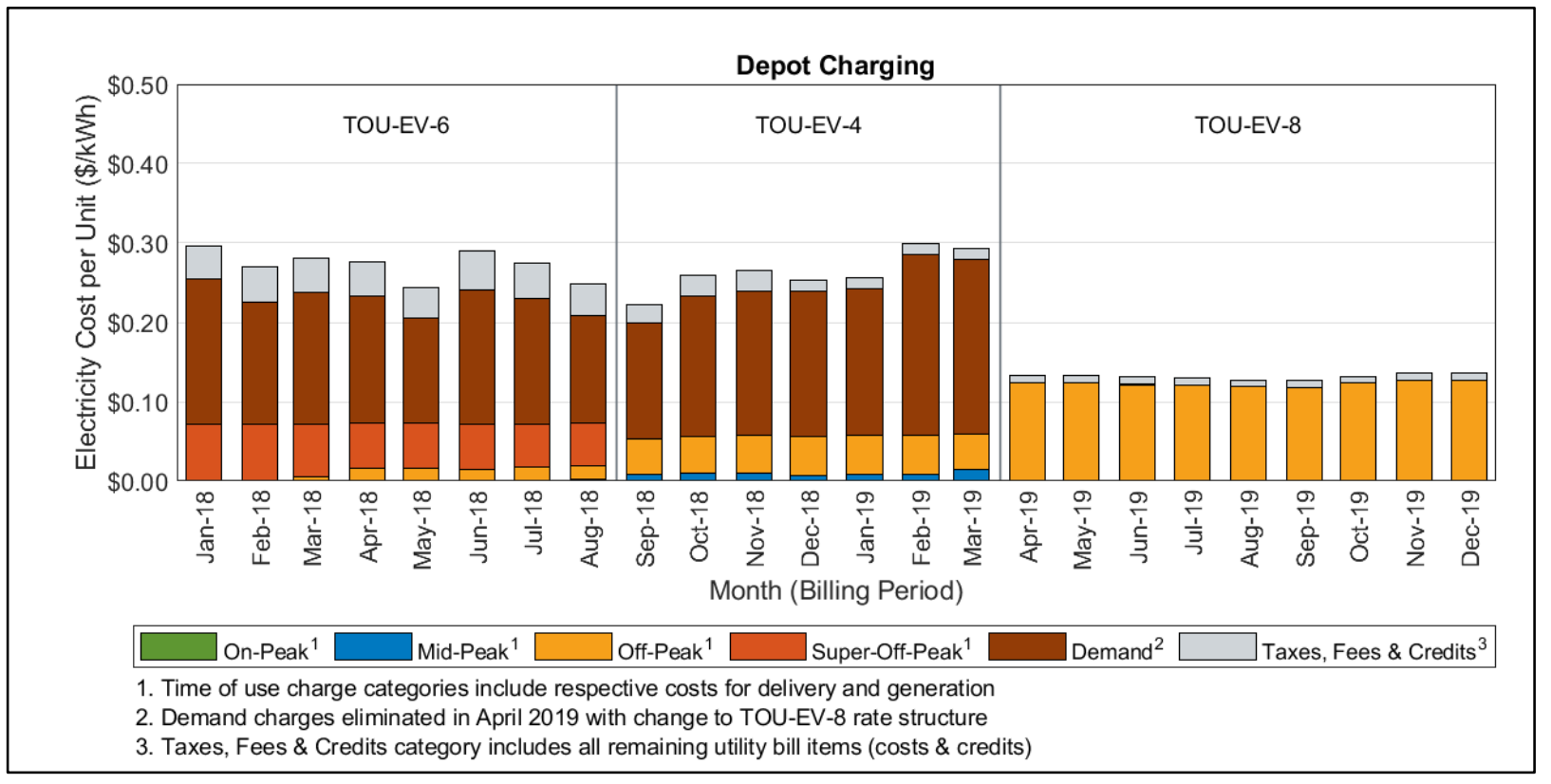

Figure 21. Electric utility component costs for depot charging (Evaluation Period)

Table 7 outlines the difference in cost per kilowatt-hour for the three electricity rate schedules LBT has been subject to during the evaluation. The change from TOU-EV-6 to TOU-EV-4 was not significant; however, the new average cost per $\mathrm{kWh}$ under TOU-EV-8 is approximately half the cost per kWh under the other rates for LBT. Under the first two rate schedules (combined), the average overall electricity price paid by LBT for depot charging was $\$ 0.267 / \mathrm{kWh}$, which is equivalent to $\$ 10.05 / \mathrm{dge}$. This included the average cost for electricity consumption $(\$ 0.065 / \mathrm{kWh}, 24.2 \%)$, the cost for electricity demand $(\$ 0.171 / \mathrm{kWh}, 63.9 \%)$, and the combined cost for all other taxes and fees on the utility bills $(\$ 0.032 / \mathrm{kWh}, 11.9 \%)$. Under TOU-EV-8 rates, 
the average overall price was $\$ 0.131 / \mathrm{kWh}$, or $\$ 4.93 /$ dge. The average electricity consumption cost was $\$ 0.123 / \mathrm{kWh}$, which accounts for $93.4 \%$ of the bill. The remaining $6.6 \%$ was $\$ 0.009 / \mathrm{kWh}$ for the taxes, fees, and credits category. So, although the unit cost for electricity consumption approximately doubled, the overall average for LBT decreased by half due to elimination of demand charges.

Table 7. Summary of LBT's Electric Rate Schedules

\begin{tabular}{|c|c|c|c|c|c|c|}
\hline & \multicolumn{2}{|c|}{ TOU-EV-6 } & \multicolumn{2}{c|}{ TOU-EV-4 } & \multicolumn{2}{c|}{ TOU-EV-8 } \\
\hline $\begin{array}{c}\text { Electricity Consumption } \\
(\$ / \mathrm{kWh})\end{array}$ & 0.072 & $26.5 \%$ & 0.056 & $21.6 \%$ & 0.123 & $93.4 \%$ \\
\hline $\begin{array}{c}\text { Electricity Demand } \\
(\$ / \mathrm{kWh})\end{array}$ & 0.157 & $57.7 \%$ & 0.186 & $71.1 \%$ & 0 & $0 \%$ \\
\hline $\begin{array}{c}\text { Taxes, Fees \& Credits } \\
(\$ / \mathrm{kWh})\end{array}$ & 0.043 & $15.8 \%$ & 0.019 & $7.3 \%$ & 0.009 & $6.6 \%$ \\
\hline Total (\$/kWh) & 0.272 & $100 \%$ & 0.261 & $100 \%$ & 0.131 & $100 \%$ \\
\hline Total (\$/dge) & 10.24 & - & 9.83 & - & 4.93 & - \\
\hline
\end{tabular}

Figure 22 outlines the fuel cost per unit for the CNG buses separated by actual fuel cost, station maintenance cost, and the cost of electricity to operate the station. The variability in cost each month is primarily driven by the commodity cost for CNG fuel, which fluctuated in late 2018 through early 2019 due to disruptions in regional CNG supply. At its highest, the CNG unit cost was more than $\$ 2.50 /$ dge. The average for the full evaluation period was $\$ 1.51 /$ dge.

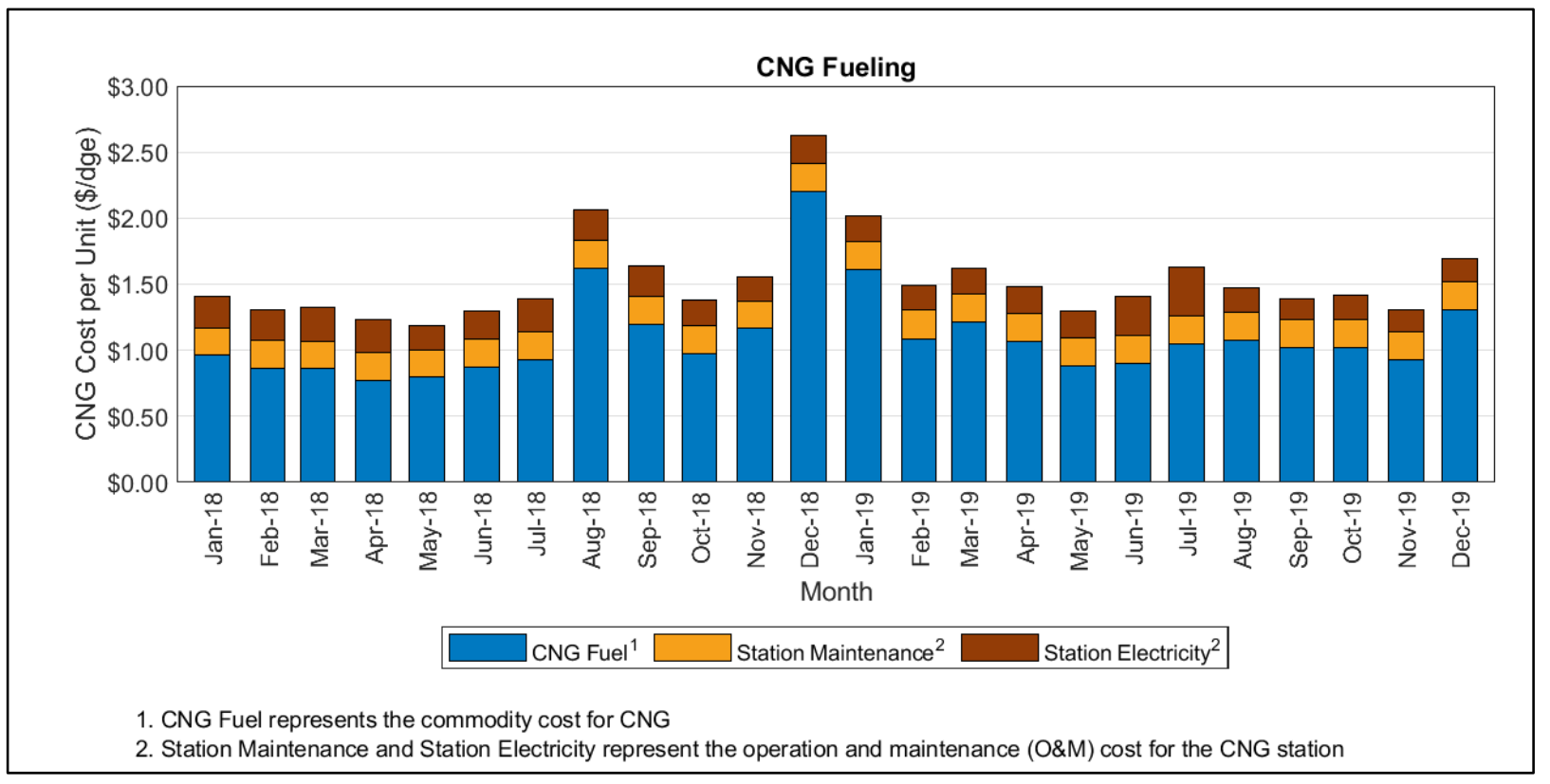

Figure 22. CNG fuel component costs (Evaluation Period)

The average monthly price per unit for the two fuels is compared in Figure 23, shown in equivalent units and adjusted to correspond to the calendar month. The equivalent average price 
for electricity was approximately $\$ 7.34 /$ dge, significantly higher than the average CNG price of $\$ 1.51 /$ dge.

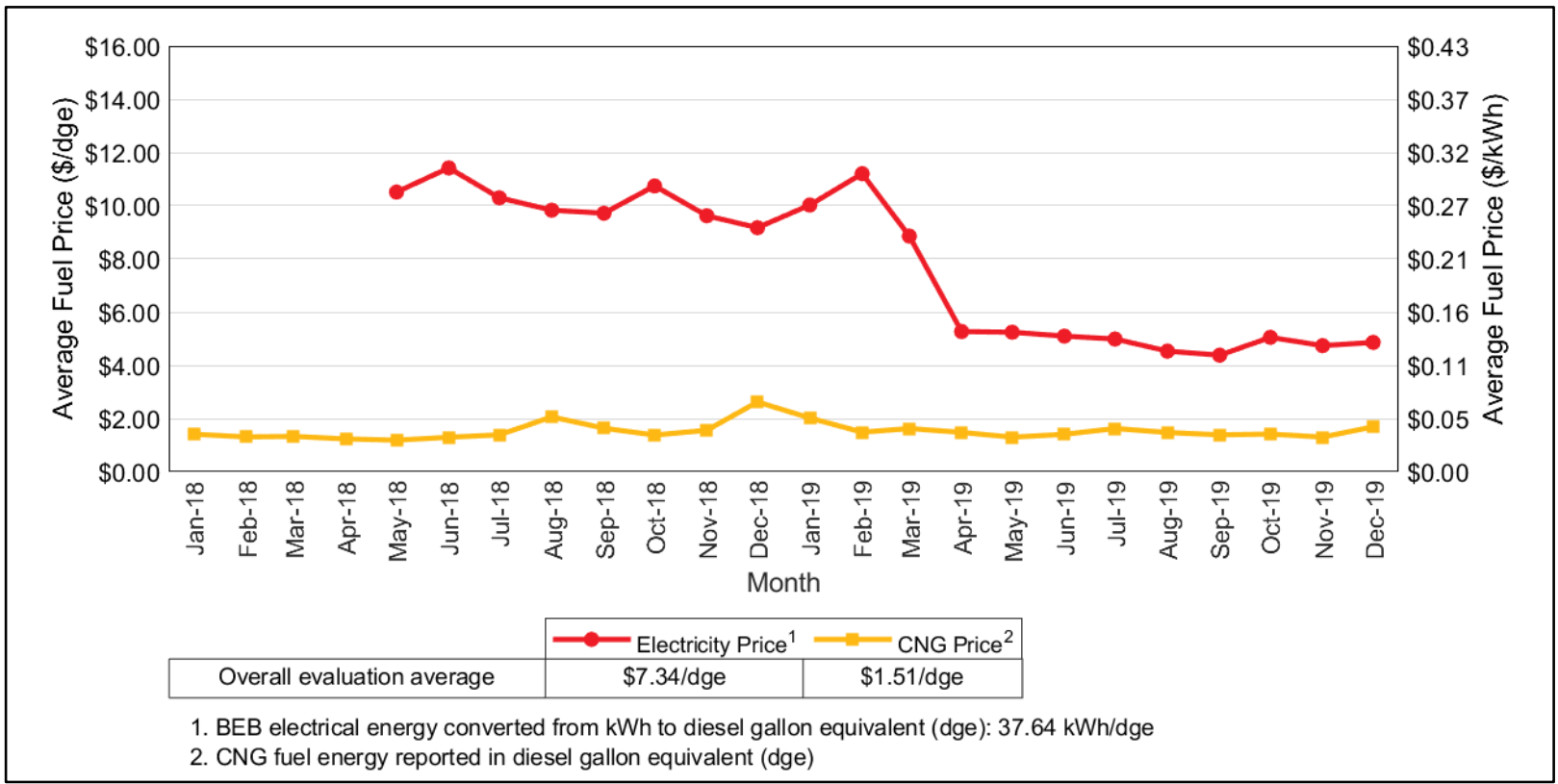

Figure 23. Equivalent monthly average fuel price for the BEB and CNG fleets (Evaluation Period)

Combining the fuel economy of each fleet with the unit price for their respective fuels provides the monthly fuel cost per mile, as shown in Figure 24. In 2018, the fuel economy benefit of the BEB fleet offset much of the impact of the higher fuel price, resulting in a similar-yet still higher - average fuel cost per mile for the BEB fleet compared to the baseline. The lower electricity cost beginning in April 2019 had a significant effect on the fuel cost per mile of the BEB fleet, highlighted in Figure 25. Under TOU-EV-6 and TOU-EV-4, the average cost per mile was approximately $\$ 0.60$. The BEB fleet average decreased to $\$ 0.30$ per mile under the TOU-EV-8 schedule (April 2019 through December 2019), which is 25\% lower than the CNG fleet average of $\$ 0.40$ per mile during the same period. 


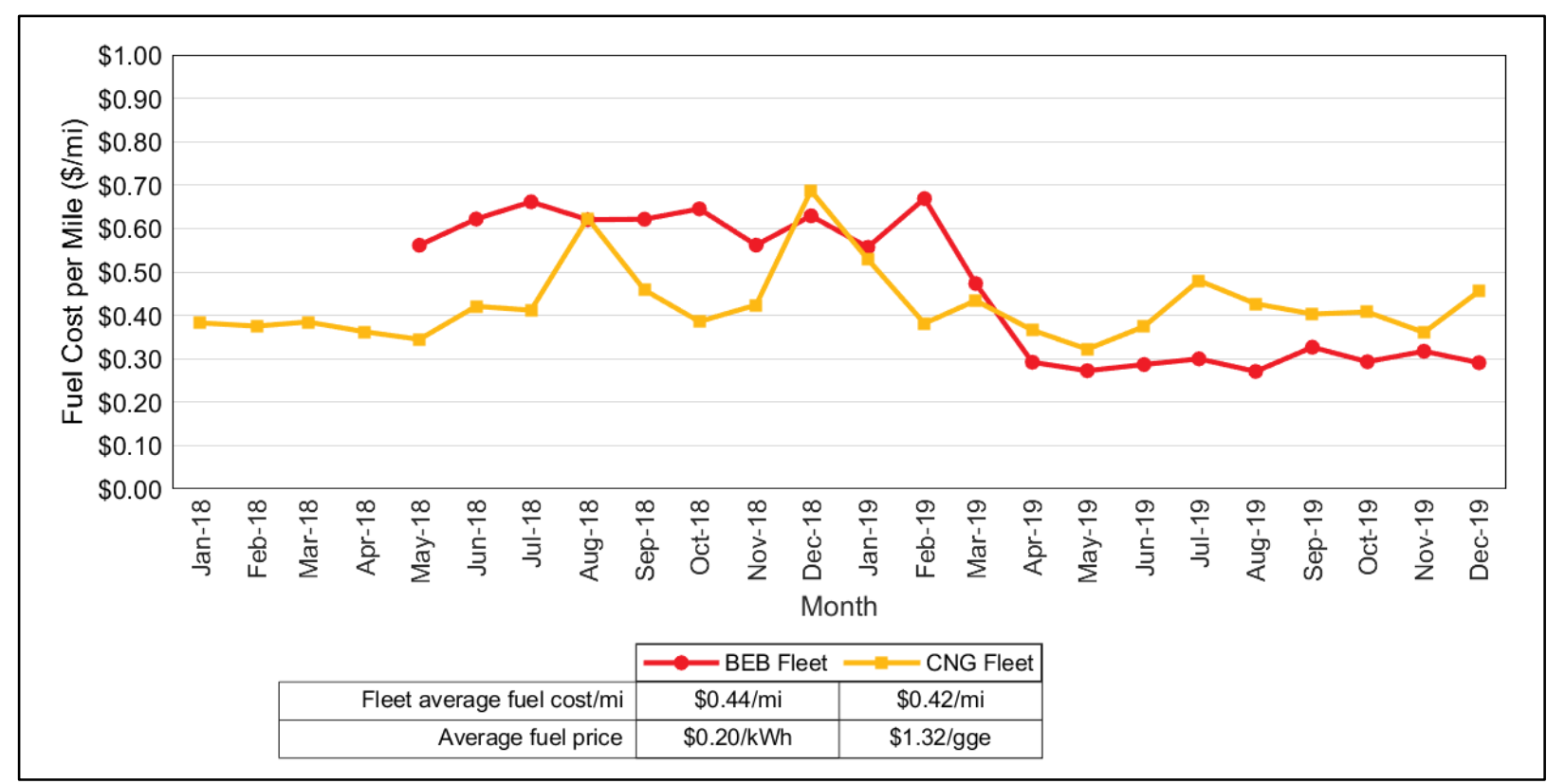

Figure 24. Monthly average fuel cost per mile for the BEB and CNG fleets (Evaluation Period)

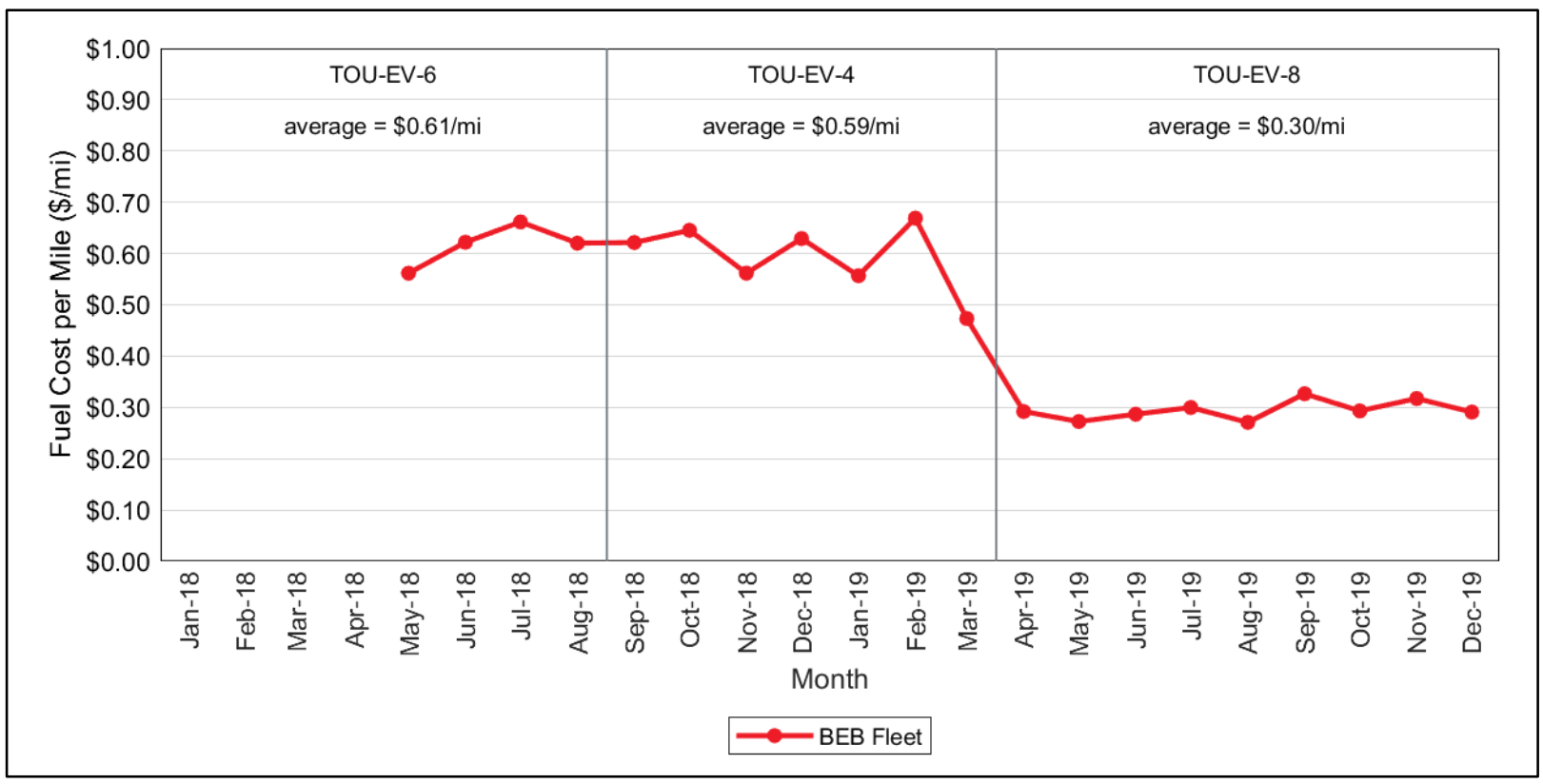

Figure 25. Fuel cost per mile for the BEB fleet under each electricity rate schedule

\section{Road Call Analysis}

A road call, or revenue vehicle system failure (as named in the National Transit Database ${ }^{6}$ ), is defined as a failure of an in-service bus that causes the bus to be replaced on route or causes a significant delay in schedule. If the problem with the bus can be resolved during a layover and

${ }^{6}$ Federal Transit Administration, “The National Transit Database (NTD),” https://www.transit.dot.gov/ntd . 
the schedule is kept, this is not considered a road call. The analysis described here includes only road calls that were caused by "chargeable" failures. Chargeable road calls include systems that can physically disable the bus from operating on route, such as interlocks (doors, air system), engine, or things that are deemed to be safety issues if operation of the bus continues. They do not include road calls for problems with radios, fareboxes, or destination signs.

The transit industry measures reliability as the mean distance between failures, also documented as miles between road calls (MBRC). MBRC is a fleet metric that is calculated by dividing the total fleet miles by the number of road calls. Table 8 provides the MBRC for the BEBs and CNG buses categorized by total bus road calls, propulsion-related road calls, and ESS-related road calls. Propulsion-related road calls include all road calls due to propulsion-related systems, including the battery system (or engine for a conventional bus), electric drive, fuel, exhaust, air intake, cooling, non-lighting electrical, and transmission systems. The ESS-related road calls and ESS-related MBRC are included for the BEBs. This road call analysis includes data accumulated since the clean point of January 2018.

Table 8. Road Calls and MBRC (Evaluation Period)

\begin{tabular}{|l|c|c|}
\hline & BEB & CNG \\
\hline Dates & $1 / 1 / 2018-12 / 31 / 2019$ & $1 / 1 / 2018-12 / 31 / 2019$ \\
\hline Total fleet mileage & 353,281 & 659,618 \\
\hline Bus road calls & 80 & 64 \\
\hline Bus MBRC & 4,416 & 10,307 \\
\hline Propulsion-related road calls & 30 & 37 \\
\hline Propulsion-related MBRC & 11,776 & 17,828 \\
\hline ESS-related road calls & 5 & - \\
\hline ESS-related MBRC & 70,656 & - \\
\hline
\end{tabular}

Figure 26 presents the cumulative MBRC by category for the BEBs and CNG baseline buses. The upper plot tracks the overall MBRC for the two bus fleets; the lower plot tracks the MBRC for propulsion-only road calls and ESS-related road calls for the BEBs. DOE and FTA have not established performance targets specific to BEBs, but the MBRC targets established for fuel cell electric buses ${ }^{7}$ were based on typical conventional buses, and the targets could be considered appropriate for any advanced technology on the path to full commercialization. The ultimate target for bus MBRC $(4,000)$ is included in the upper plot of Figure 26 as a black dotted line. The overall MBRC for the BEBs $(4,416)$ is much lower than the incumbent CNG technology (10,307), but the cumulative trend has surpassed the ultimate target. The propulsion-related MBRC for the BEBs continues to increase over time, surpassing 11,000. The ESS-related MBRC for the BEBs also shows a steady increase over time, reaching 70,656. This indicates that the ESS is not the system causing in-service issues.

\footnotetext{
${ }^{7}$ Fuel Cell Technologies Office, "Fuel Cell Bus Targets," Fuel Cell Technologies Program Record \#12012, Sept. 2012, www.hydrogen.energy.gov/pdfs/12012 fuel_cell bus targets.pdf.
} 


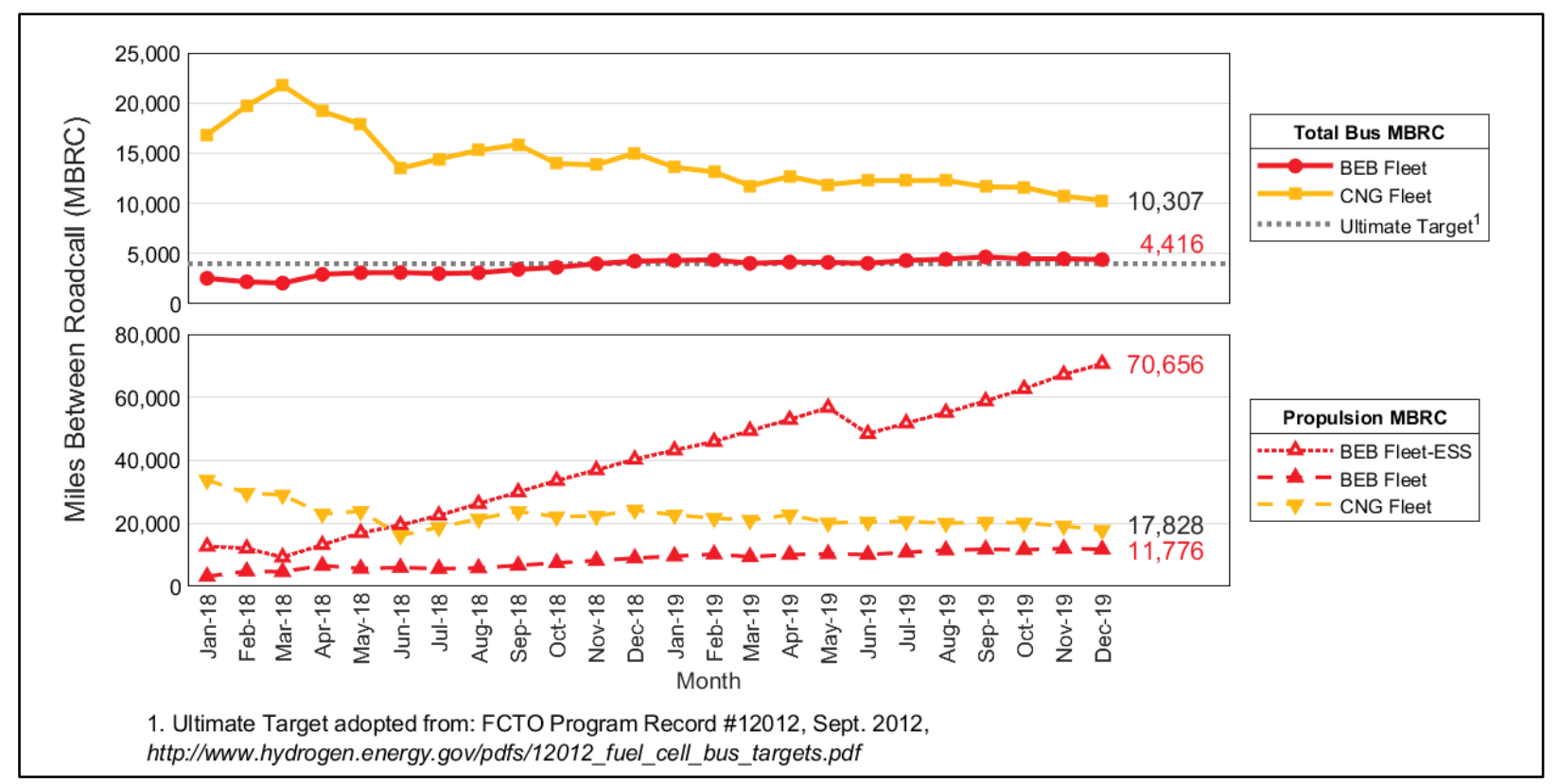

Figure 26. Cumulative bus MBRC and propulsion-related MBRC (Evaluation Period)

\section{Maintenance Analysis}

This section evaluates total maintenance costs, as well as maintenance costs by bus system. Costs for accident-related repair, which are extremely variable from bus to bus, were eliminated from the analysis for both BEB and CNG bus fleets. NREL also excludes warranty repairs from the calculations. The BEBs were under warranty support by the original equipment manufacturer (OEM) during the full evaluation period. The CNG buses were out of the warranty period for most systems. Any work covered under warranty was removed from the data set. NREL uses a constant maintenance labor rate of $\$ 50$ per hour to calculate labor costs; this does not reflect an average rate for LBT.

\section{Total Work Order Maintenance Costs}

Table 9 shows maintenance costs per mile for the BEB and CNG buses and includes scheduled cost, unscheduled cost, and total cost. Scheduled costs include preventive maintenance based on the OEMs' recommendations. All other maintenance is included in unscheduled costs. During the 2019 data period, the maintenance cost for the BEBs was 15.7\% lower than that of the CNG buses. 
Table 9. Total Work Order Maintenance Costs (2019 Data Period)

\begin{tabular}{|c|r|r|r|r|c|c|}
\hline Bus Fleet & Mileage & Parts (\$) & $\begin{array}{c}\text { Labor } \\
\text { Hours }\end{array}$ & $\begin{array}{c}\text { Scheduled } \\
\text { Cost per Mile } \\
\mathbf{( \$ )}\end{array}$ & $\begin{array}{c}\text { Unscheduled } \\
\text { Cost per Mile } \\
\mathbf{( \$ )}\end{array}$ & $\begin{array}{c}\text { Total } \\
\text { Cost per } \\
\text { Mile } \\
\mathbf{( \$ )}\end{array}$ \\
\hline 1601 & 23,338 & $3,225.54$ & 165.5 & 0.14 & 0.35 & 0.49 \\
\hline 1602 & 15,234 & $1,334.84$ & 127.9 & 0.10 & 0.41 & 0.51 \\
\hline 1603 & 19,649 & $1,062.10$ & 136.5 & 0.09 & 0.31 & 0.40 \\
\hline 1604 & 17,927 & $1,757.03$ & 101.6 & 0.10 & 0.28 & 0.38 \\
\hline 1605 & 25,086 & 942.73 & 159.0 & 0.16 & 0.19 & 0.35 \\
\hline 1606 & 20,664 & 717.57 & 139.5 & 0.09 & 0.29 & 0.37 \\
\hline 1607 & 24,696 & $6,511.99$ & 169.0 & 0.10 & 0.51 & 0.61 \\
\hline 1608 & 16,533 & $2,182.85$ & 102.5 & 0.07 & 0.37 & 0.44 \\
\hline 1609 & 10,811 & $4,770.81$ & 111.0 & 0.27 & 0.69 & 0.95 \\
\hline 1610 & 18,068 & $1,332.89$ & 133.0 & 0.16 & 0.29 & 0.44 \\
\hline BEB Fleet & 192,006 & $\mathbf{2 3 , 8 3 8 . 3 5}$ & $\mathbf{1 , 3 4 5 . 4}$ & $\mathbf{0 . 1 2}$ & $\mathbf{0 . 3 5}$ & $\mathbf{0 . 4 7}$ \\
\hline 1521 & 46,594 & $13,452.02$ & 285.0 & 0.18 & 0.41 & 0.59 \\
\hline 1522 & 46,586 & $11,277.59$ & 296.0 & 0.15 & 0.41 & 0.56 \\
\hline 1523 & 43,819 & $9,608.73$ & 220.0 & 0.14 & 0.33 & 0.47 \\
\hline 1524 & 49,069 & $12,329.31$ & 302.8 & 0.15 & 0.41 & 0.56 \\
\hline 1525 & 46,815 & $10,113.47$ & 232.8 & 0.13 & 0.34 & 0.46 \\
\hline 1526 & 29,627 & $12,430.11$ & 155.5 & 0.12 & 0.56 & 0.68 \\
\hline 1527 & 43,589 & $14,745.23$ & 242.3 & 0.18 & 0.44 & 0.62 \\
\hline 1528 & 38,137 & $9,786.86$ & 265.5 & 0.16 & 0.45 & 0.60 \\
\hline CNG Fleet & $\mathbf{3 4 4 , 2 3 6}$ & $\mathbf{9 3 , 7 4 3 . 3 0}$ & $\mathbf{1 , 9 9 9 . 9}$ & $\mathbf{0 . 1 5}$ & $\mathbf{0 . 4 1}$ & $\mathbf{0 . 5 6}$ \\
\hline & & & & & & \\
\hline
\end{tabular}

The monthly scheduled and unscheduled maintenance cost per mile for the buses are shown as stacked columns in Figure 27. LBT reports that minor repairs identified during preventive maintenance are sometimes completed during the scheduled preventive maintenance and not separated out as unscheduled repairs. This results in scheduled maintenance costs that are slightly higher and unscheduled maintenance costs that are slightly lower (by an equal amount), and does not impact the total maintenance cost, only the fractional split between schedule and unscheduled. This is the case for both bus fleets. 


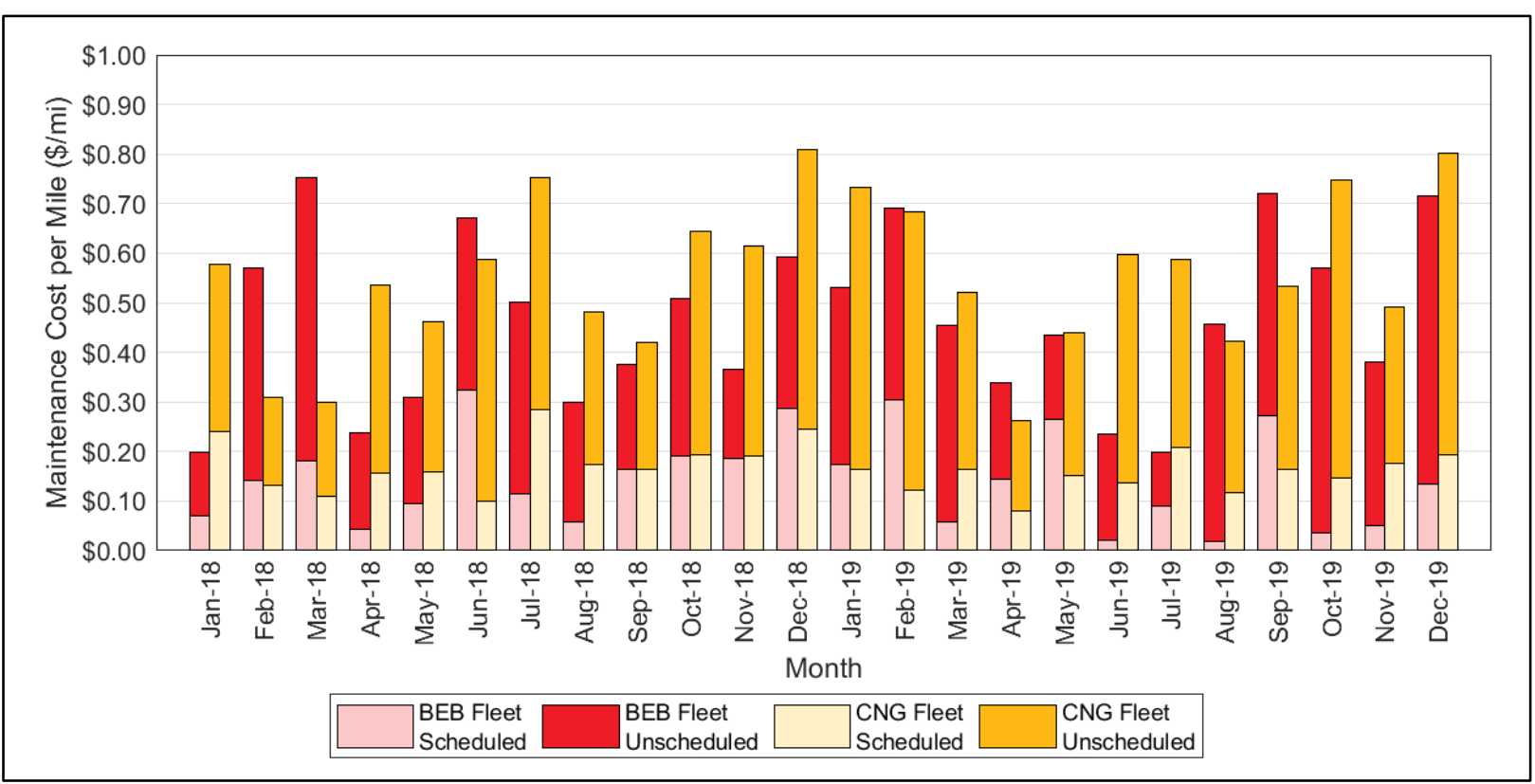

Figure 27. Monthly scheduled and unscheduled maintenance cost per mile (Evaluation Period)

Figure 28 shows the same monthly maintenance data separated by parts and labor costs for the BEB and CNG fleets. As mentioned earlier, the BEBs were under warranty during this 2019 data period and most parts costs were covered by the manufacturer. As a result, the BEB parts costs were significantly lower than that of the CNG buses. The average parts cost for the BEBs was $\$ 0.12$ per mile, compared to $\$ 0.27$ per mile for the CNG buses.

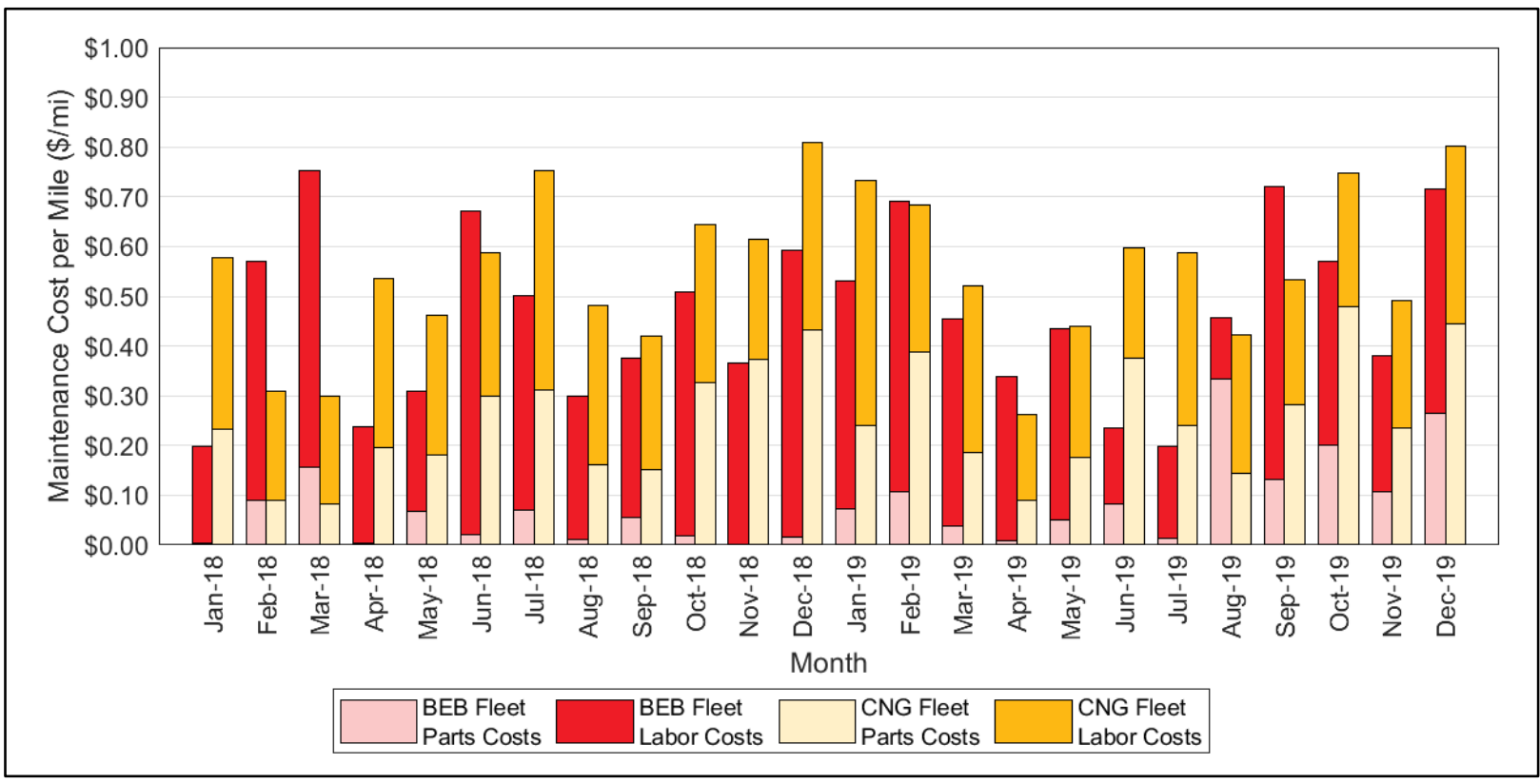

Figure 28. Monthly parts and labor maintenance cost per mile (Evaluation Period)

\section{Work Order Maintenance Costs Categorized by System}

Table 10 shows each bus fleet's maintenance costs per mile by vehicle system based on American Trucking Association Vehicle Maintenance Reporting Standards (VMRS) categories, 
excluding warranty costs. The color shading denotes the systems with the highest percentage of maintenance costs: orange for the highest, green for the second highest, and purple for the third highest. The vehicle systems shown in the table are as follows:

- Propulsion-related systems: Repairs for exhaust, fuel, engine, electric motors, battery modules, propulsion control, non-lighting electrical (charging, cranking, and ignition), air intake, cooling, and transmission

- Cab, body, and accessories: Includes body, glass, cab and sheet metal, seats and doors, and accessory repairs such as hubodometers, fareboxes, and radios

- Preventive maintenance inspection (PMI): Labor for inspections during preventive maintenance

- Brakes: Includes brake pads, disks, calipers, anti-lock braking system, and brake chambers

- Frame, steering, and suspension

- Heating, ventilation, and air conditioning (HVAC)

- Lighting

- Air system (general)

- Axles, wheels, and drive shaft

- Tires

Table 10. Work Order Maintenance Cost per Mile by System ${ }^{a}$ (2019 Data Period)

\begin{tabular}{|l|c|c|c|c|}
\hline \multicolumn{1}{|c|}{ System } & $\begin{array}{c}\text { BEB } \\
\text { Cost } \\
\text { per } \\
\text { Mile } \mathbf{( \$ )}\end{array}$ & $\begin{array}{c}\text { BEB } \\
\text { Percent } \\
\text { of Total } \\
\mathbf{( \% )}\end{array}$ & $\begin{array}{c}\text { CNG } \\
\text { Cost } \\
\text { per } \\
\text { Mile } \mathbf{( \$ )}\end{array}$ & $\begin{array}{c}\text { CNG } \\
\text { Percent } \\
\text { of Total } \\
\mathbf{( \% )}\end{array}$ \\
\hline Propulsion-related & 0.04 & 9 & 0.21 & 38 \\
\hline Cab, body, and accessories & 0.24 & 52 & 0.16 & 28 \\
\hline PMI & 0.11 & 23 & 0.08 & 14 \\
\hline Brakes & 0.02 & 4 & 0.01 & 2 \\
\hline Frame, steering, and suspension & 0.02 & 3 & 0.03 & 5 \\
\hline HVAC & 0.01 & 2 & 0.03 & 5 \\
\hline Lighting & 0.01 & 2 & 0.01 & 1 \\
\hline General air system repairs & 0.02 & 3 & 0.02 & 3 \\
\hline Axles, wheels, and drive shaft & 0.01 & 2 & 0.02 & 4 \\
\hline Tires & 0.00 & 0 & 0.00 & 0 \\
\hline Total & $\mathbf{0 . 4 7}$ & 100 & $\mathbf{0 . 5 6}$ & 100 \\
\hline
\end{tabular}

a The top three categories for maintenance for each fleet are color coded as follows: orangehighest, green — second highest, and purple - third highest.

The systems with the highest percentage of maintenance costs for the BEB fleet were: (1) cab, body, and accessories; (2) PMI; and (3) propulsion-related. The systems with the highest percentage of maintenance costs for the CNG buses were: (1) propulsion-related; (2) cab, body, and accessories; and (3) PMI.

Figure 29 shows the monthly cost per mile by system for the BEBs, and Figure 30 shows the monthly cost per mile by system for the CNG fleet. 


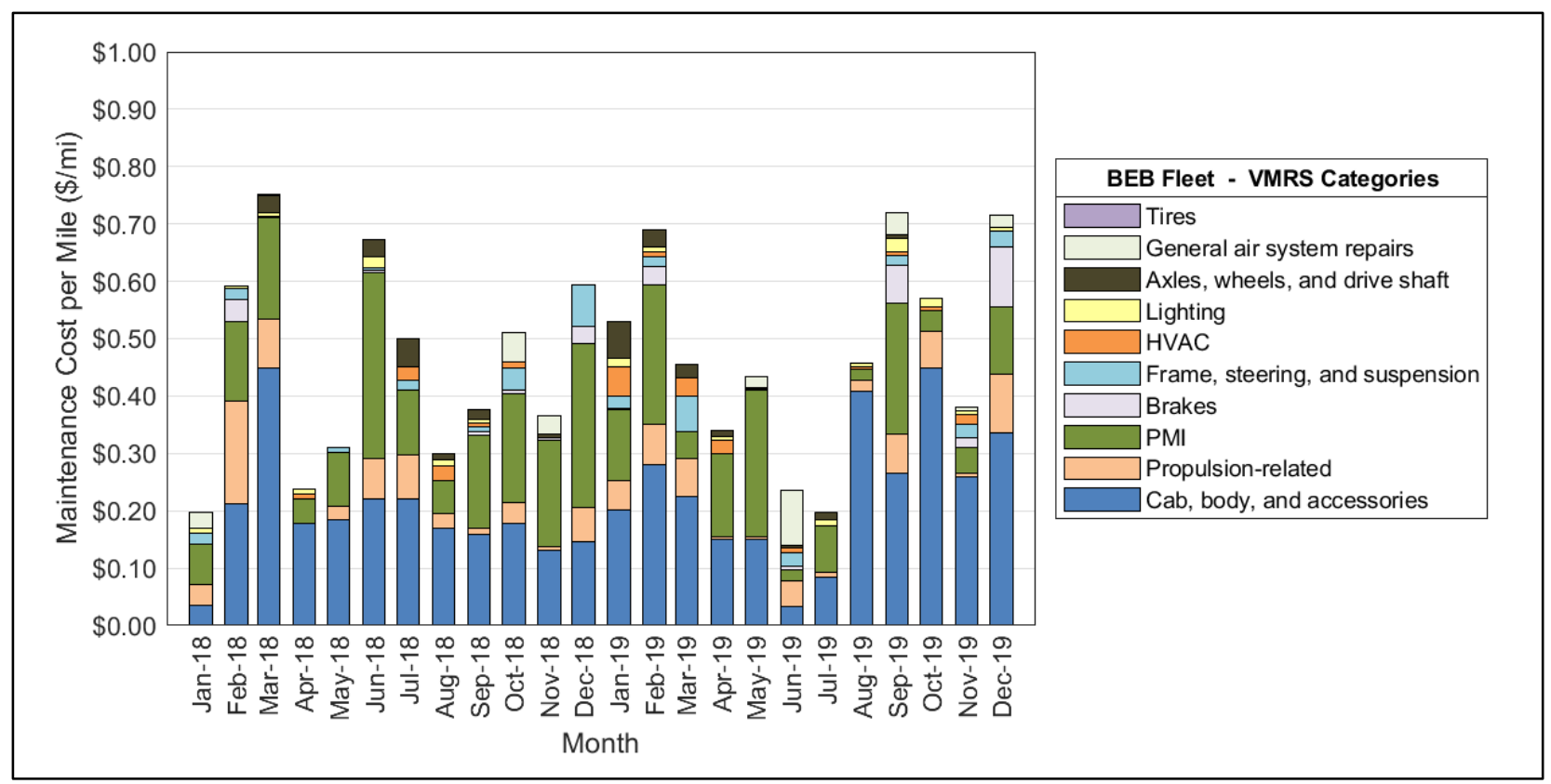

Figure 29. Monthly maintenance cost per mile by system for the BEB fleet (Evaluation Period)

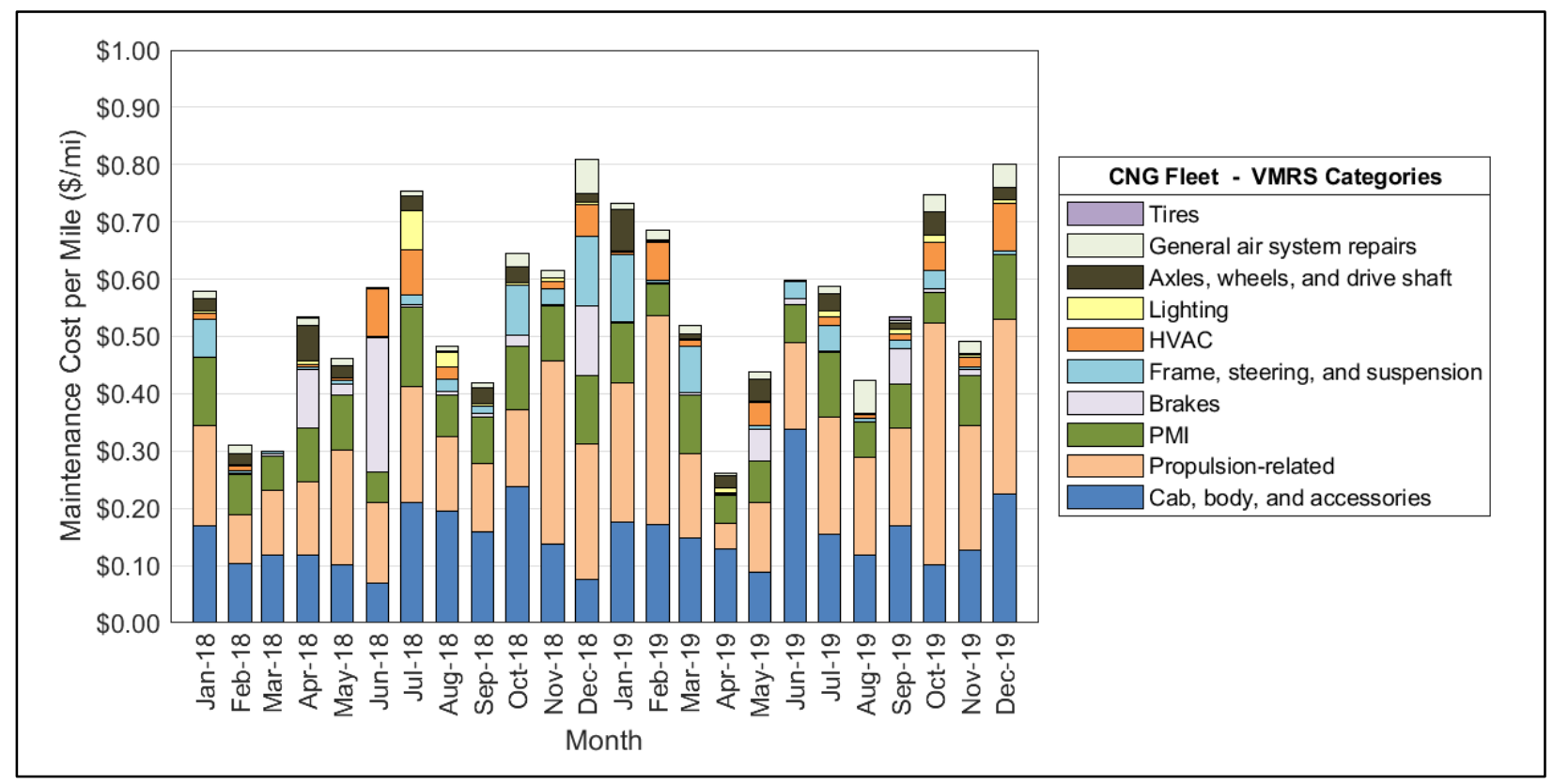

Figure 30. Monthly maintenance cost per mile by system for the CNG fleet (Evaluation Period)

\section{Propulsion-Related Work Order Maintenance Costs}

Propulsion-related vehicle systems include the exhaust, fuel, engine, battery modules, electric propulsion, air intake, cooling, non-lighting electrical, transmission, and hydraulic systems. These vehicle subsystems have been separated to highlight how maintenance costs for the propulsion system are affected by the change from conventional technology (CNG) to advanced technology (BEB). Figure 31 and Figure 32 provide monthly propulsion-related system maintenance costs by category for the BEBs and CNG buses, respectively. Table 11 summarizes 
these costs during the 2019 data period. Parts for scheduled maintenance, such as filters and fluids, are included in the specific system categories. For example, oil and oil filters are included in the power plant (engine) subsystem parts costs, while air filters are included in the air intake subsystem parts costs. Below are the main takeaways of the propulsion system maintenance costs described in Table 11.

- Total propulsion-related-The total propulsion-related maintenance cost for the BEBs was $81 \%$ lower than that of the CNG buses; this is influenced by the respective warranty periods for the bus fleets.

- Exhaust system-Costs for the CNG buses were low. The BEBs do not have an exhaust system.

- Fuel system-Costs for this system for the CNG buses made up $15 \%$ of the total propulsion system costs. The BEBs do not have a fuel system.

- Power plant and electric propulsion-For the BEBs, the costs for the electric propulsion system and ESS made up $17 \%$ of the total cost. This is much lower than reported for the previous year (35\%). The costs were primarily for labor because most parts costs were covered under warranty. Power-plant repairs made up $40 \%$ of the total propulsion system costs for the CNG buses; there are no electric propulsion costs for the CNG buses.

- Non-lighting electrical (charging, cranking, and ignition)—Costs for this system made up $81 \%$ of the propulsion system costs for the BEBs and $31 \%$ of the total propulsion costs for the CNG buses. Costs for both fleets were for items like low-voltage batteries and electric switches. Modern ITS equipment, such as radios, cameras, and fareboxes, typically require power from the low-voltage batteries even when the bus is parked. NREL has documented other agencies experiencing issues with premature failure of these batteries when buses are parked for an extended period. The CNG bus costs also included spark plugs.

- Air intake - Costs for this system were low or zero for the BEBs and CNG buses.

- Cooling - Costs for this system were low or zero for the BEBs and CNG buses.

- Transmission-Costs for this system were low or zero for the BEBs and CNG buses.

- Hydraulic-Costs for this system were low or zero for the BEBs and CNG buses. 


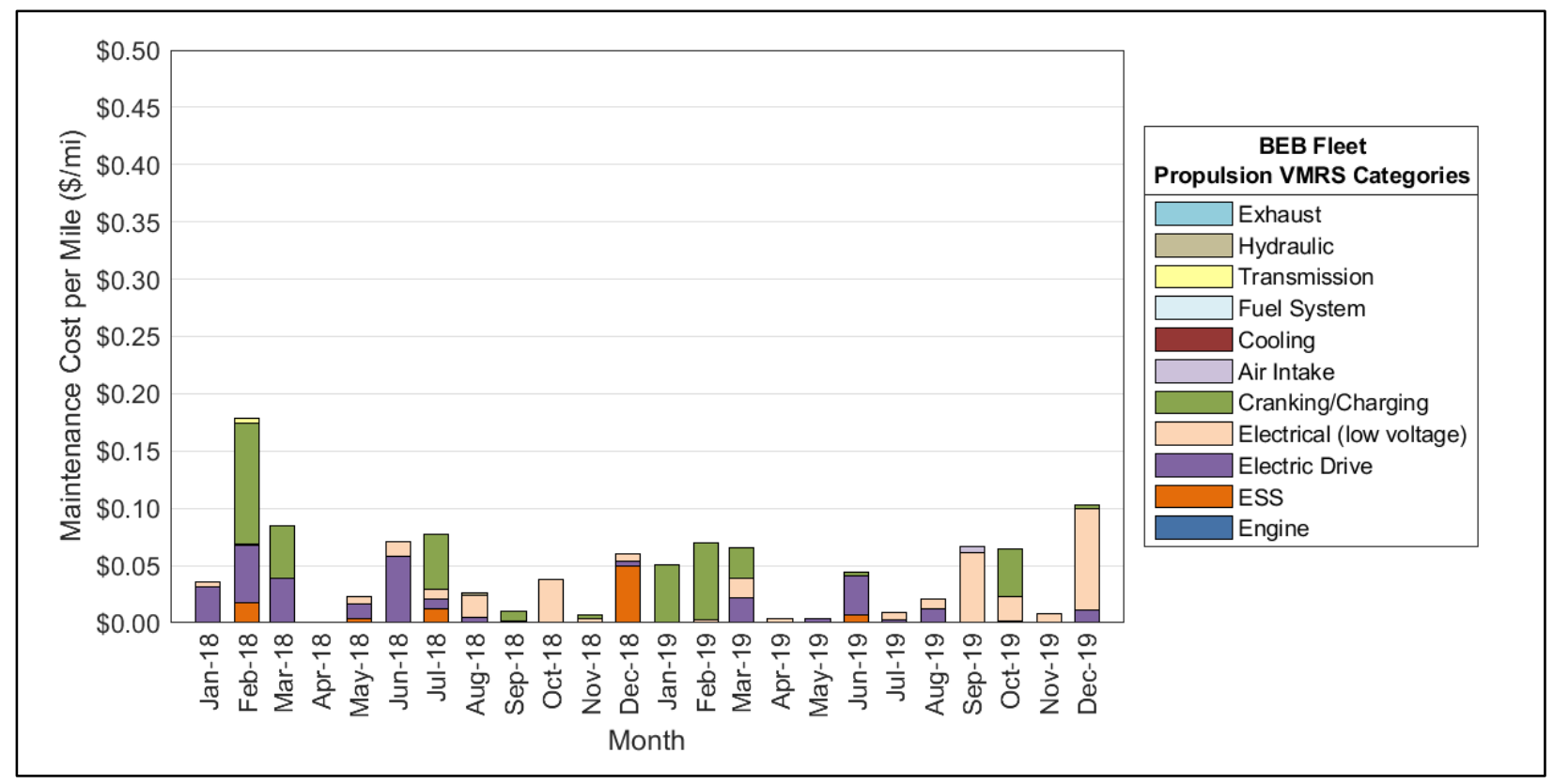

Figure 31. Monthly maintenance cost per mile by propulsion subsystem for the BEB fleet (Evaluation Period)

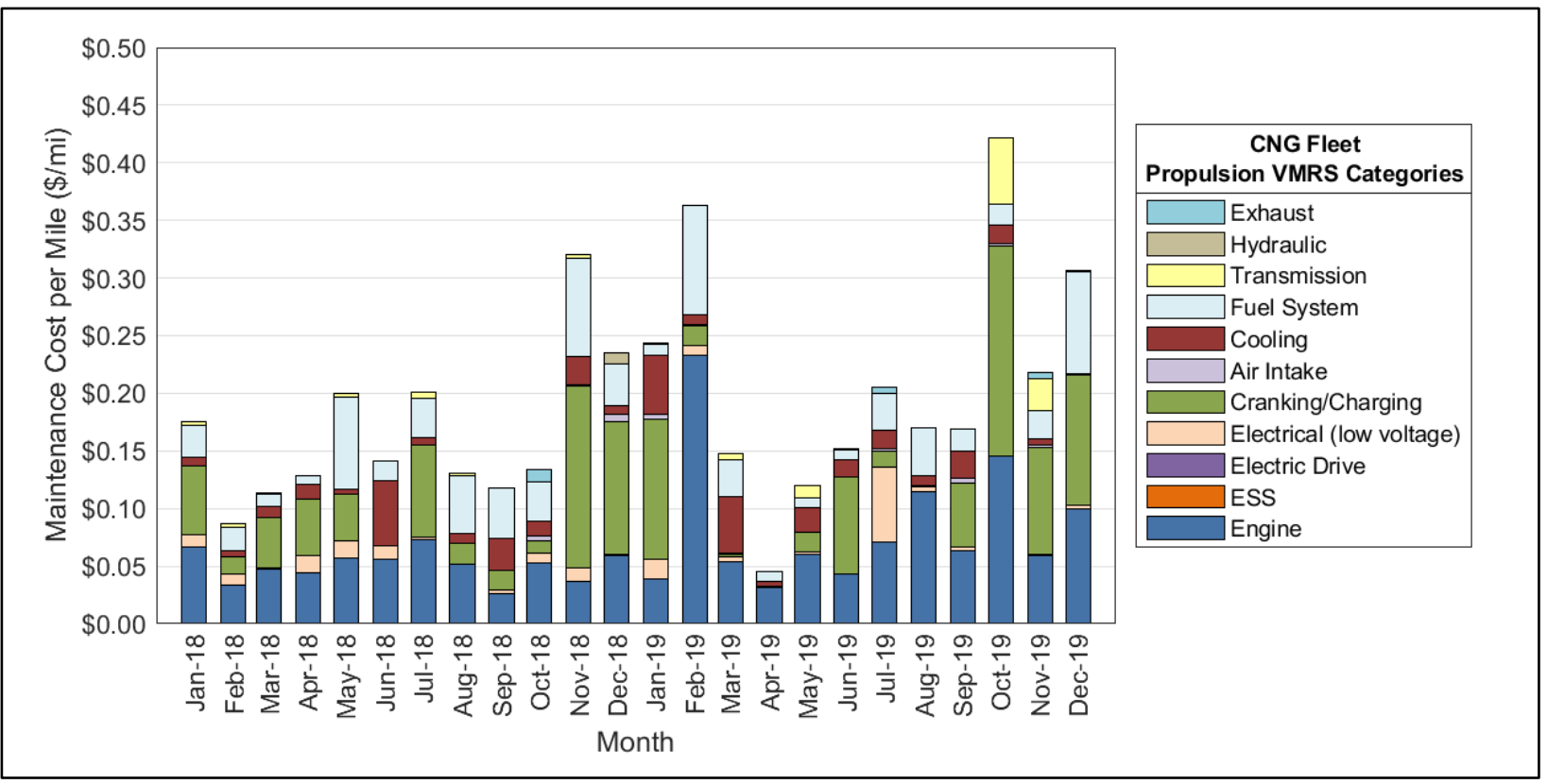

Figure 32. Monthly maintenance cost per mile by propulsion subsystem for the CNG fleet (Evaluation Period) 
Table 11. Propulsion-Related Work Order Maintenance Costs by System (2019 Data Period)

\begin{tabular}{|c|c|c|c|}
\hline Maintenance System & Maintenance Costs & BEB & CNG \\
\hline Mileage & & 192,006 & 344,236 \\
\hline \multirow{4}{*}{$\begin{array}{l}\text { Total Propulsion-Related } \\
\text { Systems (Total of all sub } \\
\text { systems below) }\end{array}$} & Parts cost (\$) & $3,775.60$ & $49,167.42$ \\
\hline & Labor hours & 83.3 & 477.0 \\
\hline & Total cost $(\$)$ & $7,938.10$ & $73,017.42$ \\
\hline & Total cost (\$) per mile & 0.04 & 0.21 \\
\hline \multirow{4}{*}{ Exhaust System Repairs } & Parts cost (\$) & 0.00 & 73.70 \\
\hline & Labor hours & 0.0 & 5.0 \\
\hline & Total cost $(\$)$ & 0.00 & 323.70 \\
\hline & Total cost (\$) per mile & 0.00 & 0.00 \\
\hline \multirow{4}{*}{ Fuel System Repairs } & Parts cost $(\$)$ & 0.00 & $8,581.84$ \\
\hline & Labor hours & 0.0 & 43.5 \\
\hline & Total cost (\$) & 0.00 & $10,756.84$ \\
\hline & Total cost (\$) per mile & 0.00 & 0.03 \\
\hline \multirow{4}{*}{$\begin{array}{l}\text { Power Plant System } \\
\text { Repairs }\end{array}$} & Parts cost $(\$)$ & 0.00 & $15,728.55$ \\
\hline & Labor hours & 2.0 & 265.0 \\
\hline & Total cost $(\$)$ & 100.00 & $28,978.55$ \\
\hline & Total cost (\$) per mile & 0.00 & 0.08 \\
\hline \multirow{4}{*}{$\begin{array}{l}\text { Electric Propulsion } \\
\text { System Repairs }\end{array}$} & Parts cost (\$) & 152.50 & 0.00 \\
\hline & Labor hours & 24.0 & 0.0 \\
\hline & Total cost $(\$)$ & $1,352.50$ & 0.00 \\
\hline & Total cost (\$) per mile & 0.01 & 0.00 \\
\hline \multirow{4}{*}{$\begin{array}{l}\text { Non-Lighting Electrical } \\
\text { System Repairs (General } \\
\text { Electrical, Charging, } \\
\text { Cranking, Ignition) }\end{array}$} & Parts cost $(\$)$ & $3,526.73$ & $18,573.29$ \\
\hline & Labor hours & 57.3 & 87.0 \\
\hline & Total cost $(\$)$ & $6,389.23$ & $22,923.29$ \\
\hline & Total cost (\$) per mile & 0.03 & 0.07 \\
\hline \multirow{4}{*}{ Air Intake System Repairs } & Parts cost (\$) & 96.37 & 420.63 \\
\hline & Labor hours & 0.0 & 0.0 \\
\hline & Total cost $(\$)$ & 96.37 & 420.63 \\
\hline & Total cost (\$) per mile & 0.00 & 0.00 \\
\hline \multirow{4}{*}{ Cooling System Repairs } & Parts cost $(\$)$ & 0.00 & $2,992.39$ \\
\hline & Labor hours & 0.0 & 68.0 \\
\hline & Total cost $(\$)$ & 0.00 & $6,392.39$ \\
\hline & Total cost (\$) per mile & 0.00 & 0.02 \\
\hline \multirow{4}{*}{$\begin{array}{l}\text { Transmission System } \\
\text { Repairs }\end{array}$} & Parts cost $(\$)$ & 0.00 & $2,797.02$ \\
\hline & Labor hours & 0.0 & 8.5 \\
\hline & Total cost $(\$)$ & 0.00 & $3,222.02$ \\
\hline & Total cost (\$) per mile & 0.00 & 0.01 \\
\hline \multirow{4}{*}{ Hydraulic System Repairs } & Parts cost (\$) & 0.00 & 0.00 \\
\hline & Labor hours & 0.0 & 0.0 \\
\hline & Total cost $(\$)$ & 0.00 & 0.00 \\
\hline & Total cost $(\$)$ per mile & 0.00 & 0.00 \\
\hline
\end{tabular}




\section{Summary of Challenges}

One of NREL's goals for advanced technology vehicle evaluation is to document the experience of early-adopter transit agencies and share critical lessons learned with the rest of the industry to increase the successful deployment of these vehicles elsewhere in similar service. LBT reports having a good relationship with BYD and that the OEM has been responsive when problems were encountered. The agency considers itself a pioneer in demonstrating the technology, working closely with the manufacturer to identify and solve the early issues with the buses. Advanced-technology demonstrations typically experience challenges and issues that need to be resolved. LBT's lessons learned were outlined in the previous report as detailed below.

\section{Lessons Learned}

Assemble an effective project team: LBT reports that a good project team leads to a better product collectively. This project could not have progressed without the commitment of each member of the team working for a successful deployment of BEBs and continual improvement.

Expect growing pains with new technologies: LBT experienced challenges in implementing the new technology from an OEM that was new to the U.S. market and in the process of completing its new bus manufacturing facility. The team encountered more issues than expected at the initial deployment. Some issues were with general bus components, such as doors and the wheelchair lift. While these components are not part of the advanced technology, the time needed to solve the issues delayed deployment of the affected buses.

Plan for sufficient training: LBT reports a steep learning curve for implementing a new technology bus. Some of the agency's early challenges arose from maintaining the buses. The necessary maintenance skill set did not exist at the agency at the time of initial deployment. An agency needs to ensure enough time is planned for the OEM to train staff in maintaining the buses. Agencies should also work closely with the OEM to ensure training materials for operating and maintaining the buses are available at the beginning of the project.

Begin planning infrastructure early in the project: Completing installation of needed BEB charging infrastructure by the time the buses are delivered can be a balancing act. An agency needs to begin planning early in the process and anticipate potential issues that could delay the installation. An agency should consider how to charge the buses in the case of an electric power outage and have a contingency plan in place.

Route planning: The effective range of a BEB depends on many factors including battery capacity, duty cycle, operator driving style, terrain, and heating/air conditioning use. An agency needs to understand how the buses perform in their specific service to select the best routes for the BEBs. LBT reports that the early operation on the Passport route helped them demonstrate the capabilities of the BEBs. Toward the end of 2019, the agency began operating the buses on other routes, selecting blocks that were within the demonstrated range of the buses. LBT reduced hours on some route blocks to allow operation of the BEBs. The agency reports that the BEBs are performing well on all assigned routes with no range issues.

Considerations for on-route charging: While LBT has not yet gathered much experience with the on-route WAVE charger, the agency has several recommendations for other agencies looking 
at this type of charging. An agency should evaluate the energy cost and demand charges associated with electric power consumption during times when a bus would use an on-route charger. Electricity rates during the day could result in much higher cost compared to overnight charging. Also, determine the amount of power that is required for the charger and what is required to get that power to the site. Working with your utility partner is vital to help answer these questions. Lastly, an agency should consider the amount of time required for on-route charging and determine the added range that would result. Route changes may be needed to ensure enough time to charge.

\section{Technical Issues and Challenges}

Early bus issues: LBT experienced issues with several bus systems in the initial deployment stage. Although most of these issues were not attributed to the advanced technology components, they resulted in downtime, keeping the buses out of service. Components included wheelchair lifts and doors. To resolve these issues, many of the buses were returned to the manufacturing facility. Once repairs were completed, the buses were returned to LBT, where they were commissioned and placed in service. Although the issues were more numerous than expected, LBT reports that BYD has worked with them to resolve the issues. Changes for one bus were rolled out to the rest of the fleet. The design modifications will be incorporated into the next bus build.

Steering/suspension/axles: LBT experienced issues with rear axle reduction gear sets on several buses. Shaft bolts were breaking on both the inner and outer gear sets. Other agencies were seeing the same issue. BYD has redesigned the components to alleviate the issue and is replacing the component on all buses under warranty. 


\section{Glossary}

\section{Term}

Availability

Clean point

Deadhead

Miles between

road calls (MBRC)

Revenue service

Road call

\section{Definition}

The number of days the buses are actually available compared to the days that the buses are planned for operation, expressed as a percentage.

For each evaluation, NREL works with the project partners to determine a starting point - or clean point - for the data analysis period. The clean point is chosen to avoid some of the early and expected operations problems with a new vehicle going into service, such as early maintenance campaigns. In some cases, reaching the clean point may require three to six months of operation before the evaluation can start. This applies to new technology buses as well as conventional buses.

The miles and hours that a vehicle travels when out of revenue service with no expectation of carrying revenue passengers. Deadhead includes leaving or returning to the garage or yard facility and changing routes.

A measure of reliability calculated by dividing the number of miles traveled by the total number of road calls, also known as mean distance between failures. MBRC results in the report are categorized as follows:

- Bus MBRC: Includes all chargeable road calls. Includes propulsion-related issues as well as problems with bus-related systems such as brakes, suspension, steering, windows, doors, and tires.

- Propulsion-related MBRC: Includes road calls that are attributed to the propulsion system. Propulsion-related road calls can be caused by issues with the transmission, batteries, and electric drive.

- ESS-related MBRC: Includes road calls attributed to the ESS only (specific to BEBs).

- Fuel cell system-related MBRC: Includes road calls attributed to the fuel cell and balance of plant only (specific to fuel cell electric buses).

The time when a vehicle is available to the general public with an expectation of carrying fare-paying passengers. Vehicles operated in a fare-free service are also considered revenue service.

A failure of an in-service bus that causes the bus to be replaced on route or causes a significant delay in schedule. The analysis includes chargeable road calls that affect the operation of the bus or may cause a safety hazard. Nonchargeable road calls can be passenger incidents that require the bus to be cleaned before going back into service, or problems with an accessory, such as a farebox or radio. 


\section{Appendix: Long Beach Transit (LBT) Fleet Summary Statistics}

Table A-1. LBT-Fleet Operations and Economics

\begin{tabular}{|l|r|r|r|r|}
\hline & \multicolumn{1}{c|}{$\begin{array}{c}\text { BEB } \\
\text { Total }\end{array}$} & \multicolumn{1}{c|}{$\begin{array}{c}\text { BEB } \\
\text { 2019 }\end{array}$} & \multicolumn{1}{c|}{$\begin{array}{c}\text { CNG } \\
\text { Total }\end{array}$} & \multicolumn{1}{c|}{2019} \\
\hline Number of vehicles & 10 & 10 & 8 & 8 \\
\hline Period used for fuel and oil analysis (month/year) & $1 / 18-12 / 19$ & $1 / 19-12 / 19$ & $1 / 18-12 / 19$ & $1 / 19-12 / 19$ \\
\hline Total number of months in period & 24 & 12 & 24 & 12 \\
\hline Fuel and oil analysis base fleet mileage & 323,413 & 179,286 & 614,020 & 331,024 \\
\hline Period used for maintenance analysis (month/year) & $1 / 18-12 / 19$ & $1 / 19-12 / 19$ & $1 / 18-12 / 19$ & $1 / 19-12 / 19$ \\
\hline Total number of months in period & 24 & 12 & 24 & 12 \\
\hline Maintenance analysis base fleet mileage & 353,281 & 192,006 & 659,618 & 344,236 \\
\hline Average monthly mileage per vehicle & 1,472 & 1,600 & 3,436 & 3,586 \\
\hline Availability & $71.1 \%$ & $71.3 \%$ & $86.6 \%$ & $83.4 \%$ \\
\hline Fleet energy usage (kWh for BEB; gge for CNG) & 610,588 & 348,660 & 195,706 & 102,892 \\
\hline Road calls & 80 & 42 & 64 & 43 \\
\hline Total MBRC & 4,416 & 4,572 & 10,307 & 8,005 \\
\hline Propulsion road calls & 30 & 12 & 37 & 24 \\
\hline Propulsion MBRC & 11,776 & 16,000 & 17,828 & 14,343 \\
\hline Fleet kWh/mile (BEB) or miles/gge (CNG) & 1.89 & 1.94 & 3.14 & 3.22 \\
\hline Representative fleet mpg (energy equiv.) & 19.93 & 19.35 & 3.60 & 3.69 \\
\hline Energy cost (\$/kWh for BEB; \$/gge for CNG) & 0.20 & 0.15 & 1.32 & 1.31 \\
\hline $\begin{array}{l}\text { Energy/fuel cost per mile (based on purchased } \\
\text { energy) (\$) }\end{array}$ & 0.44 & 0.35 & 0.42 & 0.41 \\
\hline Total scheduled repair cost per mile (\$) & 0.13 & 0.12 & 0.17 & 0.15 \\
\hline Total unscheduled repair cost per mile (\$) & 0.32 & 0.35 & 0.39 & 0.41 \\
\hline Total maintenance cost per mile (\$) & 0.46 & 0.47 & 0.55 & 0.56 \\
\hline Total operating cost per mile (\$) & $\mathbf{0 . 9 0}$ & $\mathbf{0 . 8 2}$ & $\mathbf{0 . 9 7}$ & $\mathbf{0 . 9 7}$ \\
\hline
\end{tabular}

Table A-2. LBT—Maintenance Costs

\begin{tabular}{|l|r|r|r|r|}
\hline & \multicolumn{1}{|c|}{$\begin{array}{c}\text { BEB } \\
\text { Total }\end{array}$} & \multicolumn{1}{c|}{$\begin{array}{c}\text { BEB } \\
2019\end{array}$} & \multicolumn{1}{c|}{$\begin{array}{c}\text { CNG } \\
\text { Total }\end{array}$} & \multicolumn{1}{c|}{\begin{tabular}{c}
\multicolumn{1}{c|}{ 2NG } \\
\hline
\end{tabular}} \\
\hline Fleet mileage & 353,281 & 192,006 & 659,618 & 344,236 \\
\hline Total parts cost & $\$ 30,555.98$ & $\$ 23,838.35$ & $\$ 167,383.59$ & $\$ 93,743.30$ \\
\hline Total labor hours & $2,623.4$ & $1,345.4$ & $3,928.2$ & $1,999.9$ \\
\hline Labor cost (at $\$ 50.00$ per hour) & $\$ 131,168.00$ & $\$ 67,268.00$ & $\$ 196,410.00$ & $\$ 99,995.00$ \\
\hline Total maintenance cost & $\$ 161,723.98$ & $\$ 91,106.35$ & $\$ 363,793.59$ & $\$ 193,738.30$ \\
\hline Total maintenance cost per bus & $\$ 16,172.40$ & $\$ 9,110.64$ & $\$ 45,474.20$ & $\$ 24,217.29$ \\
\hline Total maintenance cost per mile & $\mathbf{\$ 0 . 4 6}$ & $\mathbf{\$ 0 . 4 7}$ & $\$ \mathbf{0 . 5 5}$ & $\mathbf{\$ 0 . 5 6}$ \\
\hline
\end{tabular}


Table A-3. LBT_Breakdown of Maintenance Costs by System

\begin{tabular}{|c|c|c|c|c|}
\hline & $\begin{array}{l}\text { BEB } \\
\text { Total }\end{array}$ & $\begin{array}{l}B E B \\
2019\end{array}$ & $\begin{array}{l}\text { CNG } \\
\text { Total }\end{array}$ & $\begin{array}{l}\text { CNG } \\
2019\end{array}$ \\
\hline Fleet mileage & 353,281 & 192,006 & 659,618 & 344,236 \\
\hline \multicolumn{5}{|c|}{ Total Engine/Fuel-Related Systems (ATA VMRS $27,30,31,32,33,41,42,43,44,45,46,65$ ) } \\
\hline Parts cost (\$) & $6,113.27$ & $3,775.60$ & $85,497.76$ & $49,167.42$ \\
\hline Labor hours & 188.3 & 83.3 & 794.0 & 477.0 \\
\hline Labor cost (\$) & $9,412.50$ & $4,162.50$ & $39,700.00$ & $23,850.00$ \\
\hline Total cost (for system) (\$) & $15,525.77$ & $7,938.10$ & $125,197.76$ & $73,017.42$ \\
\hline Total cost (for system) per bus $(\$)$ & $1,552.58$ & 793.81 & $15,649.72$ & $9,127.18$ \\
\hline Total cost (for system) per mile (\$) & 0.04 & 0.04 & 0.19 & 0.21 \\
\hline \multicolumn{5}{|c|}{ Exhaust System Repairs (ATA VMRS 43) } \\
\hline Parts cost (\$) & 0.00 & 0.00 & 387.72 & 73.70 \\
\hline Labor hours & 0 & 0 & 5 & 5 \\
\hline Labor cost $(\$)$ & 0.00 & 0.00 & 250.00 & 250.00 \\
\hline Total cost (for system) (\$) & 0.00 & 0.00 & 637.72 & 323.70 \\
\hline Total cost (for system) per bus $(\$)$ & 0.00 & 0.00 & 79.72 & 40.46 \\
\hline Total cost (for system) per mile (\$) & 0.00 & 0.00 & 0.00 & 0.00 \\
\hline \multicolumn{5}{|l|}{ Fuel System Repairs (ATA VMRS 44) } \\
\hline Parts cost $(\$)$ & 0.00 & 0.00 & $17,759.15$ & $8,581.84$ \\
\hline Labor hours & 0 & 0 & 95 & 43.5 \\
\hline Labor cost $(\$)$ & 0.00 & 0.00 & $4,750.00$ & $2,175.00$ \\
\hline Total cost (for system) (\$) & 0.00 & 0.00 & $22,509.15$ & $10,756.84$ \\
\hline Total cost (for system) per bus $(\$)$ & 0.00 & 0.00 & $2,813.64$ & $1,344.61$ \\
\hline Total cost (for system) per mile (\$) & 0.00 & 0.00 & 0.03 & 0.03 \\
\hline \multicolumn{5}{|c|}{ Power Plant (Engine) Repairs (ATA VMRS 45) } \\
\hline Parts cost $(\$)$ & 0.00 & 0.00 & $25,137.68$ & $15,728.55$ \\
\hline Labor hours & 23.5 & 2 & 398 & 265 \\
\hline Labor cost $(\$)$ & $1,175.00$ & 100.00 & $19,900.00$ & $13,250.00$ \\
\hline Total cost (for system) (\$) & $1,175.00$ & 100.00 & $45,037.68$ & $28,978.55$ \\
\hline Total cost (for system) per bus ( $\$$ ) & 117.50 & 10.00 & $5,629.71$ & $3,622.32$ \\
\hline Total cost (for system) per mile (\$) & 0.00 & 0.00 & 0.07 & 0.08 \\
\hline \multicolumn{5}{|c|}{ Electric Propulsion Repairs (ATA VMRS 46) } \\
\hline Parts cost (\$) & 188.39 & 152.50 & 0.00 & 0.00 \\
\hline Labor hours & 73 & 24 & 0.0 & 0.0 \\
\hline Labor cost $(\$)$ & $3,650.00$ & $1,200.00$ & 0.00 & 0.00 \\
\hline Total cost (for system) (\$) & $3,838.39$ & $1,352.50$ & 0.00 & 0.00 \\
\hline Total cost (for system) per bus $(\$)$ & 383.84 & 135.25 & 0.00 & 0.00 \\
\hline Total cost (for system) per mile (\$) & 0.01 & 0.01 & 0.00 & 0.00 \\
\hline
\end{tabular}

${ }^{a}$ American Trucking Association Vehicle Maintenance Reporting Standards 
Table A-3. LBT_Breakdown of Maintenance Costs by System (continued)

\begin{tabular}{|c|c|c|c|c|}
\hline & $\begin{array}{l}\text { BEB } \\
\text { Total }\end{array}$ & $\begin{array}{l}\text { BEB } \\
2019\end{array}$ & $\begin{array}{l}\text { CNG } \\
\text { Total }\end{array}$ & $\begin{array}{l}\text { CNG } \\
2019\end{array}$ \\
\hline \multicolumn{5}{|c|}{$\begin{array}{l}\text { Electrical System Repairs (ATA VMRS 30-Electrical General, 31-Charging, 32-Cranking, 33- } \\
\text { Ignition) }\end{array}$} \\
\hline Parts cost $(\$)$ & $5,828.51$ & $3,526.73$ & $33,195.15$ & $18,573.29$ \\
\hline Labor hours & 90.25 & 57.25 & 164 & 87 \\
\hline Labor cost $(\$)$ & $4,512.50$ & $2,862.50$ & $8,200.00$ & $4,350.00$ \\
\hline Total cost (for system) (\$) & $10,341.01$ & $6,389.23$ & $41,395.15$ & $22,923.29$ \\
\hline Total cost (for system) per bus (\$) & $1,034.10$ & 638.92 & $5,174.39$ & $2,865.41$ \\
\hline Total cost (for system) per mile (\$) & 0.03 & 0.03 & 0.06 & 0.07 \\
\hline \multicolumn{5}{|c|}{ Air Intake System Repairs (ATA VMRS 41) } \\
\hline Parts cost $(\$)$ & 96.37 & 96.37 & 738.35 & 420.63 \\
\hline Labor hours & 0 & 0 & 0 & 0 \\
\hline Labor cost $(\$)$ & 0.00 & 0.00 & 0.00 & 0.00 \\
\hline Total cost (for system) (\$) & 96.37 & 96.37 & 738.35 & 420.63 \\
\hline Total cost (for system) per bus (\$) & 9.64 & 9.64 & 92.29 & 52.58 \\
\hline Total cost (for system) per mile (\$) & 0.00 & 0.00 & 0.00 & 0.00 \\
\hline \multicolumn{5}{|c|}{ Cooling System Repairs (ATA VMRS 42) } \\
\hline Parts cost $(\$)$ & 0.00 & 0.00 & $5,334.30$ & $2,992.39$ \\
\hline Labor hours & 0 & 0 & 110 & 68 \\
\hline Labor cost $(\$)$ & 0.00 & 0.00 & $5,500.00$ & $3,400.00$ \\
\hline Total cost (for system) (\$) & 0.00 & 0.00 & $10,834.30$ & $6,392.39$ \\
\hline Total cost (for system) per bus $(\$)$ & 0.00 & 0.00 & $1,354.29$ & 799.05 \\
\hline Total cost (for system) per mile (\$) & 0.00 & 0.00 & 0.02 & 0.02 \\
\hline \multicolumn{5}{|c|}{ Hydraulic System Repairs (ATA VMRS 65) } \\
\hline Parts cost $(\$)$ & 0.00 & 0.00 & 148.39 & 0.00 \\
\hline Labor hours & 0.5 & 0 & 2 & 0 \\
\hline Labor cost $(\$)$ & 25.00 & 0.00 & 100.00 & 0.00 \\
\hline Total cost (for system) (\$) & 25.00 & 0.00 & 248.39 & 0.00 \\
\hline Total cost (for system) per bus (\$) & 2.50 & 0.00 & 31.05 & 0.00 \\
\hline Total cost (for system) per mile (\$) & 0.00 & 0.00 & 0.00 & 0.00 \\
\hline \multicolumn{5}{|c|}{ General Air System Repairs (ATA VMRS 10) } \\
\hline Parts cost $(\$)$ & $2,519.08$ & $2,519.08$ & $8,781.98$ & $4,959.86$ \\
\hline Labor hours & 40 & 9.5 & 43.5 & 29.5 \\
\hline Labor cost $(\$)$ & $2,000.00$ & 475.00 & $2,175.00$ & $1,475.00$ \\
\hline Total cost (for system) (\$) & $4,519.08$ & $2,994.08$ & $10,956.98$ & $6,434.86$ \\
\hline Total cost (for system) per bus $(\$)$ & 451.91 & 299.41 & $1,369.62$ & 804.36 \\
\hline Total cost (for system) per mile (\$) & 0.01 & 0.02 & 0.02 & 0.02 \\
\hline
\end{tabular}


Table A-3. LBT_Breakdown of Maintenance Costs by System (continued)

\begin{tabular}{|c|c|c|c|c|}
\hline & $\begin{array}{l}\text { BEB } \\
\text { Total }\end{array}$ & $\begin{array}{l}\text { BEB } \\
2019\end{array}$ & $\begin{array}{l}\text { CNG } \\
\text { Total }\end{array}$ & $\begin{array}{l}\text { CNG } \\
2019\end{array}$ \\
\hline \multicolumn{5}{|l|}{ Brake System Repairs (ATA VMRS 13) } \\
\hline Parts cost (\$) & $3,143.78$ & $3,132.16$ & $10,380.99$ & $2,937.81$ \\
\hline Labor hours & 37.5 & 15.5 & 127 & 37 \\
\hline Labor cost $(\$)$ & $1,875.00$ & 775.00 & $6,350.00$ & $1,850.00$ \\
\hline Total cost (for system) (\$) & $5,018.78$ & $3,907.16$ & $16,730.99$ & $4,787.81$ \\
\hline Total cost (for system) per bus $(\$)$ & 501.88 & 390.72 & $2,091.37$ & 598.48 \\
\hline Total cost (for system) per mile (\$) & 0.01 & 0.02 & 0.03 & 0.01 \\
\hline \multicolumn{5}{|l|}{ Transmission Repairs (ATA VMRS 27) } \\
\hline Parts cost (\$) & 0.00 & 0.00 & $2,797.02$ & $2,797.02$ \\
\hline Labor hours & 1 & 0 & 20 & 8.5 \\
\hline Labor cost $(\$)$ & 50.00 & 0.00 & $1,000.00$ & 425.00 \\
\hline Total cost (for system) (\$) & 50.00 & 0.00 & $3,797.02$ & $3,222.02$ \\
\hline Total cost (for system) per bus $(\$)$ & 5.00 & 0.00 & 474.63 & 402.75 \\
\hline Total cost (for system) per mile (\$) & 0.00 & 0.00 & 0.01 & 0.01 \\
\hline \multicolumn{5}{|c|}{ Inspections Only - no parts replacements (101) } \\
\hline Parts cost (\$) & 0.00 & 0.00 & 0.00 & 0.00 \\
\hline Labor hours & 887.5 & 410.5 & 1130.25 & 537.25 \\
\hline Labor cost $(\$)$ & $44,375.00$ & $20,525.00$ & $56,512.50$ & $26,862.50$ \\
\hline Total cost (for system) (\$) & $44,375.00$ & $20,525.00$ & $56,512.50$ & $26,862.50$ \\
\hline Total cost (for system) per bus ( $\$$ ) & $4,437.50$ & $2,052.50$ & $7,064.06$ & $3,357.81$ \\
\hline Total cost (for system) per mile (\$) & 0.13 & 0.11 & 0.09 & 0.08 \\
\hline \multicolumn{5}{|c|}{$\begin{array}{l}\text { Cab, Body, and Accessories Systems Repairs (ATA VMRS 02-Cab and Sheet Metal, 50- } \\
\text { Accessories, 71-Body) }\end{array}$} \\
\hline Parts cost $(\$)$ & $17,721.00$ & $13,432.77$ & $35,461.84$ & $22,629.45$ \\
\hline Labor hours & 1191.86 & 670.36 & 1298.95 & 649.15 \\
\hline Labor cost $(\$)$ & $59,593.00$ & $33,518.00$ & $64,947.50$ & $32,457.50$ \\
\hline Total cost (for system) (\$) & $77,314.00$ & $46,950.77$ & $100,409.34$ & $55,086.95$ \\
\hline Total cost (for system) per bus $(\$)$ & $7,731.40$ & $4,695.08$ & $12,551.17$ & $6,885.87$ \\
\hline Total cost (for system) per mile (\$) & 0.22 & 0.24 & 0.15 & 0.16 \\
\hline \multicolumn{5}{|l|}{ HVAC System Repairs (ATA VMRS 01) } \\
\hline Parts cost $(\$)$ & 56.62 & 43.08 & $8,484.00$ & $5,294.97$ \\
\hline Labor hours & 64.25 & 44.25 & 141 & 69 \\
\hline Labor cost $(\$)$ & $3,212.50$ & $2,212.50$ & $7,050.00$ & $3,450.00$ \\
\hline Total cost (for system) (\$) & $3,269.12$ & $2,255.58$ & $15,534.00$ & $8,744.97$ \\
\hline Total cost (for system) per bus (\$) & 326.91 & 225.56 & $1,941.75$ & $1,093.12$ \\
\hline Total cost (for system) per mile (\$) & 0.01 & 0.01 & 0.02 & 0.03 \\
\hline
\end{tabular}


Table A-3. LBT_Breakdown of Maintenance Costs by System (continued)

\begin{tabular}{|c|c|c|c|c|}
\hline & $\begin{array}{l}\text { BEB } \\
\text { Total }\end{array}$ & $\begin{array}{l}\text { BEB } \\
2019\end{array}$ & $\begin{array}{l}\text { CNG } \\
\text { Total }\end{array}$ & $\begin{array}{l}\text { CNG } \\
2019\end{array}$ \\
\hline \multicolumn{5}{|c|}{ Lighting System Repairs (ATA VMRS 34) } \\
\hline Parts cost $(\$)$ & 873.91 & 873.70 & $2,747.47$ & 830.57 \\
\hline Labor hours & 30.5 & 13.5 & 46.5 & 19.5 \\
\hline Labor cost $(\$)$ & $1,525.00$ & 675.00 & $2,325.00$ & 975.00 \\
\hline Total cost (for system) (\$) & $2,398.91$ & $1,548.70$ & $5,072.47$ & $1,805.57$ \\
\hline Total cost (for system) per bus $(\$)$ & 239.89 & 154.87 & 634.06 & 225.70 \\
\hline Total cost (for system) per mile (\$) & 0.01 & 0.01 & 0.01 & 0.01 \\
\hline \multicolumn{5}{|c|}{ Frame, Steering, and Suspension Repairs (ATA VMRS 14-Frame, 15-Steering, 16-Suspension) } \\
\hline Parts cost $(\$)$ & 101.36 & 35.00 & $14,400.02$ & $6,876.44$ \\
\hline Labor hours & 109.5 & 60 & 114.5 & 60 \\
\hline Labor cost $(\$)$ & $5,475.00$ & $3,000.00$ & $5,725.00$ & $3,000.00$ \\
\hline Total cost (for system) (\$) & $5,576.36$ & $3,035.00$ & $20,125.02$ & $9,876.44$ \\
\hline Total cost (for system) per bus $(\$)$ & 557.64 & 303.50 & $2,515.63$ & $1,234.56$ \\
\hline Total cost (for system) per mile (\$) & 0.02 & 0.02 & 0.03 & 0.03 \\
\hline \multicolumn{5}{|c|}{$\begin{array}{l}\text { Axle, Wheel, and Drive Shaft Repairs (ATA VMRS 11-Front Axle, 18-Wheels, 22-Rear Axle, 24- } \\
\text { Drive Shaft) }\end{array}$} \\
\hline Parts cost $(\$)$ & 26.96 & 26.96 & $1,629.53$ & $1,046.78$ \\
\hline Labor hours & 73.5 & 38 & 227.5 & 118 \\
\hline Labor cost (\$) & $3,675.00$ & $1,900.00$ & $11,375.00$ & $5,900.00$ \\
\hline Total cost (for system) (\$) & $3,701.96$ & $1,926.96$ & $13,004.53$ & $6,946.78$ \\
\hline Total cost (for system) per bus ( $\$$ ) & 370.20 & 192.70 & $1,625.57$ & 868.35 \\
\hline Total cost (for system) per mile (\$) & 0.01 & 0.01 & 0.02 & 0.02 \\
\hline \multicolumn{5}{|l|}{ Tire Repairs (ATA VMRS 17) } \\
\hline Parts cost $(\$)$ & 0.00 & 0.00 & 0.00 & 0.00 \\
\hline Labor hours & 0.5 & 0.5 & 5 & 3.5 \\
\hline Labor cost $(\$)$ & 25.00 & 25.00 & 250.00 & 175.00 \\
\hline Total cost (for system) (\$) & 25.00 & 25.00 & 250.00 & 175.00 \\
\hline Total cost (for system) per bus ( $\$$ ) & 2.50 & 2.50 & 31.25 & 21.88 \\
\hline Total cost (for system) per mile (\$) & 0.00 & 0.00 & 0.00 & 0.00 \\
\hline
\end{tabular}




\section{Fleet Summary Statistics-SI Units}

Table A-4. LBT-Fleet Operations and Economics (SI)

\begin{tabular}{|c|c|c|c|c|}
\hline & $\begin{array}{l}\text { BEB } \\
\text { Total } \\
\end{array}$ & $\begin{array}{r}B E B \\
2019 \\
\end{array}$ & $\begin{array}{l}\text { CNG } \\
\text { Total } \\
\end{array}$ & $\begin{array}{l}\text { CNG } \\
2019 \\
\end{array}$ \\
\hline Number of vehicles & 10 & 10 & 8 & 8 \\
\hline Period used for fuel and oil analysis (month/year) & $1 / 18-12 / 19$ & $1 / 19-12 / 19$ & $1 / 18-12 / 19$ & $1 / 19-12 / 19$ \\
\hline Total number of months in period & 24 & 12 & 24 & 12 \\
\hline Fuel and oil analysis base fleet kilometers & 520,469 & 288,525 & 988,143 & 532,717 \\
\hline Period used for maintenance analysis (month/year) & $1 / 18-12 / 19$ & $1 / 19-12 / 2019$ & $1 / 18-12 / 19$ & $1 / 19-12 / 19$ \\
\hline Total number of months in period & 24 & 12 & 24 & 12 \\
\hline Maintenance analysis base fleet kilometers & 568,535 & 308,995 & $1,061,523$ & 553,979 \\
\hline Average monthly kilometers per vehicle & 2,369 & 2,575 & 5,529 & 5,771 \\
\hline Availability & $71.1 \%$ & $71.3 \%$ & $86.6 \%$ & $83.4 \%$ \\
\hline Fleet fuel usage in kWh/CNG liter equiv. & 610,588 & 348,660 & 740,827 & 389,489 \\
\hline Road calls & 80 & 42 & 64 & 43 \\
\hline Total kilometers between road calls (KMBRC) & 7,107 & 7,357 & 16,586 & 12,883 \\
\hline Propulsion road calls & 30 & 12 & 37 & 24 \\
\hline Propulsion KMBRC & 18,951 & 25,750 & 28,690 & 23,082 \\
\hline Rep. fleet fuel consumption (L/100 km) & 11.80 & 12.15 & 74.97 & 73.11 \\
\hline Energy cost (\$/kWh for BEB; $\$ /$ liter for $C N G)$ & 0.20 & 0.15 & 0.35 & 0.35 \\
\hline $\begin{array}{l}\text { Energy/fuel cost per kilometer (based on } \\
\text { purchased energy) (\$) }\end{array}$ & 0.28 & 0.21 & 0.26 & 0.25 \\
\hline Total scheduled repair cost per kilometer (\$) & 0.08 & 0.08 & 0.10 & 0.09 \\
\hline Total unscheduled repair cost per kilometer $(\$)$ & 0.20 & 0.22 & 0.24 & 0.26 \\
\hline Total maintenance cost per kilometer $(\$)$ & 0.28 & 0.29 & 0.34 & 0.35 \\
\hline Total operating cost per kilometer (\$) & 0.56 & 0.51 & 0.60 & 0.60 \\
\hline
\end{tabular}

Table A-5. LBT-Maintenance Costs (SI)

\begin{tabular}{|c|c|c|c|c|}
\hline & $\begin{array}{l}\text { BEB } \\
\text { Total }\end{array}$ & $\begin{array}{l}\text { BEB } \\
2019\end{array}$ & $\begin{array}{l}\text { CNG } \\
\text { Total }\end{array}$ & $\begin{array}{l}\text { CNG } \\
2019\end{array}$ \\
\hline Fleet kilometers & 568,535 & 308,995 & $1,061,523$ & 553,979 \\
\hline Total parts cost $(\$)$ & $30,555.98$ & $23,838.35$ & $167,383.59$ & $93,743.30$ \\
\hline Total labor hours & $2,623.4$ & $1,345.4$ & $3,928.2$ & $1,999.9$ \\
\hline Average labor cost (at $\$ 50.00$ per hour) $(\$)$ & $131,168.00$ & $67,268.00$ & $196,410.00$ & $99,995.00$ \\
\hline Total maintenance cost $(\$)$ & $161,723.98$ & $91,106.35$ & $363,793.59$ & $193,738.30$ \\
\hline Total maintenance cost per bus $(\$)$ & $16,172.40$ & $9,110.64$ & $45,474.20$ & $24,217.29$ \\
\hline Total maintenance cost per kilometer (\$) & 0.28 & 0.29 & 0.34 & 0.35 \\
\hline
\end{tabular}

